\title{
WestVirginiaUniversity
}

THE RESEARCH REPOSITORY @ WVU

Graduate Theses, Dissertations, and Problem Reports

2009

\section{When two become one: Marital couples' public performances and couple identity}

Carrie D. Kennedy-Lightsey

West Virginia University

Follow this and additional works at: https://researchrepository.wvu.edu/etd

\section{Recommended Citation}

Kennedy-Lightsey, Carrie D., "When two become one: Marital couples' public performances and couple identity" (2009). Graduate Theses, Dissertations, and Problem Reports. 4483.

https://researchrepository.wvu.edu/etd/4483

This Dissertation is protected by copyright and/or related rights. It has been brought to you by the The Research Repository @ WVU with permission from the rights-holder(s). You are free to use this Dissertation in any way that is permitted by the copyright and related rights legislation that applies to your use. For other uses you must obtain permission from the rights-holder(s) directly, unless additional rights are indicated by a Creative Commons license in the record and/ or on the work itself. This Dissertation has been accepted for inclusion in WVU Graduate Theses, Dissertations, and Problem Reports collection by an authorized administrator of The Research Repository @ WVU.

For more information, please contact researchrepository@mail.wvu.edu. 


\title{
When Two become One: Marital Couples' Public Performances and Couple Identity
}

\author{
Carrie D. Kennedy-Lightsey
}

\author{
Dissertation \\ Submitted to the Eberly College of Arts and Sciences \\ at West Virginia University \\ in partial fulfillment of the requirements \\ for the degree of
}

Doctor of Philosophy in Communication Studies

\author{
Matthew M. Martin, Ph.D., Chair \\ Melanie Booth-Butterfield, Ph.D. \\ Megan R. Dillow, Ph.D. \\ Ernest Goeres, Ph.D. \\ Keith Weber, Ed.D. \\ Morgantown, West Virginia \\ 2009
}

Keywords: Public Performances, Communication Theory of Identity, Marital couples

Copyright 2009 Carrie D. Kennedy-Lightsey 


\begin{abstract}
When Two become One: Marital Couples’ Public Performances and Couple Identity

Carrie D. Kennedy-Lightsey

Communication researchers know little about marital couples’ public performances, or how marital couples communicate as a nonsummative whole when in the presence of important others (e.g., friends, family, co-workers). Two studies were conducted to examine marital couples’ public performances from a Communication Theory of Identity (CTI) (Hecht, 1993) framework. In the first study, 153 marital couples completed selfreport measures to assess how marital couples’ attachment styles and relationship awareness are related to identity gaps during public performances as well as how identity gaps relate to a variety of outcomes including communication satisfaction, feelings of being understood, conversational appropriateness, relationship satisfaction, and commitment. In the second study, 46 marital couples’ public performances were examined for varying degrees of communal, individual, and impersonal content themes, continual and hierarchical communication, communication integration, and nonverbal immediacy. This study also assessed how attachment styles, public and private selfconsciousness, and couple identity are associated with marital couples' communication behaviors during their public performances. After interactions, marital couples completed identity gap, communication satisfaction, feeling of being understood, and conversational appropriateness measures while reflecting on their public performance. Together, these two studies introduced the study of marital couples’ public performances while testing their salience to marital couples as guided by CTI. Results indicated married couples are less likely to experience identity gaps when they are similar in their attachment styles,
\end{abstract}


when they are both secure in their attachment styles, when couples have a greater degree of relationship awareness, and when they communicate according to communal and impersonal themes during public performances. Identity gaps are damaging to couples’ feelings of communication satisfaction, being understood, and conversational appropriateness. When identity gaps are a more common experience, married couples’ ratings of relational satisfaction and commitment were negatively affected. 


\section{ACKNOWLEDGEMENTS}

I would like thank several people who have helped me and guided me throughout my education at WVU and my dissertation. Together, you've all contributed to my growth as an individual, a teacher, a writer, and a researcher.

First and foremost, to my husband and best friend, Jacob: I cannot thank you enough for believing in me when I didn’t believe in myself. Thank you for always being there to listen to my stories, my fears, and my successes. Thank you for putting up with me when things got stressful and I was unpleasant. Your support has meant the world to me and I am forever grateful that you're here with me. I am so thankful for your help with recruiting participants, shuffling back and forth to the school, and taking care of me during my dissertation (and doc education). I love you.

Second, to my advisor, Dr. Matt Martin: Thank you for all of your guidance and patience. You never kicked me out or turned me away all of the times I popped up in your doorway unannounced or lingered in the hallway. I truly appreciate all of your feedback and advice regarding not only my dissertation, but also my development as an academic. Thank you for looking out for me when I was headed in the wrong direction and thinking of me when new opportunities became available.

Third, to each of my committee members: Thank you for serving on my committee, offering me feedback and direction, and challenging me. To Dr. Melanie Booth-Butterfield: Thank you for challenging me with my research studies and encouraging me to go above and beyond. Your insight and alternative ways of thinking about capturing interpersonal communication are an inspiration.

To Dr. Megan Dillow: Thanks a million for all of your guidance over the past 
three years. I am so honored to have served as your research assistant and am grateful for your direction with COMM 200. Thank you for opening up your classroom and your research to me. Thank you for trusting in me.

To Dr. Ernest Goeres: Thank you for taking time out of your schedule to serve on my committee. More importantly, thank you for your kind words and believing in me, as well as your advice about the job search and the future of my dissertation.

To Dr. Keith Weber: Thank you for reading my dissertation :-) and keeping my nightmare from becoming a reality. I appreciate your help with passing on information about my study to potential participants and looking out for me when I got in over my head. Thanks also for the laughs!

Fourth, there have been several others influential to my success. To Dr. Scott Myers: Thanks so much for putting up with all of my annoying questions! Thank you also for taking time out of your day to chat with me. I truly enjoyed our chats whether they were on my way to meet "my man” or on my way to chow down on some Sam’s pizza! Thank you for the good times! Most importantly, thank you for challenging me in and outside the classroom. I will always remember that my first two pubs were with you!

To Dr. Andi Weber: Thank you so much for looking out for Jacob and I. Whether it was getting settled in Morgantown, looking for participants for my dissertation, or preparing for Lincoln's arrival, you've been so helpful.

To Ms. Renee Kisner: I can’t thank you enough for all of your help over the past three years and especially during the stressful days of participant recruitment. Your care and concern for my (and Lincoln’s) well-being has been a blessing. Thanks for looking out for me. 
To Sydney and Shannon: Thank you so much for taking time out of your crazy schedules to give me feedback and help me prepare for the end. I really appreciate your insight, which was useful for the big day and will also be useful in planning for the future of my research. I hope that we will continue to stay together at conferences as I really enjoyed your company. I wish you the best of luck in the program. Let me know what I can do to help.

To Mom and Dad: You've always encouraged me to reach for the stars and to never give up on my dreams. Most importantly, you taught me how to dream. Thank you for encouraging me and being proud of me. I remember, Dad, when you told me that one day I'd be a writer. Mom, you were convinced I'd be a performer. I bet neither of you thought these talents would be manifested in academics, but I smile every time I think of how critical you've been in my development and how blessed I am to have you for my parents.

To Pat and Roger: Thank you so much for your support and understanding as we set out to achieve my professional goals. Our time away has been difficult but you're encouragement to continue on the journey we'd set out for has been God-sent. I am so glad to be a member of the Lightsey family.

To Little Lincoln Lightsey, our Bumblebee: You've yet to arrive for the world to see, but you've been here with me. Thank you for helping me put things into perspective, to overcome several of my anxieties, and for being a good little baby in the womb. Although you wore me out occasionally, you never made me sick. Instead, you've made me smile. I love you. 


\section{TABLE OF CONTENTS}

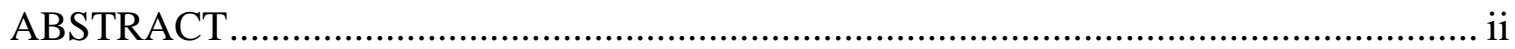

ACKNOWLEDGEMENTS ...................................................................................

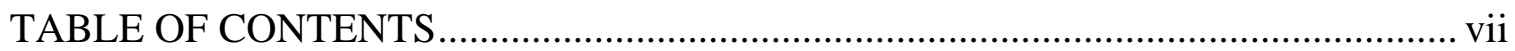

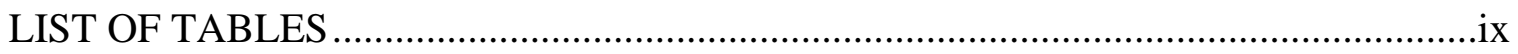

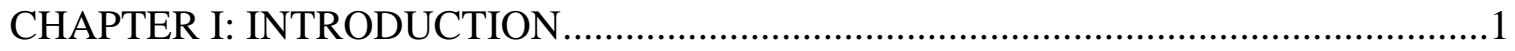

Defining Marriage and the Marital Couple.......................................................... 2

Marital Couples’ Public Behavior .............................................................. 8

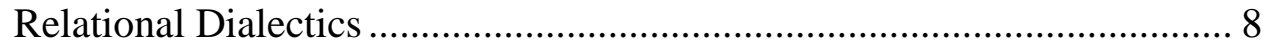

Relational Culture .......................................................................... 11

Behavioral Displays of Relational Existence........................................ 13

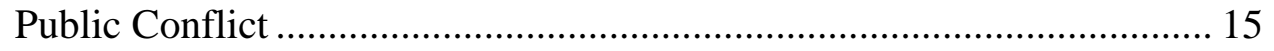

Social Networks ........................................................................... 16

Summary of Studying Couples’ Public Behavior.................................. 17

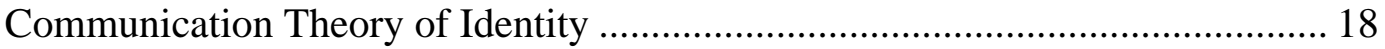

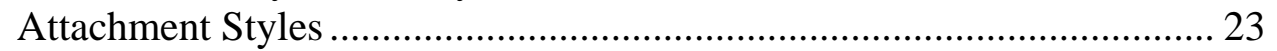

Statement of the Problem................................................................................. 30

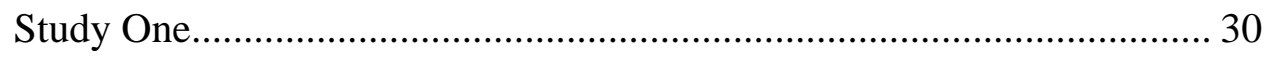

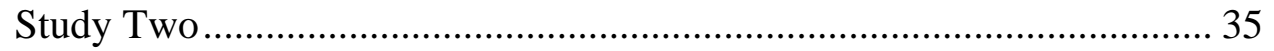

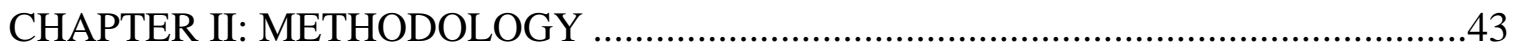

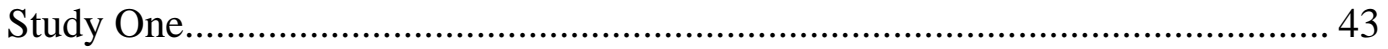

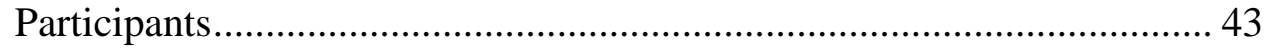

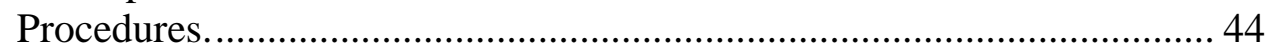

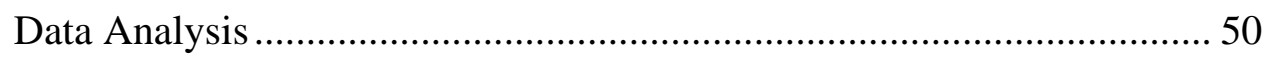

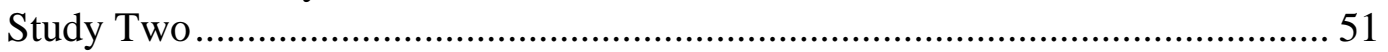

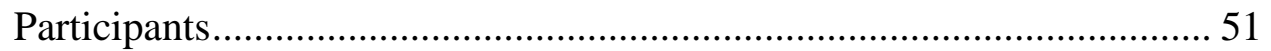

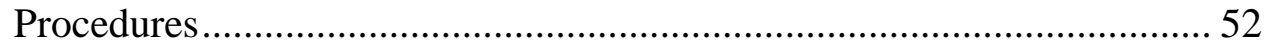

Pre-Interaction Instrumentation .................................................... 54

Post-Interaction Instrumentation................................................... 56

Coding Public Performances.................................................................. 59

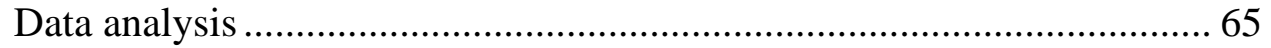

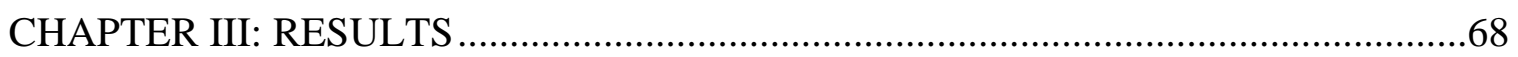

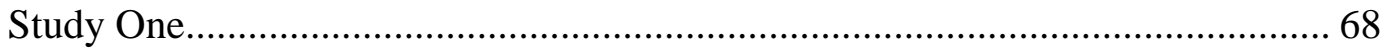

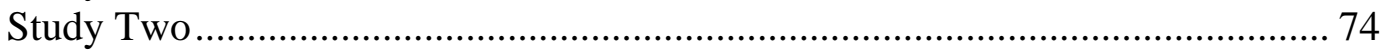




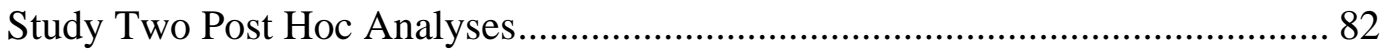

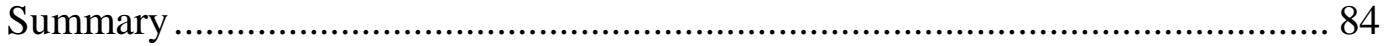

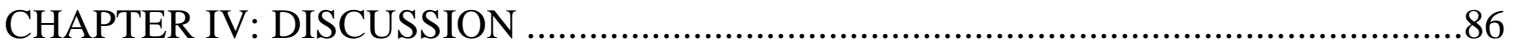

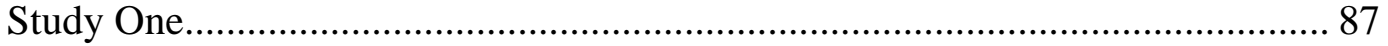

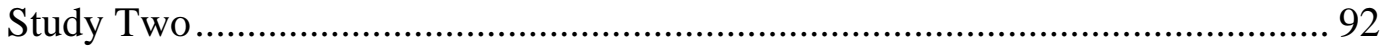

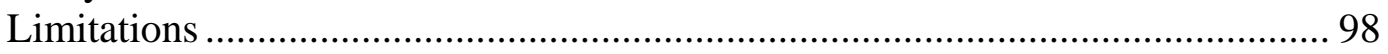

Theoretical and Practical Contributions....................................................... 100

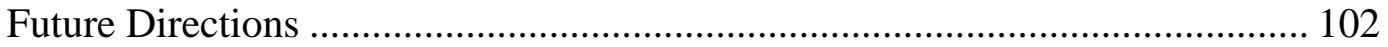

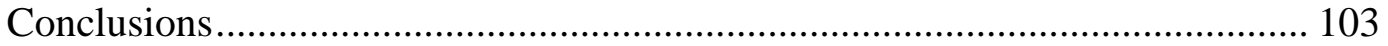

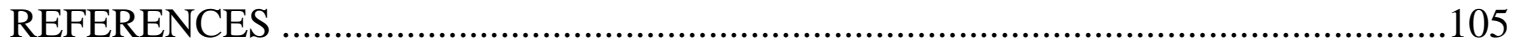

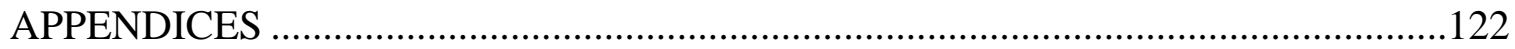

Appendix A: Study One Scales............................................................... 122

Appendix B: Study Two Pre-Interaction Scales .............................................. 136

Appendix C: Study Two Post-Interaction Scales............................................... 142

Appendix D: Conversation Directions and Questions ...................................... 149

Appendix E: Study Two Codebook ............................................................ 150

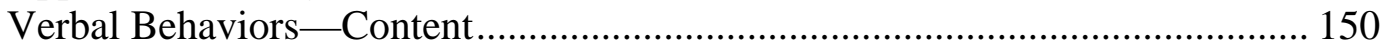

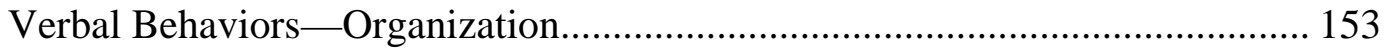

Verbal Behaviors_-Integration Chains...................................................... 154

Nonverbal Behaviors ............................................................................ 155 


\section{LIST OF TABLES}

Table 1. Descriptive Statistics for Verbal and Nonverbal Communication Observed

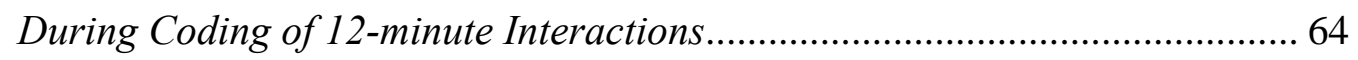

Table 2. Correlations between Couple Characteristics, Conversational and Relational

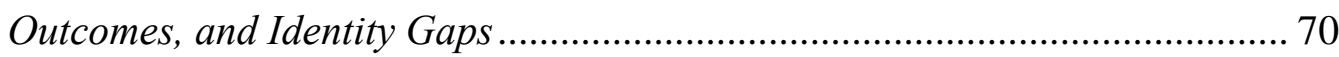

Table 3. Study One Planned Contrasts between Continuous Measures and Categorical Descriptions of Attachment Styles

Table 4. Study Two Planned Contrasts between Continuous Measures and Categorical Descriptions of Attachment Styles

Table 5. Hierarchical Regressions for Attachment Style Dimensions and Verbal and Nonverbal Communication 


\section{CHAPTER I:}

\section{INTRODUCTION}

When Two become One: Marital Couples’ Public Performances and Couple

Identity

An interesting phenomenon occurs when two individuals get married: two become one. According to the nonsummativity principle, marital couples are more than the sum of two parts (Watzlawick, Beavin, \& Jackson, 1967), but instead are unique entities in and of themselves (Montgomery \& Baxter, 1998). Baxter and Montgomery (1996) argued, “'the self’ in singular form is a misnomer” (p. 159). Communication with others and with each other is the means by which marital couples construct their identity as a unique couple (Lewis, 1973). This in turn serves as the basis from which outsiders develop expectations about the couple and its members (Wood, 1982). Yet, researchers know little about marital couples’ communication with each other and joint communication with outsiders in social contexts. Marital couples do not exist in a bubble, but in a larger web of socially constructed relationships (Brown, Werner, \& Altman, 1998). Marital couples develop joint friendships, establish social networks, and acquire support systems (Julien, Tremblay, Belanger, Dube, Begin, \& Bouthillier, 2000; Milardo, 1982). The focus of this dissertation is marital couples as social entities that communicatively construct and manage their couple identity when in the presence of important others.

Marriage has been considered one of the closest relationships (Floyd \& Haynes, 2005; Kelley et al., 1983). Marital partners are typically interdependent on each other physically, emotionally, sexually, reproductively, and financially (Floyd \& Haynes, 
2005). As such, married persons are also likely to have strongly integrated personal and relational identities (Aron \& Aron, 1996; Aron, Aron, \& Smollen, 1992; Aron, Paris, \& Aron, 1996; McCall \& Simmons, 1978). Marriage can satisfy individuals’ needs to belong (Baumeister \& Leary, 1995), as well as promote good health and a better quality of life (see Loving, Heffner, \& Kiecolt-Glaser, 2006 for a review).

\section{Defining Marriage and the Marital Couple}

Federal law mandates that “marriage” be defined as a legal union between one man and one woman and that the term "spouse” be restricted for use by heterosexual couples that have been joined legally (H. R. 3396, 1996). The legal definition of marriage is the most common way for conceptualizing a marital couple as consisting of a husband and a wife. Being lawfully bound is a fundamental distinguishing characteristic of how marital couples are different from other relationship types. Because of their legal union, marriage is more difficult to dissolve than most other relationship types (Attridge, 1994; Cupach \& Metts, 1986), with the possible exception of other family relationships. However, marriage is fundamentally different from other family relationships in that married persons theoretically have a choice (although some may not perceive they do) to dissolve their union whereas most other family members typically do not. They also choose who they will marry.

Law-governed procedures, regulations, and financial costs associated with divorce are considered external structural barriers, or factors that exist outside of the relational couple that make dissolution of marriage more difficult (Attridge, 1994; Johnson, 1991). Pressure from couples’ joint friends and each partner's family can likewise serve as external structural barriers to marital dissolution. Some married persons have strong 
religious or moral beliefs associated with marriage (Johnson, 1991; Johnson, Caughlin, \& Huston, 1999). This too serves as a barrier to divorce. Attridge (1994) referred to these as internal psychological barriers. Commitments to the marital bond, children, an identity that is associated with the relationship or the partner, and personal investments are also considered internal psychological barriers to marital dissolution. Although other romantic couple types, such as seriously dating couples, may encounter barriers to relationship dissolution, they do not encounter those associated with dissolving a legal bond (Cupach \& Metts, 1986).

From a communication perspective, marriage is a relationship that is established and maintained communicatively and is typically marked by a heightened degree of interdependence. This dissertation's focus is on the marital couple, or on the third entity that is created by marital partners via the communication that occurs between them. Buber (1965) considered the concrete communication between two persons as where the abstract, latent entity, or relationship, exists. Rather than a listening-responding communication event being positioned wholly "in" one partner or the other, it is “between” partners (Stewart, 1998, p. 35).

Relational communication researchers have conceptualized and captured relationships in three primary ways. The behavioral perspective conceives of relationships as existing in the communicative and behavioral patterns between relational partners (Metts, 1998). Researchers have observed couples’ micro-level behaviors such as eye contact and speech patterns (e.g., Rogers \& Escuardo, 2004; Rogers \& Farace, 1975) as well as episodic types of behaviors such as conflict (e.g., Gottman, 1982) for evidence of the relationship. These behaviors may or may not be known to relational 
partners. One central criticism of the behavioral perspective is that it overlooks marital couples' “mental image of 'the relationship"” (Metts, 1998, p. 116).

The cognitive perspective focuses on partners' interpretations of communication behaviors rather than partners’ frequency and sequencing of relational behavior (Metts, 1998). Central to this perspective are mental structures such as prototypes and schemata that guide individuals’ future behaviors as well as serve as filters for interpreting partners’ behaviors (e.g., Anderson, 1993; Planalp, 1985). Shared mental representations, such as relationship norms, expectations, and symbols, represent the relationship from a cognitive perspective (e.g., Baxter, 1987).

The systems perspective places the relationship itself at the central point of study. This perspective conceives of relationships as interdependent systems. The above-noted nonsummativity principle, which states that marital couples are more than the sum of two parts, is one construct within this perspective. Kelley et al.’s (1983) model of close relationships could be classified as one example of this perspective (Metts, 1998). They contended that close relationships exist in the causal interconnections between two individuals such that one partner's actions, thoughts, and feelings influence the other partners' action, thoughts, and feelings. Huston and Robins (1982) similarly conceived of relationships as interdependent on an interactional or behavioral level and on a psychological or covert response level. Each of these perspectives recognizes that there is something unique between relational partners that is not embodied in a physical form but exists nevertheless.

The present dissertation embraces all three perspectives. From a behavioral perspective, outsiders can observe marital couples’ relationships via their public 
performances. That is, through communication, married couples make their relationship known to others. From a cognitive perspective, marital couples establish relational norms and rules that guide their relational behavior during public performances. Moreover, the communication that occurs during public performances can influence how the partners perceive their relationship. From a systems perspective, this dissertation's focus on marital couples' public performances places the couple as the central unit of analysis. This dissertation operates from the assumption that married couples are distinct from married persons such that the presence of both partners creates a unique communication event.

Although Buber was unable to clearly operationalize the sphere of between, he could recognize when he saw it in seminars, plays, and casual conversations (Stewart, 1998). In these instances, he could witness two people communicating with each other. Public performances are the verbal and nonverbal behaviors of marital couples that occur in the presence of intended others. Communication directed at each other when in the presence of intended others or toward outsiders would match this conceptualization. Intended others include those individuals and/or couples with whom marital couples are purposefully communicating. This dissertation is not interested in the broad study of marital couples' public displays as is the case in observational research of public touch (Guerrero \& Anderson, 1991; Hall \& Veccia, 1990; Steir \& Hall, 1984; Willis \& Briggs, 1992), but is limited to the communication that occurs in front of and with third parties when marital couples are aware of their presence. It is during interactions with network members that marital couples are most likely to be aware of and motivated to protect how others perceive their relationship (Parks, 2000). 
Parks (2000) called for greater attention to the "communicative dance through which relational partners and network members reveal, conceal, and distort their judgments” (p. 74). It is during such interactions that relationships can be defined, even without overt communication about the relationship (Sillars, Pike, Jones, \& Murphy, 1984). There are two primary reasons why such interactions would be important to marital couples and therefore should be of interest to researchers. The first reason is because of individuals' tendency to engage in social comparison (Festinger, 1954). Titus (1980) found married persons compared their friends' marriages to their own. These comparisons are likely to influence how marital couples perceive their own relationship and its quality (Acitelli, 2002), because marital couples were likewise found to refer to their friends' marriages as a basis for establishing and reinforcing their own relationship norms (Titus, 1980). It is plausible that marital couples co-jointly communicate in a manner that protects their relationship or couple identity.

The second reason to believe interactions with intended others are important to marital couples is because of couples' reliance on network members, especially for support (Dindia \& Baxter, 1987; Parks, 2007). Explicitly, when partners appear to network members as more committed to the relationship, network members may express more support for the relationship (Parks, 2000). Premarital partners appear to be aware of the importance of network members' impressions such that they often adapt how they talk about their relationship and their partner with network members (Leslie, Huston, \& Johnson, 1986). It is conceivable that marital couples are likewise aware of the importance of favorable impressions for developing support systems and adapt their communication accordingly. 
Support from network members can come in the form of validation or approval of the relationship (Agnew, Loving, \& Drigotas, 2001; Flemlee, 2001; Leslie et al., 1986) or in the form of providing instrumental and emotional support (Belsky \& Rovine, 1984). Relying on social networks for support is also one way in which marital couples can maintain their relationship (Canary \& Dainton, 2006; Stafford \& Canary, 1991). If members of marital couples' networks (potential or already existing) feel uncomfortable as a result of marital couples' public performance, marital couples are at risk of losing or failing to develop support systems as well as losing a possible relational maintenance strategy.

During interactions with outsiders, marital couples may choose to disclose about their relationship as a way of constructing and managing identity (Julien et al., 2000; Leslie et al., 1986). It should be noted, however, that one partner's disclosure about the relationship away from the other partner does not constitute public performance. Kelley et al. (1983) contended that a prominent feature of a relationship is that events associated with each partner are causally connected to the events of the other partner. The study of public performances is limited to when both spouses are present to witness the communication event and are knowingly susceptible to the damage to self, partner, and relational image (Goffman, 1967) rather than disclosures that are performed by one marital partner away from the presence of their spouse.

The current dissertation is the first study to define marital couples' public performances in this way. No previous research is available on marital couples' public performances. Instead, researchers have previously examined couples’ public behavior in general. In the next section, a review of previous research on marital couples' behavior in 
public is offered.

\section{Marital Couples’ Public Behavior}

Exploring prior research on marital couples’ public behavior yields five overarching areas that can inform future directions of research by exposing how the study of public performances is unique from public behavior research. The first area is focused on relational dialectics theories (e.g., Baxter \& Montgomery, 1996) and the tensions couples experience when interacting with others outside of the relationship. Seeking a balance in these tensions is one possible reason for couples’ development of personalized communication to be used in public (Hopper, Knapp, \& Scott, 1981). The second area is focused on couples' interactions with each other (e.g., stories, personal idioms) that legitimize the relationship and aid in the establishment of a relationship culture (Wood, 1982). The third area is couples' public behaviors (e.g., nonverbal displays of affection or tie-signs) that aim to signal the existence of their relationship to outsiders (Afifi \& Johnson, 1999). The fourth area is focused on rules regarding public conflict that guide marital partners' communication decisions (Jones \& Gallois, 1989). The fifth area is focused on couples' social networks with emphasis on the characteristics of networks and the salience of them to couples (Milardo, 1982). Each of these areas is reviewed briefly.

\section{Relational Dialectics}

Dialectical theories suggest that individuals experience contradictory tensions, or opposing forces that are interdependent of each other but also counteract each other (Baxter \& Montgomery, 1996). Such tensions are inevitable and evoke constant struggles between marital couples, referred to as internal tensions, as well as with those outside of the relationships, referred to as external tensions. These tensions are managed via 
communication, which in turn contributes to the emergence of the couple's uniqueness. Baxter and Montgomery presented three "supra-dialectics" that encompass six internal and external dialectical tensions. The first supra-dialectic is integration-separation, which includes internal struggles of interdependence and autonomy between partners and external struggles of inclusion and seclusion with individuals outside the relationship. In explaining external tensions, Baxter and Montgomery claimed that couples need private time to develop their relational culture, but simultaneously require interaction with others to legitimize their relationship.

The second supra-dialectic is stability-change, which entails competing internal desires for predictability and novelty as well as external desires for conventionality and uniqueness. Within the relationship, marital couples desire predictable events, which may explain couples’ developments of relational routines and rituals (Bruess \& Pearson, 1997). Yet, too much predictability can lead to boredom (e.g., planned dinners week after week), driving couples to seek spontaneity (e.g., unplanned dinner at a restaurant). Externally, couples abide by conventional norms and expectations (e.g., get along with each other when with those outside the relationship) but develop relational identity from perceptions of the relationship as unique from others (e.g., tell personal stories to outsiders, tease each other when with others). The last supra-dialectic is expressionprivacy. Internally, marital partners regulate desires for openness (e.g., highly disclosive) to build intimacy while maintaining closedness (e.g., privacy) for the protection of the other. Externally, couples manage revealment and concealment tensions with members of their social network.

The experience of contradictions becomes more complex when considering the 
multiple levels on which opposing tensions are experienced. Specifically, not only do individuals experience competing desires within themselves and marital partners experience opposing forces between them, but the introduction of another individual (or couple) external to the relationship introduces another tension (or set of tensions). The complexity of this dynamic is partially responsible for scholarly focus on tensions expressed communicatively between marital partners and their role in the turning points or dramatic changes in the relationship. This focus is somewhat warranted because of the centrality of internal dialectics to the evolution of romantic relationships (Baxter \& Erbert, 1999) such that as couples work through the tension they change. In Baxter and Erbert's study of relational turning points, however, one turning point (interference from a social network) was especially problematic for couples’ struggles with inclusionseclusion and revealment-concealment tensions. That is, couples struggled with decisions about how much time to spend with individuals outside the relationship versus alone as well as with how much information to share with outsiders. Although they found the conventional-uniqueness dialectic to be less central to romantic couples' turning points, Baxter and Erbert contended that couples are likely to experience a shift in their relationship when their couple uniqueness is challenged.

Petronio’s (2002) Communication Privacy Management (CPM) Theory elaborates specifically on the expression-privacy dialectic. CPM theory suggests a metaphorical boundary management system in which co-owners (in this case, marital partners) communicatively construct boundaries around their private information. Through coordination and negotiation, marital couples can regulate access to their private information at their discretion. Hest, Pearson, and Child (2006) discovered regulating 
private information was one reason marital couples created cover stories, which are narratives that marital partners co-construct and deliver to outsiders. These stories often do not reveal the truth and are created to protect the couple's image. One example is a couple's decision to say the wife is going to the doctor for reasons other than the true purpose. Although managing private information was a less common reason for constructing cover stories, regulating private information was important to marital couples. Baxter and Widenmann (1993) found some dating partners concealed the very existence of their relationship from their social network for the purpose of upholding the relationship’s privacy boundary rules. The next section focuses on research within the boundaries of relationships that, when performed in public, can establish a couple’s culture.

\section{Relational Culture}

Marital couples co-jointly construct identities through the use of rituals/routines, stories, and play. From a relational cultural perspective (Fitzpatrick \& Best, 1977; Wood, 1982), marital couples create unique microcultures by co-constructing symbolic activities with shared meaning that is maintained by the couple (Baxter, 1987; Bruess \& Pearson, 1997, 2000). Relational culture is a central influence on couples' ways of “knowing, being, and acting in relation to each other and the outside world” (Wood, 1982, p. 75). Baxter's (1987) examination of relational symbols revealed five categories of symbols common to friendships and romantic relationships. These included physical objects, cultural artifacts, special places, special times in the relationship, and behavioral actions (i.e., linguistic and non-linguistic). Of these five categories, dating couples engaged in behavioral actions most frequently. Within the behavioral actions category, the most 
frequently reported behaviors were joint activities and interaction routines, which typically included joking and teasing each other. From the participants' perspectives, these enactments made their relationship different from others'.

Relational culture has been likewise examined with regard to intimate forms of play between friends and dating partners (Baxter, 1992). Although one category is “public performance," this category included times when couples collectively performed a joke on a third party observer such as pretending to argue for the sake of watching observers' reactions. The most frequent type of play displayed in dating relationships was private verbal code, which included idiomatic expressions or private jokes. Private verbal code was a strong indicator of intimacy such that this form of playfulness was associated with perceptions of relational partners as close to one another. Dating couples likewise engaged in verbal teasing and prosocial physical play rather frequently. Prosocial physical play was typically displayed nonverbally in the form of mimicking conventional prosocial behavior such as playfully waltzing. When comparing romantic couples and friends, romantic couples engaged in fewer behavioral rituals and routines than friends, but were more likely to use physical objects such as pictures to represent their relationship identity (Baxter, 1987, 1992).

Hopper et al. (1981) found eight common idioms used by marital couples when in private and public settings. These included partner nicknames, expressions of affection, labels for others outside the relationship, confrontations, requests and routines, sexual references and euphemisms, sexual invitations, and teasing insults. The most frequently used idioms were teasing insults, which were more commonly expressed verbally than nonverbally, and expressions of affection, which were more commonly expressed 
nonverbally than verbally. Idioms were more frequently used in private than in public and were used more during the early stages of the relationship (from dating to the first three years of marriage). The authors proposed personal idioms are more salient for relational development rather than maintenance.

Bell, Buerkel-Rothfuss, and Gore’s (1987) follow-up examination validated Hopper et al.'s (1981) categories of idiomatic communication as well as assessed marital couples' liking, love, and commitment as they related to the functions of idiom use. They found both sexes' loving, commitment, and closeness scores were associated with more frequent use of idioms for the purposes of expressing affection, initiating sexual encounters, and referring to sexual matters in general. Such idioms, however, were typically reserved for private use whereas labels for outsiders and teasing insults were more common in public.

\section{Behavioral Displays of Relational Existence}

When in public, relational partners also nonverbally communicate with each other and as a couple to outsiders. According to Goffman (1971), individuals engage in behaviors such as holding hands and putting their arms around each other's shoulders in public as ways of informing others of their relationship and its status. While individuals often verbally disclose to others about their relationship (Baxter \& Widenmann, 1993; Goffman, 1971), tie signs are considered the nonverbal equivalent. Public touch, one type of tie-sign, has received more attention than other displays.

Although touch in general is the most powerful type of tie-sign, it is overall a less frequent form of expression in public (Stier \& Hall, 1984). Yet, frequency of touching behavior is different depending on the type of relationship being observed. Seriously 
dating couples tend to engage in more public touching than causally dating and marital couples (Guerrero \& Andersen, 1991). Marital couples engage in public touching less frequently (Willis \& Briggs, 1992), but they are more likely to match or reciprocate their partner’s touching behavior (Guerrero \& Andersen, 1994). Researchers have discovered that in dating relationships, men initiated more touch, whereas in married relationships, women initiated more touch (Guerrero \& Andersen, 1994; Willis \& Briggs, 1992). In Hall and Veccia’s (1990) field observations of dyads, whose relationship to each other remained unknown, younger men initiated touch more than older men, but younger women initiated touch less than older women.

Patterson (1988) proposed seven purposes for nonverbal behavior in close relationships. These include information giving, interaction regulation, intimacy expression, social control, presentation, affect management, and service-task. The presentational function is the only function in which the individuals engage in public nonverbal behavior to purposefully manage a desired image. Patterson noted that the presentation function is not only with regard to individuals' self-image, but the image or identity of the relationship (i.e., relationship-presentation). Afifi and Johnson (1999) examined Patterson's (1988) functions of nonverbal behavior in opposite-sex friendships and dating relationships from the perspective of both relational partners. Although initiators reported they were motivated to use tie-signs in dating couples for the purpose of expressing physical affection, receivers often perceived their dating partners' use of tie-signs as motivated by relationship presentation goals. Afifi and Johnson concluded that individuals are "poor interpreters of tie sign functions” (p. 32). Couples may not only be engaging in tie-signs for the purpose of communicating affection to each other, but for 
the sake of presenting a desired image of their relationship to others.

Buchanan, O’Hair, and Becker (2006) examined marital partners’ resistance strategies to partner initiated dissolution. They found some marital partners resisted dissolution by engaging in public physical and verbal displays to inform others that they were a couple. Physical possession signals included engaging in public touching with the spouse to inform others of the relationship and verbal expression included engaging in public verbal communication with the spouse to inform others of the relationship. Conversely, Baxter and Widenmann (1993) discovered that some dating couples concealed their relationship from social networks by engaging in fewer displays of affection when in front of their friends. For instance, one participant noted that he and his dating partner maintained further distances from each other, never touched each other, and never teased each other when in public. Together, these studies, although more situation specific in their focus, suggest individuals are at least occasionally strategic in their use of tie-signs in public.

\section{Public Conflict}

Researchers have also explored couples' rules about conflict while in a public setting. Conflict is one of the most common issues experienced in marriage (Argyle \& Furnham, 1983), but when in public, spouses appear to shift their focus away from resolving the conflict to self-presentation goals (Jones \& Gallois, 1989). Jones and Gallois had marital couples role-play conflict in simulated private and public settings (each couple engaged in both). After the role-play, they had each couple observe their own videotaped interaction and report which rules of conflict they violated. From their analysis, five overall rules were identified and were further examined in a follow-up 
study, which revealed rationality rules were most important in the public context.

Rationality rules were those that regulated that couples should not get angry, aggressive, or raise voice, and should not bring up issues that cause conflict. Wives perceived this rule as more important in public than did husbands, but by comparison to the other rules the rationality rule was rated as significantly less important than the other rules, including self-expression and conflict resolution, regardless of context or sex. From their study, Jones and Gallois likewise found that couples' reviews of their own videotaped conflicts helped couples see for themselves the rules they were violating. Several couples commented that it was easier to identify the rules they were breaking than the rules they were following. Jones and Gallois recognized that individuals within the relationship might not have the most accurate perceptions of their own behavior. Viewing videotapes can be beneficial to married persons and researchers for identifying what constitutes rule compliance and rule violation. Overall, their study suggests that marital couples avoid conflict in public to protect how others perceive their relationship.

Social Networks

Studies that have focused on marital couples' external interactions have examined the size and composition of social networks as they relate to the development of romantic relationships. Generally, as relationships progress through the stages of development from casually dating to marriage and become more interdependent, the individuals in the relationship interact with fewer people for shorter durations less often such that frequency and duration of interaction were low when interacting with intermediate friends and acquaintances (Milardo, Johnson, \& Huston, 1983). Typically, romantic partners move away from their independent social networks and develop more shared networks 
(Milardo, 1982). When accounting for the duration of relationships, Agnew et al. (2001) found that those dating couples who had a higher proportion of joint friends (versus those with a lower proportion of joint friends) in their social networks were more committed, satisfied, and invested in their relationships, perceived fewer alternatives to the relationship, and perceived their relational partner as an extension of themselves. These dating couples were also more likely to still be in their relationship six months later. Spending time with joint friends seems to validate and confirm the couple's ongoing relationship (Agnew et al., 2001). Although the size of the shared network increases over time, the frequency of activity with networks decreases (Surra, 1985). Yet, interactions with networks are one of the ways that marital couples maintain their relationship (Stafford \& Canary, 1991). Thus, although there is limited activity with others, the activities that do occur appear to be salient to marital couples.

\section{Summary of Studying Couples’ Public Behavior}

The prior section reviewed five general areas of research that can guide future research on marital couples and their public behavior. The review of dialectical theories offers insight to the opposing tensions that affect couples' interactions with others outside of the relationship, while simultaneously affecting the couple. Studies of couples’ development and use of stories and private language aid in understanding how couples create a mini-culture, and studies of public behavior in the form of tie-signs and touch are indicative of how couples inform others of their relationship. Research on conflict indicates that couples are aware of the rules surrounding conflict in public places or in the presence of others. Research on social networks informs us that marital couples are more satisfied when they have shared joint friends (although activities with others appear to be 
relatively infrequent). Thus, this review is informative about married couples, in part by revealing where research on marital couples and their interactions with others is lacking.

First, several of these studies focus on young romantic (typically dating) couples with considerably less focus directed at understanding marital couples who have already engaged in a public ceremony that legally binds their relationship. Second, prior research has overlooked marital couples’ strategic preparation before public performance as well as their evaluation after public performance (Elkin, 1958). Third, although prior research has examined marital couples as unique entities and their reported use of specific communication strategies in public (Hest et al., 2006; Hopper et al., 1981), researchers know little about marital couples’ public performances. These oversights in the literature expose a number of possibilities for building a program of research on marital couples and their public performances. To extend current understanding of marital couples’ public performances, especially with regard to how they are conceptualized here, Communication Theory of Identity (CTI) (Hecht, 1993; Hecht, Collier, \& Ribeau, 1993; Hecht, Jackson, Lindsley, Strauss, \& Johnson, 2001) is proposed. In the following section, a review of the theory and related research is offered.

\section{Communication Theory of Identity}

According to CTI (Hecht, 1993; Hecht et al., 1993; Hecht et al., 2001), identity is not simply a product or outcome of communication, nor is communication a product or outcome of identity. Rather, identity is communication that must be understood as a transactional exchange of messages (Hecht, 1993). The theory posits that individuals internalize roles and relationships as identities, and identities are in turn enacted via communication. 
CTI recognizes four frames of identity: personal, enacted, relational, and communal (Hecht et al., 2001). Personal identity is considered a characteristic of an individual and is one's self-concept or self-image. The cognitions, feelings, and spiritual sense of being individuals have of themselves denote how they define themselves generally and in specific situations. Enacted identity is one's identity that he or she performs or expresses communicatively to others. Rather than being a mere expression, however, CTI declares the enacted identity is the identity itself. Hecht (1993) noted that the only way we can experience identity is through communication. Relational identity is mutually constructed during social interactions (Hecht, 1993). The relational identity frame has four levels. The first level is ascribed relational identity, which is a person's internalization of how others’ perceive him or her (Jung \& Hecht, 2004). The second level is a person's identification with his or her role in a relationship with another, such as spouse or friend. The third level is a person's multiple identities in relation to each other, such as wife and mother. The fourth level is a couple's joint identity, which is when the relationship constructs and establishes a unique identity shared by relational partners (Hecht, 1993; Wood, 1982). Communal identity is a group identity that bonds individuals together. This layer of identity is a characteristic of a collective such that it explains more persons than any one individual. For instance, terms such as AfricanAmerican and Asian-American identify a communal identity shared by many. Within the context of marriage, couples could be considered part of the overall communal identity of being "married."

All four frames of identity are interwoven or "interpenetrated" to comprise one’s overall identity (Jung \& Hecht, 2004) or what Cupach and Imahori (1993) refer to as 
one's total identity. Individuals' total identity is comprised of multiple smaller components as well as their nonsummative interactions (Cupach \& Imahori, 1993). The four frames can be considered separately, however, for analytical purposes. Separating the four frames can be favorable because they do not always complement each other, but occasionally contradict, such as when a partner's ascribed relational identity does not match one’s self-defined identity (Hecht, Faulkner, Meyer, Niles, Golden, \& Cutler, 2002). Identity gaps are the discrepancies between or among any two, three, or all four of the frames of identity (Jung \& Hecht, 2004). These are problematic because they can cause stress and tension.

When individuals experience gaps between their personal and enacted identities as well as their personal and relational identities, they experience lower levels of communication satisfaction, lesser feelings of being understood, and overall reduced perceptions of communication appropriateness and effectiveness (Jung \& Hecht, 2004). Identity gaps between personal and enacted identities have also been associated with depression among Korean immigrants (Jung \& Hecht, 2008) and international students (Jung, Hecht, \& Wadsworth, 2007). International students have also reported less education satisfaction as a result of identity gaps between their personal and enacted identities, but not between their personal and relationally ascribed identities (Wadsworth, Hecht, \& Jung, 2008). This suggests that, at least in the classroom, one’s own communication is more critical to the negative effects of identity gaps. Students reported smaller identity gaps when they were more acculturated into their host country and perceived less discrimination from others (Wadsworth et al., 2008). Personal-enacted identity gaps appear to mediate the association between acculturation and perceived 
discrimination (Jung et al., 2007).

There are three dimensions of cultural identity that can be extended to understanding individuals’ enactment of their overall total identity (Collier \& Thomas, 1988; Cupach \& Imahori, 1993; Hecht et al., 1993) that may influence the negative effects of identity gaps on individuals and are of interest here on marital couples. Scope is the number of people who potentially share an identity with others. Married persons’ communal identities will naturally have larger scopes than their shared couple identities. For example, to be classified as "married" indicates a communal identity that several people embrace and therefore has a larger scope. Yet, each specific married couple is different in some way. Their shared couple identity is limited to the two of them and therefore has a smaller scope. Salience is the degree of importance of one aspect of a person's total identity by comparison to other aspects of that person's identity. A marital couple's joint identity may be more important than other aspects of each partner's total identity in certain situations. For instance, a marital couple’s joint identity may be in the forefront when being evaluated as suitable parents for adoption or when developing joint social networks. Intensity is the strength with which individuals communicate certain aspects of their identity. Acitelli, Rogers, and Knee (1999) contended that spouses in close relationships may have general relational identities toward others as well as more specific couple identities in their exclusive relationship. To demonstrate, women who embrace their relational role identity as wives may intensely communicate this aspect of their identities socially, but downplay this aspect when with work associates. Given this dissertation's focus on couple identity, spouses may encounter identity gaps when they disagree on the degree of intensity with which their couple identity should be 
communicated in a specific context.

These three dimensions of cultural identity are interdependent. When a certain aspect of one's identity is more salient, that person is more likely to intensely enact that aspect of their identity. Hecht et al. (2002) found Jewish Americans who self-identified as conservative Jews and considered this to be a central characteristic of their personal identity were more overt and constant in their enacted identity. Similarly, when one aspect of one's identity is narrower in scope, it may be considered more unique (Baxter \& Montgomery, 1996) and therefore, more salient to the individuals. When an aspect of one's identity is more salient to an individual, it is more likely that he or she will want to protect that identity from damage (Goffman, 1967). Similarly, when a joint couple identity is more salient to a marital couple, they are more likely to protect it when interacting with others.

As noted above, individuals' total identities are the culmination of all four frames of identity. Although prior research has indicated personal-relational identity gaps have less of an impact on outcomes than personal-enacted identity gaps (Jung \& Hecht, 2008; Wadsworth et al., 2007), research has yet to examine identity gaps in the context of marital couples. One goal of this dissertation is to extend CTI and the study of identity gaps to married couples. Studying attachment styles in conjunction with CTI can inform why couples enact certain joint identities as well as aid in explaining why some couples may suffer more identity gaps. In particular, attachment styles are working models or cognitive representations that individuals have of themselves and who they are in relation to others (Bartholomew, 1990). Such models in turn influence how individuals communicate (Le Poire, Shepard, \& Duggan, 1999; Noller, 2005). In the context of a 
marital relationship, partners may have differing working models (Feeney, 2003) and therefore they may communicate in differing ways. This in turn may cause identity gaps between personal, relational, and enacted identities for married partners (or couples), especially during public performances. Although a number of factors can influence outward behavior, attachment styles are relationship specific characteristics that can be examined at the dyadic level (Feeney, 2003). One partner’s security (or insecurity) in attachment provides a context for the other partner. As such, partners can exacerbate each other's attachment tendencies that can ultimately lead to positive (or negative) relational outcomes and overall healthy (or unhealthy) relationships. It is important to explore the communication processes, such as public performances, by which relational outcomes are achieved (Simon \& Baxter, 1993). In the following section, attachment styles research is reviewed.

Attachment Styles

Attachment research was originally introduced to explain the connection between children and their primary caregivers (Bowlby, 1969). Since its inception, researchers have extended the study of attachment to adult romantic relationships (Hazan \& Shaver, 1987) and the subsequent effects of attachment styles on satisfaction levels (Treboux, Crowell, \& Waters, 2004) and relational quality (Ben-Ari \& Lavee, 2005). Of specific interest to communication researchers, and this dissertation, are the connections between individuals’ attachment and their outward behavior (Guerrero \& Jones, 2003, 2005; Le Poire et al., 1999; Noller, 2005). Researchers have projected that attachment styles are reinforced through social interaction such that individuals’ behaviors stimulate reinforcement of their working models of self and/or others (Bartholomew, 1990). From a 
CTI perspective, outward behavioral displays, influenced by individuals’ attachment styles, may be problematic for shared couple identity and associated identity gaps. CTI may provide a theoretical basis for why married couples who are similar in their attachment styles fare better than others (Luo \& Klohnen, 2005).

Adult attachment styles research has indicated there are two underlying dimensions: anxiety and avoidance (Bartholomew \& Horowitz, 1991). The anxiety dimension refers to individuals' sense of self-worth and acceptance of others and the avoidance dimension refers to the degree to which individuals approach or avoid intimacy and interdependence with others. The intersection of these dimensions results in four attachment styles: secure, preoccupied, fearful avoidant, and dismissive.

The first style is the secure attachment style. Secure individuals are able to depend on others without fear of abandonment (Collins \& Feeney, 2004; Guerrero \& Jones, 2003). They feel a sense of worthiness and perceive others as generally caring (Bartholomew \& Horowitz, 1991). Secures are comfortable with both intimacy and autonomy (Bartholomew, 1990) and are therefore able to maintain relationships without losing their autonomy (Collins \& Feeney, 2004). Secure individuals are behaviorally flexible (Guerrero \& Jones, 2003). They display trust (Guerrero, 1996), self-confidence, and warmth toward others (Bartholomew \& Horowitz, 1991). Secure marital couples display fewer depressive symptoms (Scott \& Cordova, 2002), engage in less conflict, and overall, report higher levels of satisfaction (Treboux et al., 2004) and better quality marriages (Ben-Ari \& Lavee, 2005) than insecure couples. When experiencing stress and suffering from negative life events, secure marital partners are unlikely to let these things impact their positive feelings toward their relationship or their secure base (Treboux et 
al., 2004). Crowell, Treboux, and Waters' (2002) longitudinal examination of attachment in marital couples revealed secure individuals indicated stronger feelings of dedication to their marriage, more intimacy, fewer arguments with their partner, and less verbal aggression toward their partner than insecure individuals. They were also less likely to threaten to leave the relationship. Secure individuals use more maintenance strategies with their romantic partners than those with any other attachment style (Dainton, 2007; Guerrero \& Bachman, 2006), an alternative explanation to the matching hypothesis for their high quality relationships (Simon \& Baxter, 1993).

The second style is the preoccupied attachment style. Unlike those individuals who are secure in their attachment style, preoccupied individuals feel negatively about themselves and feel unworthy of others' care and affection. Yet, preoccupied individuals feel positively about others (Bartholomew, 1990) and are comfortable with intimacy and closeness (Collins \& Feeney, 2004). These individuals are high anxiety but low avoidance. They strive for acceptance from others to boost their self-acceptance (Bartholomew \& Horowitz, 1991). They are typically anxious and fearful that they will be abandoned by relational partners whom they perceive as unwilling to commit to relationships (Collins \& Feeney, 2004). Preoccupied individuals can be characterized by their over-dependence on their relationship partners or their clinginess (Bartholomew, 1990). Preoccupied individuals are overly sociable and expressive, highly sensitive, and less emotionally controlled (Guerrero \& Jones, 2003). When others show decreased involvement during interaction, preoccupied individuals are likely to compensate by increasing their own involvement (Guerrero \& Burgoon, 1996). They also engage in more inappropriate self-disclosure and are often perceived as autocratic and competitive 
by friends (Bartholomew \& Horowitz, 1991). With regard to marital relationship maintenance behaviors, the preoccupied attachment style has been negatively associated with positivity and integrative conflict management strategies but positively associated with assurance strategies (Dainton, 2007). Preoccupied men (dating, engaged, and married) self-reported they used low levels of positivity, but high levels of openness, assurances, support, and comfort to maintain their relationships (Guerrero \& Bachman, 2006). Surprisingly, however, individuals were less likely to use assurances when their partner was preoccupied (Guerrero \& Bachman, 2006).

The third attachment style is the fearful avoidant attachment style. Fearful avoidant individuals feel negatively about themselves and about others. They are highly anxious and avoidant. According to Bartholomew (1990), fearful avoidant individuals desire intimacy and social interaction, but their ever-present distrust for others and fear of rejection stands in the way of satisfying these desires. As such, these individuals typically avoid situations where they perceive themselves as vulnerable, and when in social situations, they are typically introverted and sub-assertive (Bartholomew, 1990). They report less self-disclosure, intimacy, romantic involvement, reliance on others, and use of others as a secure base when upset (Bartholomew \& Horowitz, 1991). When both spouses have fearful avoidant attachment styles, they tend to have poor marital quality (Ben-Ari \& Lavee, 2005). As with the preoccupied attachment style, the fearful avoidant attachment style has been negatively associated with use of integrative conflict management and positivity, but positively associated with assurant relational maintenance strategies (Dainton, 2007). Contrarily, fearful avoidant individuals have also been found to use less frequent assurances, romantic affection, and openness as means for 
maintaining their relationships (Guerrero \& Bachman, 2006).

The fourth attachment style is the dismissive attachment style. Dismissive individuals feel positively about themselves but negatively about others. These individuals are low anxious but high avoidance. They distance themselves in the face of rejection as a means of maintaining a positive self-image (Bartholomew, 1990). Dismissive individuals place little importance on relationships and greater importance on independence. As such, they are cold (Bartholomew \& Horowitz, 1991), not socially sensitive, and not very sociable or expressive (Guerrero \& Jones, 2003). Friends typically rate dismissive individuals as introverted and low in nurturing (Bartholomew \& Horowitz, 1991). They are noted to be less attuned to romantic partners’ relational maintenance attempts and infrequently use relational maintenance behaviors themselves (Dainton, 2007). Guerrero and Bachman (2006), however, found dismissive individuals used similar degrees of positivity, social networks, sharing tasks, and support and comfort as securely attached individuals. Openness, assurances, and romantic affection were not frequently used maintenance strategies employed by dismissives, possibly due to a degree of comfort with commitment and closeness they signify (Guerrero \& Bachman, 2006).

Married partners may differ in how they view themselves and others. Although attachment styles have traditionally been examined as a distinguishing characteristic of an individual (e.g., Bartholomew, 1990; Ben-Ari \& Lavee, 2005; Hazan \& Shaver, 1987), some researchers have embraced attachment as a relationship variable (e.g., Baldwin, Keelan, Fehr, Enns, \& Koh-Rangarajoo, 1996) and still others have noted it illusionary to conceive of attachment styles as either/or but consisting of fundamental characteristics of 
both individuals and relationships (Feeney, 2003). Conceiving of attachment styles as a marital couple characteristic is warranted because of the effects these styles can have on couples. Attachment styles serve as specific cognitive schemata that filter individuals’ encoding of behavior and decoding of other's behavior. Noller (2005) projected that those who are secure in their attachment should be relatively accurate in their decoding of and sensitivity to positive and negative affect expressions. Conversely, she projected that insecures are more likely to decode "ambiguous" or neutral messages toward their bias. For instance, those with high anxiety are likely to have trouble decoding closeness from others because of their negative view of themselves. Avoidants would be hindered in their decoding of nonverbal behaviors. Thus, not only do attachment styles affect marital couples’ outward behavior (Guerrero, 1996; Guerrero \& Burgoon, 1996), but also their interpretations of each other’s behaviors (Bachman \& Bippus, 2005; Guerrero \& Jones, 2003).

There are three implications of prior attachment research that inform the current examination of marital couples’ joint identity and public performances. First, attachment style schemata are likely to influence the degree to which married people embrace the idea that they have a shared couple identity. Insecurely attached individuals are likely to have difficulty conceiving of themselves and their relational partners as an entity that shares a unique identity. Second, attachment styles will influence married couples’ encoding and decoding of public performances. Guerrero (1996) found fearful avoidants sat furthest from their relational partners during semi-public interactions and along with preoccupieds were more vocally anxious. Other reports of partners’ skills revealed differing perceptions based on one's own attachment anxiety and avoidance. As such, it 
seems plausible that attachment styles will impact marital couples' interpretation of enacted identities. Third, when marital partners differ in their underlying self-schemata, marital couples may be more likely to suffer identity gaps. Specifically, because selfschemata affect outward behavior, couples may struggle with how to enact their couple identity. For instance, a securely attached person who is married to an insecurely attached person may suffer an identity gap between his or her personal identity (how he or she perceives him or herself) and his or her enacted couple identity (how he or she co-jointly engages in a public performance with his or her spouse) because of differences in outward behavior Previously, researchers have found individuals prefer romantic partners who are similar in their attachment style (Kirkpatrick \& Davis, 1994; Luo \& Klohnen, 2005). From a CTI perspective, differences in behaviors and decoding problems are likely to cause gaps in personal, relational, and enacted identities. 


\section{Statement of the Problem}

Two studies were conducted to explore marital couples’ public performances. Study one explored marital couples’ experiences with identity gaps during public performances in general and how they are associated with marital couples' feelings about their public performances and their relationship. Study two utilized observational methods for validation of marital couples’ public performances while also further examining how identity gaps during public performances affect couples’ perceptions and evaluations of communication events.

\section{Study One}

Hecht (1993) declared, "the self that emerges (i.e., who one is) is influenced by who one is with” (p. 80). Communication Theory of Identity also states that as social entities, relationships develop identities. Marital couples, like individuals, communicatively enact their identities and internalize how others perceive their relationship (Titus, 1980). Communication events sometimes result in what Jung and Hecht (2004) refer to as identity gaps, where individuals' frames of identity (personal or couple identity and enacted identity) are incongruent, meaning how individuals see themselves is not aligned with the identity they have performed during communication with others. Marital couples are susceptible to the negative effects of identity gaps between their couple identity and their enacted couple identity. Given that marital couples consist of two individuals, identity gaps may occur for one marital partner when in public but not for another. Such identity gaps are likely to be distressing for marital couples in addition to each of the marital partners. Moreover, identity gaps may be more distressing for some couples but not for others. The distress associated with identity gaps 
may result in marital couples' decisions to opt out of frequent interaction with others, hurting their chances for developing social networks and support systems and losing a relational maintenance option.

Previously, Jung and Hecht (2004) assessed communication satisfaction, feelings of being understood, and conversational appropriateness as they pertained to identity gaps. According to Hecht (1978), communication satisfaction is the affective outcome of rewarding communication and communication is rewarding when it matches individuals' experiences and expectations. More importantly, when individuals feel more satisfied with themselves in communication episodes, they feel more communication satisfaction in general (Hecht \& Sereno, 1985). Conversely, in communication that does not allow for individuals to achieve their "inner standards," which is the case when identity gaps occur, individuals experience less communication satisfaction (Jung \& Hecht, 2004). Weger (2005) noted that relational partners look to each other for evidence that their partner understands and accepts them for who they are. In social situations where marital partners experience identity gaps, this confirmation or verification is typically not present; thus, feeling understood is less likely in the face of identity gaps (Jung \& Hecht, 2004). Spitzberg and Hecht (1984) noted satisfactory interactions are appropriate. Again, identity gaps hinder communicators’ abilities to accomplish appropriateness (Jung \& Hecht, 2004).

In addition to these outcomes, it is necessary to assess the effects identity gaps can have on couples' feelings about the relationship. Two outcomes under consideration here are relationship satisfaction and commitment. Relationship satisfaction refers to the degree of overall happiness with a relationship (Fincham \& Beach, 2006). Spouses are 
happier when they feel more understood by their partners (Cahn, 1990) and are more satisfied with their relationship when their partners are similar to them in their communication skills (Burleson \& Denton, 1992). Similarities in communication skills should result in fewer identity gaps during public performances and greater feelings of satisfaction with the relationship. Acitelli et al. (1999) found that marital couples' shared identity moderated the association between positive thinking about the relationship and relationship satisfaction. They did not find differences according to biological sex, leading the researchers to conclude that couples' identity is a more important moderator of the association between relationship thinking and satisfaction. Thus, relationship satisfaction should be inversely related to identity gaps.

Commitment is conceptualized as one's allegiance to a relationship characterized by one’s sense of “we-ness” or psychological attachment to his or her partner (Agnew, Van Lange, Rusbult, \& Langston, 1998). Couple identity has been identified as one component of individuals' personal commitment to their marriages (Johnson et al., 1999). As such, when couples experience identity gaps between their couple, personal, and enacted identities, they are likely to report lower levels of commitment.

Based on prior discovery that identity gaps can have negative effects, this study projected identity gaps will be inversely associated with communication satisfaction, feelings of being understood, and conversational appropriateness. Furthermore, married couples' identity gaps during public performances will be associated with lower levels of relationship satisfaction and relational commitment. The following hypotheses were proposed.

H1: Marital couples' identity gaps will be inversely related to their levels of 
communication satisfaction, feelings of being understood, and conversational appropriateness.

H2: Married couples' identity gaps will be inversely related to their levels of relationship satisfaction and commitment.

This study also examined how two characteristics of individuals and relationships, attachment and relationship awareness, affect couples' experiences with identity gaps. As attachment styles have been associated with outward verbal and nonverbal behavior (Guerrero, 1996; Guerrero \& Burgoon, 1996), marital partners’ differences in their attachment styles could be problematic when enacting their couple identity during public performances. Yet, research on relationship awareness suggests some individuals may be more attuned to their relationship (Acitelli, 2002) and therefore be less likely to experience identity gaps during public performances.

CTI may explain why extant research on attachment styles has found that for the most part individuals prefer romantic partners who are similar in their attachment styles (Baldwin et al., 1996; Kirkpatrick \& Davis, 1994). Attachment styles are likely to influence marital couples’ public behavior (Le Poire et al., 1999; Guerrero, 1996; Guerrero \& Burgoon, 1996) and are likely to affect marital couples’ public performances and couple identities. Guerrero (1996) found secures and preoccupieds engaged in more receptivity, gaze, facial pleasantness, vocal pleasantness, general interest, and attentiveness than dismissives. Fearful avoidants sat farthest from their partners, displayed less fluency, and had longer response latencies. Preoccupieds and fearful avoidants were the most vocally anxious. Guerrero and Burgoon (1996) examined partner's reciprocation and compensation behaviors in response to their partners' 
increased and decreased involvement. They found all four attachment styles reciprocated increased involvement and compensated for decreased involvement but the pattern was strongest for preoccupieds and weakest for secures and fearful avoidants. Differences in behavior could cause problems such that one’s partner may enact behaviors not endorsed by the other. As such, mixed couples' enacted identity can result in an identity gap. Prior research has also indicated that secure individuals tend to be behaviorally flexible (Guerrero, 1996) and overall more satisfied in their relationships (Treboux et al., 2004). With regard to public performances, secure couples (wherein both partners are secure) are least likely to experience identity gaps associated with public performances.

Married couples’ experiences with identity gaps are also likely to be associated with couples’ degree of relationship awareness (Acitelli, 1993, 2002). Relationship awareness is one's attentiveness to his or her relationship via thinking and talking about the relationship. Acitelli (2002) argued that the relationship that exists between two individuals is a unique entity in and of itself. Marital couples who think and talk about their relationship (higher degree of relational awareness) should be attuned to their relationship in public. To put it differently, marital couples who have a heightened awareness of their relationship will likewise have a heightened awareness of their couple identity. Although relationship awareness has been positively related to individuals’ reports of satisfaction, Acitelli et al. (1999) found that when marital couple identity moderated the association it became negative. Heightened awareness of one’s relationship and its identity may mean these individuals are less likely to experience identity gaps and be less susceptible to their negative effects. Informed by the proceeding logic, the following hypotheses were proposed. 
H3: Marital couples that consist of partners with different attachment styles will report more identity gaps between their personal and enacted couple identities.

H4: Securely attached marital couples will experience the fewest identity gaps.

H5: Relationship awareness will be inversely associated with identity gaps. Study Two

The purpose of the second study was to capture marital couples' enacted joint identities by observing a public performance. Additionally, this study assessed how marital couples' attachment style and private and public self-consciousness are associated with their public performances. Sillars and his colleagues (Sillars, Burggraf, Yost, \& Zietlow, 1992; Sillars, Weisberg, Burggraf, \& Wilson, 1987) discovered that when married couples are more psychologically interdependent, they talked according to more communal themes (versus individual and impersonal themes). According to Sillars et al. (1987), communal themes are communicative representations of the marriage as "the product of joint or interdependent qualities of the couple" (p. 506). A sense of "we-ness" is revealed in the couples' communication categorized into togetherness, cooperation, and communication. Communal themes of togetherness are reflected in couples' accounts of spending time together engaging in joint activities, sharing interests, and having similar attitudes. Cooperation is reflected in couples' accounts of working together collectively, engaging in joint decision making, and managing conflict. Communication is reflected in couples' accounts of talking and sharing thoughts as a couple as well as understanding each other.

In addition to assessing the content of marital couples’ accounts, Sillars et al. 
(1992) examined the degree of integration in couples' accounts when engaging in joint discussion, arguing that integrated accounts can signify greater interdependence. Individuals in more interdependent marriages are more likely to take into consideration each other's accounts when responding, whereas individuals in more autonomous marriages would have separate accounts of their relationship. Thus, Sillars and colleagues analyzed conversations for continuity and hierarchy of themes.

Continuity refers to the chaining out of themes by subsequent speakers. They referenced the notion of a thought or idea causing a chain reaction in a partner to exemplify continuity. For instance, continuity occurs during conversations when one spouse contributes to the other spouse's discussion of how they manage conflict by further discussing the topic. In the same instance, continuity is absent when the spouse changes the topic rather than contributing to the conversation topic. Hierarchy refers to the differing levels of abstractness of marital couples' accounts. They recognized that some accounts were more specific and concrete, whereas others referenced more abstract and transcended specific instances. For example, hierarchy occurs during conversations when one spouse's reference to a prior comment made by his/her significant transcends any specific instance to demonstrate an abstract thought or belief of the couple.

Analysis of accounts for verbal content (e.g., communal, etc) and organization (e.g., continuity and hierarchy) yielded three types of integration chains: blending, differentiating, and balancing. When couples' accounts were more integrated such that there was greater continuity and hierarchy as well as more communal communication themes, they were categorized as a blending chain. When couples accounts displayed little to no integration such that there was less continuity and hierarchy and more 
individual communication themes, they were categorized as a differentiating chain. When couples' accounts were somewhat integrated such that there was some degree of continuity and hierarchy but also individual communication themes, they were categorized as a balancing chain.

Based on Sillars and colleagues’ conceptualization and analyses of marital communication themes and chains, it would seem that married couples who identify themselves as more overlapping in their personal and relational identities would communicatively enact more communal themes and display more blended chains during their public performances. When such communicative behavior is not present during public performances, couples who self-identify as more overlapping in their identities are more likely to experience identity gaps between their personal and enacted couple identities as well as between their couple and their enacted couple identities. Conversely, marital couples who identify themselves as less overlapping in their personal and couple identity would communicatively enact less communal themes and display less blended chains during their public performances. Theoretically, the presence of communal themes and blended chains in turn should cause an identity gap for marital couples who do not identify themselves as overlapping in their personal and relational identities. Married couples are more overlapping in their identities when they perceive themselves as one unit versus two (Aron et al., 1992) and when they believe their relationship is more central to their life than other aspects such as their careers (Agnew et al., 1998). After public performances, these identity gaps should likewise be associated lower levels of communication satisfaction, feeling understood, and conversational appropriateness. The following hypotheses were proposed. 
H6: Marital couples who perceive themselves as having overlapping personal and couple identities will communicate more communal themes and blended chains, whereas marital couples who do not self-identify as having overlapping personal and couple identities will communicate less communal themes and blended chains.

H7: Marital couples will experience identity gaps when the communication they engage in during their public performance is incongruent with their self-perceived identity (more or less overlapping).

H8: Marital couples’ who experience identity gaps after their public performances will report lower communication satisfaction, feeling understood, and communication appropriateness.

Marital couples’ public performances are also likely to be marked by distinctive nonverbal cues. Thus, in addition to the verbal characteristics of marital couples' public performances, the present study examined marital couples’ nonverbal immediacy behaviors during public performances. Nonverbal immediacy is the cluster of approach behaviors that function to stimulate physical or psychological closeness between individuals (Andersen, Andersen, \& Jensen, 1979; Mehrabian, 1971). When married persons perceived their spouses as more immediate, they reported greater liking toward their spouse (Hinkle, 1999). During public performances, such behaviors can likewise function as tie-signs to inform third parties of the relationship’s existence (Goffman, 1971) and the couple’s identity.

There are five commonly studied immediacy behaviors: physical proximity, eye contact, body lean, smiling, and touching (Burgoon, Buller, Hale, \& deTurck, 1984; 
Mehrabian, 1971). Communicating at closer physical distances with more eye contact, leaning forward, smiling, and touching are considered more immediate. In addition to creating feelings of closeness, these behaviors can also communicate greater intimacy, attraction, and trust, less emotional arousal, and greater composure (Burgoon et al., 1984). Yet, high eye contact and close proximity alone communicate greater control and dominance. Thus, it is important to study the collection of behaviors because they operate simultaneously (Andersen et al., 1979). Individuals who display little eye contact, a distal position, leaning away, and do not smile or touch are less immediate and communicate greater detachment. Although married couples engage in less frequent touching than dating couples when in public (Guerrero \& Andersen, 1991; Willis \& Briggs, 1992), previous studies have failed to observe touch and overall immediacy during public performances. Although the degree to which marital couples perceive themselves as overlapping in their personal and relational identities is likely to influence marital couples’ nonverbal immediacy during public performances, little is known about how overlapping identities will affect nonverbal immediacy behavior. Thus, the following research questions were posed.

RQ1: How nonverbally immediate are marital couples during public performances?

RQ2: How is marital couples’ degree of overlap in their individual and couple identities associated with their nonverbal immediacy during their public performances?

As previously noted, attachment styles have been found to impact couples’ communicative behavior (Guerrero, 1996; Guerrero \& Burgoon, 1996; Guerrero \& Jones, 
2003, 2005). The present study questioned how marital couples' verbal and nonverbal behaviors during public performances are associated with attachment styles. Previously, secure individuals were found to engage in more reciprocation of partner's behaviors (Guerrero \& Burgoon, 1996). Such reciprocation would suggest secure marital couples will exhibit more of a joint identity (more communal themes and blending chains) during a public performance than insecure marital couples. Yet, it is important to question if secure couple types will display more or less nonverbal immediacy than insecure couple types. While secure couples may engage in reciprocation of partners' immediacy, insecure couples may feel the need to engage in more tie signs because of their insecurities. The following research questions and hypothesis were forwarded.

RQ3: How do marital couples' attachment styles relate to their verbal and nonverbal behavior during public performances?

H9: Secure marital couples will exhibit more communal themes and blending chains during their public performances than non-secure couples.

RQ4: Do secure marital couples exhibit more nonverbal immediacy during their public performances than non-secure couples?

Some people continually think about their own behavior and motives whereas others do so minimally. This varying degree of awareness is self-consciousness and according to Fenigstein, Scheier, and Buss (1975), there are two separate aspects of selfconsciousness: private and public. Private self-consciousness is one’s awareness, internal contemplation, or mulling about oneself. Individuals who are privately self-conscious have a great deal of personal knowledge of themselves with regard to who they are and what they believe (Scheier, 1980). Private self-consciousness may intensify the effects of 
attachment style on public performances. If high privately self-consciousness individuals (or couples) are more attuned to who they are, they are also more likely to have a heightened awareness of themselves as secure, preoccupied, fearful avoidant, or dismissive in their attachment style. Attachment style should therefore serve as a mediating variable between private self-consciousness and marital couples’ public performances.

Public self-consciousness is one’s awareness and concern for him or herself as a “social object” (Fenigstein et al., 1975). These individuals are concerned with social appearances and the impression they make on others (Scheier, 1980). As such, they are more aware of how others see them and are more sensitive to other's rejection of them (Fenigstein, 1979), which may explain why they tend to match others' behaviors and attitude (Crawford \& Novak, 2007; Scheier, 1980). According to Fenigstein (1979), public self-consciousness is different from self-monitoring such that self-monitors are more focused on the situation, monitoring others and their own behavior, than individuals who are publicly self-conscious whose attention in solely self-focused. Although public self-consciousness has not been previously examined at the couple level (versus the individual level), public self-consciousness should be associated with marital couples’ public performances in two ways. First, married couples’ degree of public selfconsciousness should be associated with the couples’ nonverbal matching behavior during public performances. For instance, when a third party couple displays greater immediacy with each other during a public performance, more publicly self-conscious couples may interact with greater immediacy. Second, married couples that are higher in public self-consciousness may be more likely to behave in socially desirable ways, such 
as being more integrated than those who are lower in public self-consciousness. The following hypotheses were proposed.

H10: Attachment style will mediate the association between private selfconsciousness and marital couples’ verbal and nonverbal behavior during public performances.

H11: Marital couples’ public self-consciousness will be directly associated with marital couples’ nonverbal matching behavior during public performances.

H12: Marital couples' who report high public self-consciousness will display more integrated communication (communal themes, blended chains, nonverbal immediacy) during public performances than those who report low public self-consciousness. 


\section{CHAPTER II:}

\section{METHODOLOGY}

Given that the focus of both studies is on married couples and their public performances, the central criteria for participation was that couples must currently be married and both partners must be living. Participation was not limited to those couples who have been married for a certain period of time or any other demographic variable. Study One

Participants. Participants were 153 married couples (153 husbands, 153 wives) who ranged from ages 18 to $79(M=39.29, S D=12.44)$. Of the sample, $90.6 \%(n=279)$ were White/Caucasian, 4.2\% $(n=13)$ were African American, 1.3\% $(n=4)$ were Asian American, $1 \%(n=3)$ were Hispanic, $1 \%(n=3)$ were Native American, and the remaining $1 \%(n=3)$ were self-identified as Other. The majority of couples resided in West Virginia (52.6\%, $n=162)$, followed by Pennsylvania (12\%, $n=36)$, Maryland (9.1\%, $n=28)$, New Jersey $(8.8 \%, n=27)$, Virginia $(4.9 \%, n=15)$, Ohio $(1.9 \%, n=6)$ and other Northeastern or Midwestern states ( $8.8 \%, n=27)$. On average, the couples were married for 13.42 years $(S D=11.45$, Range $=$ four months to 55.5 years $)$ and had been a couple for 16.22 years ( $S D=11.63$, Range $=$ eight months to 57.5 years). For the majority of married persons, this was their first marriage (86.7\%, $n=267)$, whereas $10.1 \%(n=31)$ reported this was their second marriage, and $8.8 \%(n=3)$ reported this was their third marriage. Each spouse reported approximately how many hours a week they spend as a couple engaging in joint activities (e.g., going to the movies, working out at the gym) and with friends. Several participants $(40.6 \%, n=125)$ reported they spend approximately 5.5 or more hours a week engaging in joint activities. Of the remaining 
married persons, 33.8\% $(n=104)$ reported 3.5 to 5 hours, $18.2 \%(n=56)$ reported 1.5 to 3 hours, and 6.2\% $(n=19)$ reported 0 to 1 hour per week. With regard to time spent with friends, $12.7 \%(n=39)$ reported 5.5 or more hours, $32.5 \%(n=100)$ reported 3.5 to 5 hours, $41.2 \%(n=127)$ reported 1.5 to 3 hours, and $12.3 \%(n=38)$ reported 0 to 1 hour per week. No other demographic data was collected.

Procedures. Participating couples were recruited through students enrolled in communication courses at a large Mid-Western university. Specifically, the primary researcher contacted students in their classroom where they were informed of the criteria for participation and the delivery of study materials. Students who met the criteria were allowed to participate directly. Those who did not were asked to pass along two survey packets and envelopes for each partner to a married couple. Student participants and recruiters received partial course credit for their assistance in this process.

After reading the study cover letter, participants completed a series of measures. Participants self-reported on their attachment styles (Bartholomew \& Horowitz, 1991; Guerrero, 1996), relationship awareness (Snell, Hampton, \& McManus, 1992; Stafford, Dainton, \& Haas, 2000), relationship satisfaction (Spanier, 1976), and commitment (Rusbult, Martz, \& Agnew, 1998). Then, while reflecting on their public performances in general, participants completed identity gap measures (Jung \& Hecht, 2004), their general feelings of communication satisfaction (Hecht, 1978; Rubin, Perse, \& Barbato, 1988), feeling understood (Cahn \& Shulman, 1984), and their perceptions of conversational appropriateness (Canary \& Spitzberg, 1987) during public performances.

Attachment styles. Attachment styles were measured using two scales. First, participants completed Guerrero’s (1996) 30-item continuous measure. The scale consists 
of five dimensions that have achieved high reliabilities: general avoidance (e.g., "I feel uncomfortable when people get close to me,” original $\alpha=.87$ ), lack of confidence (e.g., “I sometimes worry that I do not really fit in with other people,” original $\alpha=.83$ ), preoccupation (e.g., "I feel a very strong need to have close relationships, ” original $\alpha=$ .81), fearful avoidance (e.g., "I would like to trust others, but I have a hard time doing so,” original $\alpha=.78$ ), and relationships as secondary (e.g., “Achieving things is more important to me than building relationships,” original $\alpha=.84$ ). Participants indicated to what degree each statement is true of them on 7-point Likert scales $(1=$ very unlike me; 7 = very like me) (Guerrero \& Burgoon, 1996). Cronbach alpha reliabilities, means, and standard deviations for the current study were as follows: general avoidance, $\alpha=.80$, item $M=3.22$, overall $M=22.59, S D=6.86$; lack of confidence, $\alpha=.77$, item $M=3.17$, overall $M=15.87, S D=5.17$; preoccupation, $\alpha=.72$, item $M=3.88$, overall $M=27.19$, $S D=6.48$; fearful avoidance, $\alpha=.84$, item $M=3.35$, overall $M=16.77, S D=5.85$; relationship as secondary, $\alpha=.46$, item $M=3.82$, overall $M=19.09, S D=3.87$. Second, participants completed Bartholomew and Horowitz’s (1991) categorical descriptions measure. Participants read four short paragraphs, one for each of the four attachment styles. To demonstrate, the dismissive attachment style paragraph read: "I am comfortable without close emotional relationships. It is very important to me to feel independent and self-sufficient, and I prefer not to depend on others or have others depend on me.” After reading all four paragraphs, participants selected the description that best characterizes their personal attachment style by placing a check mark next to it. The categorical description approach to measuring attachment styles is common (Guerrero \& Burgoon, 1996). The current study included this discrete measure for the 
comparison to and extension of prior research. The current study, however, recognizes categorical approaches oversimplify attachment styles and suffer several limitations (Collins \& Read, 1990). Hence, this study included Guerrero’s (1996) continuous measure, which has been validated with Bartholomew and Horowitz's measure (Guerrero \& Burgoon, 1996).

Relationship awareness. According to Acitelli (2002), relationship awareness is couples’ degree of thinking and talking about their relationship. Unfortunately, prior research did not yield a self-report measure that captured both of these dimensions. Thus, the current study operationalized relationship awareness using Snell et al.’s (1992) 9-item Relational Consciousness subscale and Stafford et al.’s (2000) 7-item Openness subscale. The relational consciousness subscale assesses individuals' awareness of their interactions with intimate partners and their overall relationship (e.g., "I think about my close relationships more than most people do”). This subscale has achieved a high internal reliability of .81 and an acceptable re-test reliability of .70 (Pollina \& Snell, 1999). The openness subscale assesses individuals’ direct discussions of their relationship and feelings about the relationship (e.g., "I talk about where we stand”). This subscale has also achieved a high internal reliability of .87 (Stafford et al., 2000). Participants indicated their level of agreement with a total of 16 statements on 7-point Likert-type scales $(1$ = strongly disagree, 7 = strongly agree $)$. In the current study, the Cronbach alpha reliability for the relational consciousness subscale was .86 (item $M=4.86$, overall $M=43.70, S D=8.08$ ) and for the openness subscale was .90 (item $M=5.13$, overall $M=$ 35.88, $S D=7.73$ ). Cronbach alpha for the overall measure was .94 (item $M=4.97$, overall $M=79.58, S D=14.67)$. Higher scores indicate greater relationship awareness. 
Relationship satisfaction. Participants completed Spanier’s (1976) 10-item Relationship Satisfaction Subscale. Participants indicated how often they encounter $(0=$ never, 7 = all of the time) eight related experiences or discussions (e.g., "how often do you or your spouse leave the house after a fight?”). On a Likert-type scale ranging from 1 (extremely unhappy) to 7 (perfect), participants also indicated their overall happiness in their relationship by circling the dot that corresponds with how they feel. The last item asks participants to indicate with a check mark which statement of five possible statements best describes how they feel about the future of their relationship (e.g., "I want desperately for my relationship to succeed, and would go to almost any length to see that it does”). This measure has previously achieved a Cronbach alpha of .94 (Spanier, 1976). In the current study, the Cronbach alpha reliability was .84 (item $M=4.45$, overall $M=$ 44.52, $S D=8.67$ ). Higher scores reflect greater marital satisfaction.

Commitment. Participants completed Rusbult et al.’s (1998) 7-item Commitment Scale. This scale includes Likert-type items measuring participants’ level of agreement (1 = strongly disagree, 7 = strongly agree) with five positively worded items (e.g., "I am committed to maintaining my relationship with my partner”) and three negatively worded items (reverse coded, e.g., "Our relationship is likely to end in the near future”). Rusbult et al. reported a Cronbach alpha of .95. The Cronbach alpha in the current study was .89 (item $M=6.19$, overall $M=43.32, S D=7.43$ ). Higher scores reflect greater commitment. Identity gaps. Participants completed two separate identity gap measures adapted from Jung and Hecht’s (2004) personal-enacted identity gap scale. Participants indicated on 7-point Likert-type scales their level of agreement with each statement $(1=$ strongly disagree, $7=$ strongly agree $)$. The couple-enacted couple identity gap scale consists of 11 
items that assess participants' perceptions that there is an identity gap between the couple’s self-perceived identity and their enacted identity during public performances. The scale was adapted to reflect the couple versus the individual, reflected in the form of using plural versus singular pronouns. For instance, Jung and Hecht’s (2004) original item read, "When I communicate with my communication partners, they get to know the 'real me.'” The adapted item reads, "When we communicate with others (e.g., friends, family, acquaintances), they get to know the 'real us.'” The Cronbach alpha for the current study was .90 (item $M=2.78$, overall $M=30.55, S D=11.35$ ).

The personal-enacted couple identity gap scale also consists of 11 items, but this scale assessed participants' perceptions that there is an identity gap between their personal self-perceived identity and their enacted identity during marital couples' public performances. The scale was adapted so that each item was prefaced by the statement "When my spouse and I are interacting with others...," but the original use of "I" was retained. For instance, the same example item noted above was adapted to read, "When my spouse and I are interacting with others, I communicate in a way so that they get to know the 'real me.'” Jung and Hecht (2004) reported a reliability of .89 for their original version of the scale. The Cronbach alpha for the current study was .70 (item $M=3.16$, overall $M=34.81, S D=7.76$ ).

Communication satisfaction. Participants completed VanLear's (1991) 8-item version of Hecht's (1978) Interpersonal Communication Satisfaction Inventory. For this study, the items were adapted to reflect individuals' degree of communication satisfaction with their public performances in general (e.g., "I enjoy our conversations with others”). Participants indicated on a 7-point Likert-type scale their level of agreement with each 
statement $(1$ = strongly disagree, 7 = strongly agree $)$. This shortened version has previously achieved a reliability of .93 (VanLear, 1991; Venable \& Martin, 1997). For the current study, the Cronbach alpha was .92 (item $M=5.47$, overall $M=43.80, S D=$ 6.98).

Feeling understood. Participants completed Cahn and Shulman’s (1984) 16-item Feelings of Understanding/Misunderstanding Scale (FUMS). This scale assesses individuals’ feelings when seeking understanding from others during communication. Participants rated on a 5-point scale $(1=$ very little, $5=$ very great $)$ the degree to which they experience 16 feelings. Eight feeling words reflect those typically associated with perception of being understood (PBU), including satisfaction, relaxation, pleasure, good, acceptance, comfortableness, happiness, and importance, and eight words reflect those typically associated with perception of being misunderstood (PBM), including dissatisfaction, annoyance, discomfort, insecurity, sadness, failure, incompleteness, and uninterestingness. The scale likewise includes eight filler words, but for the sake of brevity, the filler words were excluded. Cahn and Schulman reported a Cronbach alpha of .89. For the current study, the overall scale achieved a Cronbach alpha of 89 (item $M=$ 4.07, overall $M=65.05, S D=8.84)$.

Conversational appropriateness. Participants completed Canary and Spitzberg’s (1987) 20-item conversational appropriateness scale. This scale assesses individuals’ perceptions of their partners as appropriate with regard to specific aspects of conversations as well as more general or global perceptions of appropriateness. In the current study, participants indicated their level of agreement $(1=$ strongly disagree, $7=$ strongly agree) with each statement on a 7-point Likert-type scale. Previously, the scale 
has achieved Cronbach alphas of .85 and .80 for specific and general appropriateness, respectively (Canary \& Spitzberg, 1987). The overall scale achieved a Cronbach alpha of .94 (item $M=5.01$, overall $M=100.25, S D=21.55$ ) in the current study. For the complete scales for study one, see Appendix A.

Data Analysis. Preliminary analyses were conducted to ensure marital couples’ length of marriage or relationship did not influence the hypothesized associations examined in this study. Before testing the first and second hypotheses, joint couple scores were calculated for identity gap measures, communication satisfaction, feeling understood, conversational appropriateness, relationship satisfaction, and commitment. For hypotheses one and two, simple Pearson Correlations were conducted to assess the associations between identity gaps and the above-noted outcome measures.

Before testing hypotheses three and four, planned contrasts were conducted to validate the categorical description measure. According to Guerrero (1996; Guerrero \& Burgoon, 1996), dismissive and fearful avoidant individuals should score higher on general avoidance than preoccupied and secure individuals because of their negative models of others. Fearful avoidant and preoccupied individuals should score higher on lack of confidence than dismissive and secure individuals because of their negative models of self. In their study, as expected, preoccupied individuals scored highest on preoccupation, fearful avoidant individuals scored highest on fearful avoidance, and dismissive individuals scored highest on relationships as secondary.

After validating the categories, marital partners' style ratings were paired with their spouses and categorized as either matched (both partners have the same attachment style) or mismatched (both partners do not have the same attachment style) to test for 
differences in marital couples' reports of identity gaps (hypothesis three). Specifically, an Independent samples $t$-test was conducted. Marital couples were also categorized as either secure (both partners are secure), insecure (both partners are of insecure styles such as preoccupied and fearful avoidant), or mixed (one partner is secure, but the other is insecure) for hypothesis four testing. An ANOVA was conducted with a Scheffe post hoc analysis. A Pearson Correlation was conducted to test hypothesis five, which predicted marital couples' relationship awareness scores would be negatively associated with marital couples’ identity gaps.

Study Two

Participants. Participants were 46 married couples (46 husbands, 46 wives) who ranged from ages 20 to $83(M=41.62, S D=13.44)$. Of the sample, $88 \%(n=81)$ were White/Caucasian, 1.1\% $(n=1)$ were Asian American, 2.2\% $(n=2)$ were Hispanic, 3.3\% $(n=3)$ were Native American, and the remaining 5.4\% $(n=5)$ self-identified as Other. (It should be noted that a total of 49 couples participated in the study, but three couples were excluded because they either did not meet the definition of marriage outlined by this dissertation or because their interaction couple did not show up for their scheduled time and they therefore interacted with a non-romantic dyad). The majority of couples resided in West Virginia $(91.3 \%, n=84)$, followed by Pennsylvania $(6.5 \%, n=6)$ and New Jersey $(2.2 \%, n=2)$. On average, the couples were married for 15.29 years $(S D=13.80$, Range $=$ one month to 55 years $)$ and had been a couple for 18.41 years $(S D=13.61$, Range $=$ eight months to 55 years). For the majority of married persons, this was their first marriage $(84.8 \%, n=78)$, whereas $15.2 \%(n=14)$ reported this was not their first marriage. Specifically, 85.7\% $(n=12)$ reported this was their second marriage and 14.3\% 
$(n=2)$ reported this was their third marriage. Each spouse reported approximately how many hours a week they spend as a couple engaging in joint activities (e.g., going to the movies, working out at the gym) and with friends. Several participants $(52.2 \%, n=48)$ reported they spend approximately 5.5 or more hours a week engaging in joint activities. Of the remaining married persons, $16.3 \%(n=15)$ reported 3.5 to 5 hours, $27.2 \%(n=25)$ reported 1.5 to 3 hours, and $4.3 \%(n=4)$ reported 0 to 1 hour per week. With regard to time spent with friends, $6.5 \%(n=6)$ reported 5.5 or more hours, $13 \%(n=12)$ reported 3.5 to 5 hours, 29.3\% $(n=27)$ reported 1.5 to 3 hours, and $51.1 \%(n=47)$ reported 0 to 1 hour per week. No other demographic data was collected.

Procedures. Several recruiting techniques were utilized. Students in communication courses at a large Mid-Atlantic university recruited married couples to come into the lab to participate in an observational study of marital couples' public performances. While some student recruiters received partial course credit for their assistance, others were simply asked to pass along information to potential interested parties. Student recruiters were contacted in their classrooms where the primary researcher informed them of the criteria for inclusion in the study and how participants can register for a lab time. Participants were provided with a copy of the study advertisement that offered a general explanation of what would be expected of participants, the primary researcher's contact information, and the rewards offered to participating couples. Laboratory days and times were based on a first come, first serve basis.

Advertising around campus and the surrounding town was also utilized. Specifically, the study was announced online via the campus announcements webpage, 
the faculty e-newsletter, the college Facebook page, and the local newcomer's webpage. Family and friends of the principal investigator recruited by passing along information about the study to others whom they knew. After completion of the study, several participants likewise offered to help recruit additional participants.

Upon arrival at the lab, the primary researcher informed the couple of the general procedures of the study before obtaining consent from each married partner. After giving consent, the couple was separated to provide demographic data and complete measures of attachment style (Bartholomew \& Horowitz, 1991; Guerrero, 1996), private and public self-consciousness (Fenigstein et al., 1975), and couple identity (Agnew et al., 1998; Aron et al., 1992). After scale completion, couples were reunited and escorted to the laboratory with another married couple with whom they were to engage in a 15-minute conversation. After their conversations, couples were again separated to complete postinteraction measures of communication satisfaction, feeling understood, conversational appropriateness, and identity gaps. For these measures, participants were instructed to think about the public performance in which they had just participated. Couples were then asked to provide their information for the drawing of two $\$ 50$ gift certificates to a local restaurant before being debriefed, thanked, and paid $\$ 10$ (per couple) for their participation. The entire process took approximately one hour.

Each 15-minute conversation occurred between two married couples (four spouses). To guide the conversation, couples were provided with a stack of note cards with one "get-to-know-you" conversation topic on each card. They were instructed to discuss topics one at a time in the designated order for as long as they choose (Sillars et al., 1987) within their given 15 minute time-frame (see Appendix D for the questions and 
order). They were also directed that each couple should be given a chance to answer the question before advancing to the next card. Each couple was observed through a one-way mirror as well as a video recording. Although the entire 15-minute conversation was coded, the first three minutes of conversation were excluded from the statistical analysis of the conversations. This three-minute time segment was deemed as the time in which couples could become familiarized with the lab and would hopefully behave more naturally.

Pre-Interaction Instrumentation

Attachment styles. As in study one, attachment styles were measured using Guerrero’s (1996) 30-item continuous measure and Bartholomew and Horowitz’s (1991) categorical descriptions. Specifically, participants completed 7-point Likert-type scales (1 = very unlike me; 7 = very like me) that measure general avoidance (e.g., "I feel uncomfortable when people get close to me,” original $\alpha=.87$ ), lack of confidence (e.g., “I sometimes worry that I do not really fit in with other people,” original $\alpha=.83$ ), preoccupation (e.g., "I feel a very strong need to have close relationships, ”original $\alpha=$ .81), fearful avoidance (e.g., "I would like to trust others, but I have a hard time doing so,” original $\alpha=.78$ ), and relationships as secondary (e.g., “Achieving things is more important to me than building relationships,” original $\alpha=.84$ ) (Guerrero, 1996). Cronbach alpha reliabilities, means, and standard deviations for the current study were as follows: general avoidance, $\alpha=.82$, item $M=3.06$, overall $M=21.43, S D=6.79$; lack of confidence, $\alpha=.83$, item $M=3.36$, overall $M=16.78, S D=6.03$; preoccupation, $\alpha=$ .68 , item $M=3.85$, overall $M=19.25, S D=5.30$; fearful avoidance, $\alpha=.79$, item $M=$ 3.03, overall $M=15.13, S D=5.22$; relationship as secondary, $\alpha=.42$, item $M=3.31$, 
overall $M=13.22, S D=3.16$. Due to an even lower initial level of reliability, three items were removed from the preoccupation measure. These included "Intimate relationships are the most central part of my life," "I feel a very strong need to have close relationships,” and “Sometimes others seem reluctant to get as close to me as I would like.” Participants also read four short paragraphs that reflect each of the four attachment styles and selected the description that best characterizes their personal attachment style by placing a check mark next to it.

Self-consciousness. Participants completed Fenigstein et al.'s (1975) private and public self-consciousness measures. Private self-consciousness was measured with 10 items that indicate individuals’ self-reflection and personal awareness (e.g., “I’m constantly examining my motives”). Public self-consciousness was measured with seven items that reflect individuals' concern and awareness of how they present themselves to others (e.g., "I usually worry about making a good first impression”). Participants indicated on a 7-point Likert-type scale the degree to which they agree with each statement $(1$ = strongly disagree, 7 = strongly agree $)$. Fenigstein et al. (1975) reported a test-retest reliability of .79 for private self-consciousness and .84 for public selfconsciousness. Booth-Butterfield and Booth-Butterfield (1994) reported internal reliabilities of .68 and .69 for private self-consciousness and .85 and .87 for public selfconsciousness. In the current study, the Cronbach alpha for private self-consciousness was .70 (item $M=4.55$, overall $M=31.86, S D=6.06$ ) after three items were excluded. The following items were excluded because of a low reliability initially: “Generally, I'm not very aware of myself,” “I never scrutinize myself,” and “I sometimes have the feeling that I'm off somewhere watching myself.” The Cronbach alpha for public self- 
consciousness in the current study was .77 (item $M=4.38$, overall $M=30.65, S D=$ 6.97). Higher scores reflect greater private and public self-consciousness.

Couple identity. Participants' perceptions of their couple identity were measured using Aron et al.'s (1992) IOS scale and Agnew et al.'s (1998) measure of relationship centrality. The IOS scale represents varying degree of overlap between two circles in Venn-like diagrams. The scale is intended for participants to choose among the seven pairs of circles which diagram best depicts the closeness of their relationship with their spouse. A greater degree of overlap depicted by the circle is representative of a closer relationship. Participants were instructed to circle the diagram that best represents how they perceive themselves in relation to their partner. The scale has previously been validated in experimental and correlational research (see Aron et al., 1992). The Vennlike diagrams were treated as an additional item to Agnew et al.'s measure of relationship centrality, which consists of four items that assess how critical one's relationship is to him or her in comparison to other aspects of one’s life. Participants responded to each statement on a 7-point Likert-type scale $(1=$ other things are of some importance, $7=$ nothing else is of any importance). Agnew et al. reported a Cronbach alpha of .82 for the four-item measure. In the current study, the Cronbach alpha for the five-item measure was .73 (item $M=5.40$, overall $M=26.99, S D=3.97$ ).

Post-Interaction Instrumentation

Identity gaps. Participants completed two separate identity gap measures adapted from Jung and Hecht’s (2004) scale. Participants indicated on 7-point Likert-type scales their level of agreement with each statement $(1=$ strongly disagree, $7=$ strongly agree $)$ based on the conversation they just completed. The couple-enacted couple identity gap 
scale consists of 11 items that assess participants' perceptions of an identity gap between their couple identity and their enacted identity during the specified public performance. The scale was adapted to reflect the couple versus the individual, as in study one. The Cronbach alpha for the current study was .80 (item $M=2.12$, overall $M=23.27, S D=$ 7.96).

The personal-enacted couple identity gap scale also consists of 11 items, but this scale assessed participants’ perceptions of an identity gap between their personal identity and their enacted identity during the specified public performance. The scale was adapted in the same manner as study one. Jung and Hecht (2004) reported a reliability of .89 for their original version of the scale. The Cronbach alpha for the current study was .90 (item $M=1.95$, overall $M=21.42, S D=8.67)$.

Communication satisfaction. Participants indicated their degree of communication satisfaction on a 14-item measure that was adopted from VanLear's (1991) 8-item version of Hecht’s (1978) Interpersonal Communication Satisfaction Inventory. Specifically, participants indicated on a 7-point Likert-type scale their level of agreement with each statement $(1=$ strongly disagree, $7=$ strongly agree $)$ while reflecting on communication with their spouse (6 items; e.g., "I felt accepted and respected by my spouse during the conversation”), the other couple (6 items; e.g., "I felt accepted and respected by my spouse during the conversation”), and the overall communication event (2 item; e.g., "I enjoyed our conversation” and “Our conversation flowed smoothly”). The shortened version has previously achieved a reliability of .93 (VanLear, 1991; Venable \& Martin, 1997). The Cronbach alpha for the overall 14-item measure utilized in this study was .91 (item $M=6.07$, overall $M=84.94, S D=9.37$ ). 
Feeling understood. Participants completed Cahn and Shulman’s (1984) 16-item Feelings of Understanding/Misunderstanding Scale (FUMS). This scale assesses individuals’ feelings when attempting to achieve understanding during communication with others. Participants were directed to complete the scale based on the conversation they just completed. Participants rated on a 5 -point scale $(1=$ very little, $5=$ very great $)$ the degree to which they experienced 16 feelings. Eight feeling words reflect those typically associated with perception of being understood (PBU), including satisfaction, relaxation, pleasure, good, acceptance, comfortableness, happiness, and importance, and eight words reflect those typically associated with perception of being misunderstood (PBM), including dissatisfaction, annoyance, discomfort, insecurity, sadness, failure, incompleteness, and uninterestingness. The scale likewise includes eight filler words, but for the sake of brevity, the filler words were excluded. Cahn and Schulman reported a Cronbach alpha of .89. The Cronbach alpha for the current study was .89 (item $M=4.05$, overall $M=64.74, S D=7.98)$.

Conversational appropriateness. Participants completed Canary and Spitzberg’s (1987) 20-item conversational appropriateness scale. This scale assesses individuals’ perceptions of their partners as appropriate with regard to specific aspects of conversations as well as more general or global perceptions of appropriateness. In the current study, participants indicated their level of agreement $(1=$ strongly disagree, $7=$ strongly agree) with each statement on a 7-point Likert-type scale. Participants completed the measure while reflecting on the public performance they had just completed. Previously, the scales have achieved Cronbach alphas of .85 and .80 for specific and general appropriateness, respectively (Canary \& Spitzberg, 1987). The 
Cronbach alpha for the current study was .91 (item $M=6.40$, overall $M=128, S D=$ 14.27). For the complete scales for study two, see Appendices B and C.

\section{Coding Public Performances}

Trained coders observed and coded marital couples’ public performances for content (communal, individual, and impersonal themes), organization (continuity and hierarchy), and nonverbal immediacy (as it occurred between spouses in the same relationship). For the verbal coding training sessions, coders were provided with Sillars et al.'s descriptions of the themes and their associated sub-categories in addition to examples of each sub-category (Appendix E). Coders were instructed to read and familiarize themselves with the each of the sub-categories outlined. Coders' concerns and questions were discussed before and after watching their first videotaped interaction. For the nonverbal coding training sessions, coders were instructed on how to make ratings before watching an eight-minute video clip from "Meet the Fockers." They viewed the video clip three times, focusing on a different couple each time, and practiced making ratings. Coders' concerns and questions were discussed before and after their viewing of the videotape. Practicing the coding nonverbal communication was especially important because coding for nonverbal communication was conducted live during the public performance, whereas coding for verbal communication was conducted from videotapes.

Coding for both verbal content and organization was conducted from videotapes of marital couples' interactions. Coders independently marked their ratings after the first three minutes of conversation followed by two-minute segments for the remaining 12 minute observation period. At each time segment, the pairs of coders were instructed to pause the video, read each of the categorical descriptions, and assign a rating between 0 
and 6 to the designated time segment for all of the content and organization categories. The ratings of each pair of coders were averaged for data analysis. Together, the content and organization of marital couples’ public performances were further analyzed for their thematic chains (blending, differentiating, and balancing).

Five different pairs of coders analyzed marital couples’ nonverbal immediacy behaviors during their live public performances. Coders made their ratings after the first three minutes of conversation followed by two-minute segments for the remaining 12minute observation period. Specifically, coders examined two-minute segments for eye contact, smiling, physical proximity, body leans, touch, and behavioral matching from behind the one-way mirror during the public performance because some nonverbal behaviors are more difficult to code from a videotape (Guerrero \& Burgoon, 1996). Each of the verbal and nonverbal coding schemes are further described below.

Verbal Behaviors. Each couple’s communication was coded by one pair of coders for three main content categories: communal, individual, and impersonal themes (Sillars et al., 1987). The Ebel's intraclass correlation for this pair of coders was .98. Communal themes represent marital couples' accounts that reflect beliefs that marriage is the product of the two partners. There are five sub-categories of communal themes. Marital couples' accounts of sharing time, activities, and interests were coded as togetherness, whereas their accounts of working together collectively were coded as cooperation. Couples’ accounts of talking and sharing thoughts as a couple were coded as communication, couples' accounts of shared affection, mutual attraction, and being in love were coded as romanticism, and couples' accounts of each partner directly affecting each other were coded as interdependence. 
Individual themes represent marital couples’ beliefs of marriage as the outcome of separate identities or roles. The individual theme category has three sub-categories. Marital couples’ accounts of having separate time, activities and interests were coded as separateness, their accounts of having unique individual traits, habits, and skills were coded as personality, and their accounts of having separate roles or performing separate roles were coded as role.

Impersonal themes represent marital couples' beliefs that marriage is the product of external factors that are outside of the couple's control. This category consists of three sub-categories. Marital couples' accounts that the nature of the marriage is governed by normative, society driven, or intrinsic characteristics such as family background, gender, age, or physical condition were coded as organic properties. Marital couples' accounts of some aspects or problems as inherent in marriage and that a degree of acceptance of moderate standards is necessary for satisfaction were coded as stoicism. Marital couples’ accounts that choices are preempted by the couple's situation such as references to externally imposed stressors and scarce resources were coded as environmental influence.

After coding for the themes reflected in the content of marital couples’ communication, a separate pair of coders analyzed the organization of marital couples’ public performances (Sillars et al., 1987). The Ebel's intraclass correlation for this pair of coders was .93 . Continuity refers to the chain reaction of a partner to the other partner's statement such that the partner is continuing the conversation of the other. When coding for continuity, coders looked for agreement (or disagreement) between the partners on ideas that are expressed as well as on the evaluative implications of their statements. Coders also looked for continuation of a topic from speaker to speaker. Hierarchy refers 
to the degree of specificity or abstractness in marital couples’ communication. When analyzing the transcripts for hierarchy, coders looked for differing degrees of abstractness versus concreteness in marital couples' accounts, partners' elaboration on themes evoked by their partner, and their mention of the same or similar themes elsewhere in the performance.

Using the codes derived from analysis of content themes and organization, public performances were analyzed for three different levels of integration by a separate, independent coder (Sillars et al., 1987). The blending chain represents the highest degree of integration between married partners. The blending chain explains couples who present undifferentiated couple identities and are more overlapping in their communication. Their accounts are marked by communal themes, greater continuity, and greater hierarchy. Specifically, the content of their communication reflects shared knowledge and experiences, and the structure of their communication is affirming such that they often finish each other's statements.

The differentiating chain represents the least degree of integration between married partners. The differentiating chain explains couples who present separate identities and are less overlapping in their communication. Their accounts are marked by individual themes, less continuity, and less hierarchy. The content of their communication emphasizes separation in their activities and experiences and differences in their personality. The structure of their communication is marked by few references of each other's accounts and little integration.

The balancing chain represents a moderate degree of integration between married partners. The balancing chain explains couples characterized by some degree of 
differentiation but these couples manage their differences with communication. Sillars et al. (1992) noted, “Individual traits, moods, and roles were transcended and integrated through processes of communication, situational mitigation (e.g., environmental themes), or cooperation” (p. 143). Couples whose communication reflected the balancing chain were more likely to note they had a complementary relationship where each partner served as a balance for the other.

Nonverbal Behavior. Each couple’s public performance was coded by two live coders for eye contact, smiling, body leans, touch, and behavioral matching (Guerrero \& Burgoon, 1996). A total of five different pairs of coders were utilized for live coding. The Ebel's intraclass correlations for the five pairs of nonverbal coders ranged from .80 to .90. Eye contact between the partners was rated using three 7-point semantic differential scales: unsteady/steady eye gaze, no gaze/constant gaze, and never gazing/always gazing. Smiling directed at each partner was rated using two scales: frequent-none and inappropriate-appropriate. Body lean was measured using two items that gauge whether the participants leaned toward or away from each other and the duration of leaning. Touch was measured using frequency counts of discrete touches between the couple whether they are initiated or received. Nonverbal behavioral matching was rated on a global 7-point scale of matching-not matching. For the complete codebook, see Appendix E. For the descriptive statistics (i.e., minimum, maximum, range, median, mean, and standard deviations) of all coded behaviors, see Table 1. 
Table 1.

Descriptive Statistics for Verbal and Nonverbal Communication Observed During Coding of 12-minute Interactions

\begin{tabular}{|c|c|c|c|c|c|c|}
\hline Variable & Minimum & Maximum & Range & Median & Mean & $\begin{array}{r}\text { Standard } \\
\text { Deviation }\end{array}$ \\
\hline \multicolumn{7}{|l|}{ Verbal Behaviors } \\
\hline Communal & 7.00 & 48.00 & $0-180$ & 19.25 & 20.20 & 7.35 \\
\hline Togetherness & 5.50 & 17.50 & $0-36$ & 9.50 & 10.01 & 9.50 \\
\hline Cooperation & 0 & 12.50 & $0-36$ & 2.75 & 3.55 & 2.50 \\
\hline Communication & 0 & 12.00 & $0-36$ & 3.00 & 3.10 & 2.48 \\
\hline Romanticism & 0 & 4 & $0-36$ & 1.00 & 1.12 & 1.08 \\
\hline Interdependenc & & & $0-36$ & & & \\
\hline e & .50 & 6.00 & & 2.00 & 2.41 & 1.37 \\
\hline Individual & 3.50 & 22.00 & $0-108$ & 9.50 & 9.79 & 3.93 \\
\hline Separateness & 1.50 & 11.50 & $0-36$ & 5.25 & 5.67 & 2.25 \\
\hline Personality & .50 & 6.00 & $0-36$ & 2.00 & 2.38 & 1.45 \\
\hline Roles & 0 & 8 & $0-36$ & 1.00 & 1.74 & 1.78 \\
\hline $\begin{array}{c}\text { Impersonal } \\
\text { Organic }\end{array}$ & 10.50 & 24.50 & $0-108$ & 16.25 & 16.59 & 3.36 \\
\hline Properties & 3.50 & 13.00 & $0-36$ & 7.00 & 7.15 & 2.11 \\
\hline Stoicism & 0 & 5.00 & $0-36$ & .50 & .83 & 1.12 \\
\hline Environmental & & & & & & \\
\hline Influence & 5.00 & 13.00 & $0-36$ & 8.50 & 8.61 & 2.02 \\
\hline \multicolumn{7}{|l|}{ Organization } \\
\hline Continuity & 5.00 & 25.50 & $0-36$ & 13.00 & 13.61 & 4.61 \\
\hline Hierarchy & 1.00 & 21.50 & $0-36$ & 8.75 & 9.35 & 4.91 \\
\hline \multicolumn{7}{|l|}{ Integration } \\
\hline Blending & 0 & 6 & $0-6$ & 1.00 & 1.74 & 1.95 \\
\hline Differentiating & 0 & 6 & $0-6$ & 4.00 & 3.91 & 1.96 \\
\hline Balancing & 0 & 5 & $0-6$ & 2.00 & 2.28 & 1.63 \\
\hline \multicolumn{7}{|l|}{ Nonverbal } \\
\hline Immediacy & 89.50 & 182.50 & $48-420$ & 125.25 & 125.37 & 15.95 \\
\hline Eye Contact & 36.50 & 84.00 & $18-126$ & 63.00 & 62.05 & 12.40 \\
\hline Smiling & 37.50 & 77.00 & $12-84$ & 55.50 & 57.42 & 8.57 \\
\hline Matching & 16.00 & 36.00 & $6-42$ & 28.00 & 27.40 & 4.12 \\
\hline Leaning & 38.50 & 84.00 & $12-84$ & 50.75 & 51.79 & 7.75 \\
\hline Touch & 0 & 17.00 & $0-12$ & .00 & .88 & 2.58 \\
\hline
\end{tabular}


Data analysis. Prior to hypothesis testing, preliminary analyses were conducted to assess if length of marriage or relationship were associated with the outcome variables examined in study two hypotheses and research questions. Before testing hypotheses six through eight, composites were calculated for each of the communication themes, organization patterns, and integration chains. Composite scores for marital couples’ selfreported identity, identity gap scores, and outcome measures (e.g., communication satisfaction, etc) were likewise computed to create joint ratings.

To test for differences in couples' coded characteristics of their public performances according to the degree of overlap in their identity (hypothesis six), while accounting for couples' relationship and marital relationship length, an Analysis of Covariance (ANCOVA) was conducted. Specifically, marital couples with a more overlapping couple identity were compared to those with less overlapping couple identity for significant differences in their communication themes and integration during public performances. A statistical median split was used to divide couples into high and low overlapping couple identities for differences testing. This decision was governed by the hypothesis, which projected differences in couples that were more versus less overlapping in their identity. The (in)congruency between couples’ self-reported identities and their public performance ratings were dummy coded before looking for differences in couples' reported identity gaps using two Independent Samples $t$-tests (hypothesis seven). Finally, Pearson Correlations were conducted to assess the association between marital couples' reported identity gaps and their ratings of communication satisfaction, feeling understood, and conversational appropriateness (hypothesis eight). 
Research question one inquired about married couples’ nonverbal immediacy behaviors during public performances. To answer this question, descriptive statistics of marital couples' nonverbal immediacy behaviors were conducted. Research question two inquired about how married couples’ overlap in identity was associated with their nonverbal immediacy behaviors. This research question was analyzed using the couples’ identity scores and their observed nonverbal immediacy behaviors. A hierarchical regression was conducted with marital relationship length and relationship length entered on the first block of predictor variables and couple overlapping identity entered on the second block of predictor variables. Research question three was answered using Pearson Correlations to assess the associations between marital couples' verbal and nonverbal communication as they relate to general avoidance, lack of confidence, preoccupation, fearful avoidance, and relationships as secondary. To test hypothesis nine and answer research question four, marital couples’ attachment styles were dummy coded as either secure (both partners are secure in their attachment style) or non-secure (one or both partners are insecure) before conducting three Independent Samples $t$-tests; one for communal communication, one for blending chains, and one for nonverbal behaviors. Hypothesis ten was likewise tested using the continuous measures of attachment style and couples' reports of private self-consciousness. A series of hierarchical regressions were conducted with attachment style entered on the first step and private self-consciousness on the second step. Marital couples' verbal and nonverbal behaviors served as the outcome variables. Hypothesis 11 was analyzed with a Pearson Correlation to assess the association between marital couples' nonverbal matching scores and their public selfconsciousness reports. Hypothesis 12 was tested initially with Pearson Correlations to 
assess the associations between couples' reports of public self-consciousness and their verbal and nonverbal communication during their public performances. The hypothesis was further tested by separating high publicly self-conscious couples from low publicly self-conscious couples using a median split and conducting a $t$-test to examine differences in couples’ verbal and nonverbal communication. 


\section{CHAPTER III:}

\section{RESULTS}

\section{Study One}

As noted, preliminary analyses were conducted to ensure that the length of the couples' marriage and overall relationship did not influence the hypothesized associations examined in this study. As joint couple scores were calculated for testing the hypotheses, preliminary analyses were likewise conducted with couples’ joint reported outcomes. A series of Pearson Correlations were conducted and results indicated length of marriage, $r$ $(150)=.21, p<.05$, and length of relationship, $r(150)=.21, p<.01$, were significantly associated with relationship commitment, but not with the other outcome variables (see Table 2).

Hypothesis one projected identity gaps would be inversely associated with couples' ratings of communication satisfaction, feelings of being understood, and conversational appropriateness. Hypothesis two similarly predicted identity gaps would be inversely related to couples’ feelings of relationship satisfaction and commitment. Results of Pearson Correlations revealed significant, negative associations between couples’ identity gaps and the communication and relationship outcomes, as projected (see Table 2). Hypotheses one and two were supported, meaning when couples experience identity gaps in their public performances they experience less communication and relationship satisfaction, they feel less understood by their partners, they perceive the conversation as less appropriate, and they feel less satisfaction and commitment in their relationship. In light of the significant association between couples’ length of marriage and relationship with couples’ reported commitment, additional 
analysis were conducted using a hierarchical regression. Results indicated an overall significant model for commitment, $R^{2}=.51, F(4,145)=40.23, p<.001$. In the first block, marital length $(\beta=.13, t=.27, p>.01)$ and relationship length $(\beta=.08, t=.17, p>$ .01) were not significant predictors of commitment. When the second block was entered, couple-enacted couple identity gap $(\beta=-.52, t=--4.31, p<.01)$ was the only significant contributor to the model whereas marital length, relationship length, and personal-enacted couple identity did not significantly contribute to the model, $F \Delta(2,145)=73.84, p>.05$. 
Table 2.

Correlations between Couple Characteristics, Conversational and Relational Outcomes, and Identity Gaps

\begin{tabular}{|c|c|c|c|c|c|c|c|c|c|c|}
\hline & 1 & 2 & 3 & 4 & 5 & 6 & 7 & 8 & 9 & 10 \\
\hline $\begin{array}{l}\text { 1. Average } \\
\text { Marriage Length }\end{array}$ & --- & & & & & & & & & \\
\hline $\begin{array}{l}\text { 2. Average } \\
\text { Relationship } \\
\text { Length }\end{array}$ & $.99 * *$ & --- & & & & & & & & \\
\hline $\begin{array}{l}\text { 3. Communication } \\
\text { Satisfaction }\end{array}$ & .14 & .13 & --- & & & & & & & \\
\hline $\begin{array}{l}\text { 4. Feelings of } \\
\text { Being Understood }\end{array}$ & .06 & .05 & $.64 * * *$ & --- & & & & & & \\
\hline 5. Appropriateness & .09 & .11 & $.65^{* * *}$ & $.61^{* * *}$ & --- & & & & & \\
\hline $\begin{array}{l}\text { 6. Relationship } \\
\text { Satisfaction }\end{array}$ & -.02 & -.03 & $.57 * *$ & $.57 * *$ & $.69 * *$ & --- & & & & \\
\hline $\begin{array}{l}\text { 7. Relationship } \\
\text { Commitment }\end{array}$ & $.21^{*}$ & $.21^{*}$ & $.63 * *$ & $.53 * *$ & $.67 * *$ & $.71^{*}$ & --- & & & \\
\hline $\begin{array}{l}\text { 8. Relationship } \\
\text { Awareness }\end{array}$ & -.10 & -.11 & $.50 * *$ & $.46^{* *}$ & $.34 * *$ & $.48 * *$ & $.40 * *$ & --- & & \\
\hline $\begin{array}{l}\text { 9. Personal- } \\
\text { Enacted Couple } \\
\text { Identity Gap }\end{array}$ & .15 & .15 & $-.70 * *$ & $-.54 * *$ & $-.70 * *$ & $-.57 * *$ & $-.67^{* *}$ & $-.42 * *$ & --- & \\
\hline $\begin{array}{l}\text { 10. Couple- } \\
\text { Enacted Couple } \\
\text { Identity Gap }\end{array}$ & -.15 & -.13 & $-.67 * *$ & $-.51^{* *}$ & $-.70 * *$ & $-.62 * *$ & $-.70 * *$ & $-.41^{* *}$ & $.87 * *$ & --- \\
\hline
\end{tabular}


Prior to testing hypotheses three and four, planned contrasts were conducted to validate Bartholomew and Horowitz’s categorical descriptions of the four attachment styles. In the current study, secures scored significantly lower on general avoidance than dismissives, preoccupieds, and fearful avoidants. Preoccupieds and fearful avoidants scored significantly higher on lack of confidence than secures and dismissives. Secures and dismissives scored significantly lower than preoccupieds and fearful avoidants on preoccupation. Fearful avoidants scored significantly higher than secures and dismissives on fearful avoidance. Secures scored significantly lower than dismissives and dismissives scored significantly higher than preoccupieds on relationships as secondary. As in Guerrero’s (1996) study, preoccupieds rated highest on preoccupation, fearful avoidants rated highest on fearful avoidance, and dismissives rated highest on relationships as secondary (see Table 3). 
Table 3.

Study One Planned Contrasts between Continuous Measures and Categorical Descriptions of Attachment Styles

\begin{tabular}{|c|c|c|c|c|c|}
\hline & \multicolumn{4}{|c|}{ Mean Scores } & \multirow[b]{2}{*}{$F$} \\
\hline & $\begin{array}{l}\text { Secures } \\
(n=144)\end{array}$ & $\begin{array}{l}\text { Dismissives } \\
(n=89)\end{array}$ & $\begin{array}{l}\text { Fearful } \\
\text { Avoidants } \\
(n=31)\end{array}$ & $\begin{array}{l}\text { Preoccupieds } \\
(n=34)\end{array}$ & \\
\hline $\begin{array}{l}\text { General } \\
\text { Avoidance }\end{array}$ & $19.38_{\mathrm{abc}}$ & $25.21_{\mathrm{a}}$ & $27.46_{b}$ & $24.10_{c}$ & $25.34 *$ \\
\hline $\begin{array}{l}\text { Lack of } \\
\text { Confidence }\end{array}$ & $13.82_{\mathrm{abc}}$ & $16.63_{\mathrm{ad}}$ & $18.72_{b}$ & $19.91_{\mathrm{cd}}$ & $22.89 *$ \\
\hline Preoccupation & $25.66_{\mathrm{ab}}$ & $26.49_{\mathrm{c}}$ & $30.55_{\mathrm{ac}}$ & $32.23_{\mathrm{bd}}$ & $14.73 *$ \\
\hline $\begin{array}{l}\text { Fearful } \\
\text { Avoidance }\end{array}$ & $14.31_{\mathrm{abc}}$ & $17.90_{\mathrm{ad}}$ & $21.82_{\mathrm{bd}}$ & $19.48_{\mathrm{c}}$ & $24.47 *$ \\
\hline $\begin{array}{l}\text { Relationships } \\
\text { as Secondary }\end{array}$ & $18.19_{a}$ & $20.35_{\mathrm{ab}}$ & $19.94_{c}$ & $17.97 \mathrm{~b}$ & $7.92 *$ \\
\hline
\end{tabular}


Hypothesis three predicted that married couples that consist of partners with different attachment styles would report more identity gaps between their personal and enacted couple identities than those with similarly attached partners. Marital partners' style ratings were paired with their spouses and categorized as either matched (both partners have the same attachment style; $n=61$ ) or mismatched (both partners do not have the same attachment style; $n=86$ ) to test for differences in marital couples' reports of identity gaps. Results of an Independent Samples $t$-test revealed that couples who were mismatched in their attachment styles $(M=71.64, S D=12.55)$ experienced significantly more identity gaps between their personal and enacted couple identities than those who were matched, $t(145)=-2.20, p<.05(M=66.63, S D=15.05)$. Hypothesis three was supported, suggesting married couples who are alike in their attachment styles are less likely to experience identity gaps.

Hypothesis four predicted securely attached marital couples would experience the least amount of identity gaps. Marital couples were categorized as either secure (both partners are secure; $n=37$ ), insecure (both partners are of insecure styles such as preoccupied and fearful avoidant; $n=46$ ), or mixed (one partner is secure, but the other is insecure; $n=64$ ) for hypothesis four testing. Two separate ANOVAs were conducted; one for couple-enacted couple identity gaps and one for personal-enacted couple identity gaps. Results of an ANOVA revealed an overall significant model for couple-enacted couple identity gaps, $F(2,144)=11.25, p<.001$. Further analysis using a Scheffe test revealed secure $(M=50.56, S D=19.88)$ and mixed couple types $(M=59.88, S D=$ 19.38) reported significantly fewer identity gaps between their couple and enacted couple identities than insecure couple types $(M=70.98, S D=19.86)$. Results of a second 
ANOVA revealed an overall significant model for personal-enacted couple identity gaps, $F(2,144)=12.54, p<.001$. Further analysis using a Scheffe test revealed secure couple types $(M=61.90, S D=14.08)$ reported significantly fewer identity gaps between their personal and enacted couple identities than insecure $(M=76.08, S D=13.71)$ and mixed couple types $(M=69.31, S D=11.37)$. Hypothesis four was supported and suggests that secure couple types are least likely to experience identity gaps.

Hypothesis five projected relationship awareness would be inversely associated with marital couples' identity gaps. In support of this prediction, results of a Pearson Correlation indicated couples’ ratings of relationship awareness were negatively associated with their reports of couple-enacted couple identity gaps, $r(153)=-.41, p<$ .001 and personal-enacted couple identity gaps, $r(153)=-.42, p<.001$. Hypothesis five was supported, implying that when married couples have a greater degree of awareness in their relationship, they are also less likely to experience identity gaps.

Study Two

Prior to testing the hypotheses and research questions posed in study two, preliminary analyses were conducted to ensure the couples’ marriage and relationship length did not interfere with this study's predictions and research questions. Results of Pearson Correlations revealed four significant associations. Marriage length and relationship length were significantly associated with couple overlapping identity, $r(46)$ $=.34, p<.05, r(46)=.31, p<.05$, and couples' communication according to individual themes, $r(45)=.37, p<.05, r(46)=.38, p<.05$, respectively. As such, couples' marital and relationship length will be controlled for in analyses of overlapping identities.

Hypothesis six predicted that married couples who self-reported high overlapping 
identities would communicate according to significantly more communal themes and blended chains than couples who self-reported low overlapping identities. This was tested using an Analysis of Covariance (ANCOVA) because marriage and relationship length were found to be significantly associated with overlapping identity. A significant model was found for communal communication, $F(1,42)=4.26, p<.001$. Yet, marital length, $F(1,42)=.25, p>.05$, and relationship length, $F(1,42)=.13, p>.05$, were not significant covariates. Couples who identified as having a high degree of overlap in their identity $(M=22.67, S D=8.06)$ communicated significantly more communal themes than those who identified as having a low degree of overlap in their identity $(M=17.72, S D=$ 5.71). The model for blending chains, $F(1,42)=.003, p>.05$, was not significant. Marital length, $F(1,42)=2.27, p>.05$, and relationship length, $F(1,42)=3.00, p>.05$, were not significant covariates. Hypothesis six was partially supported such that couples who are high overlapping in their identities tend to communicate according to more communal themes (e.g., togetherness) than couples who are low overlapping in their identities.

Hypothesis seven projected that when couples' self-proclaimed identity was incongruent with their public performance, they would experience identity gaps. The (in)congruency between couples’ self-reported identities and their public performance rating were dummy coded before conducting two Independent Samples $t$-tests. Results indicated incongruence in couples’ self-proclaimed couple identities and communal themes did not significantly differ in couple-enacted couple identity gaps, $t(44)=-.80, p$ $>.05$, or personal-couple enacted identity gaps, $t(44)=-.003, p>.05$. It should be noted that only 14 couples experienced incongruence between their self-proclaimed identity and 
use of communal communication, whereas the remaining 32 couples did not. Hypothesis seven was not supported, implying incongruency in couples’ self-reported overlapping identities and communal themes do not impact identity gap experiences.

Hypothesis eight proposed that marital couples who experienced identity gaps after their public performance would report lower levels of communication satisfaction, feeling understood, and communication appropriateness. Results of Pearson correlations indicated when couples experienced couple-enacted couple identity gaps and personalenacted couple identity gaps during their public performances, they reported lowered communication satisfaction, $r(46)=-.56, p<.001, r(46)=-.64, p<.001$, feelings of being understood, $r(46)=-.62, p<.001, r(46)=-.48, p<.01$, and communication appropriateness, $r(46)=-.50, p<.001, r(46)=-.71, p<.001$, respectively. Hypothesis eight was supported. Once again, experiencing identity gaps is damaging to positive communication outcomes.

Research question one inquired how married couples nonverbally communicate during public performances. Coders rated couples’ nonverbal immediacy behaviors, which included eye contact, smiling, leaning toward each other, behavioral matching, and touching. As evidenced by the descriptive statistics reported earlier in Table 1, married couples displayed little nonverbal immediacy during their public performances.

Research question two focused on how married couples' nonverbal immediacy is associated with their self-reported overlapping identities. Results of a hierarchical regression revealed a non-significant model for nonverbal immediacy, $R^{2}=.02, F(2,43)$ $=1.25, p>.05$. In the first block, marital relationship length $(\beta=-.35, t=-.73, p=.47)$ and relationship length $(\beta=.22, t=-.46, p=.46)$ were not significant predictors. When 
the second block was entered, marital relationship length $(\beta=-.32, t=-.70, p=.49)$, relationship length $(\beta=.29, t=.62, p=.54)$, and overlapping couple identity $(\beta=-.26, t$ $=-1.62, p=.11)$ were not significant contributors to the model, $F \Delta(1,42)=2.62, p=$ .11. Thus, married couples’ overlapping identities are not significantly associated with their observed nonverbal immediacy.

Hypothesis nine proposed that secure married couples would exhibit more communal themes and blending chains during their public performances than non-secure married couples. Couples were coded as either secure (both partners identified as secure; $n=17$ ) or non-secure (only one or neither partner identified as secure; $n=29$ ) in their couple attachment style. Results of two Independent Samples $t$-tests revealed secure couple types $(M=18.59, S D=6.39)$ were not significantly different from non-secure couple types $(M=21.14, S D=7.81)$ in their use of communal themes, $t(44)=-1.14, p=$ .26 , or blending chains, $t(44)=.22, p=.83$, secure: $M=1.82, S D=2.13$, non-secure: $M$ $=1.69, S D=1.87$. Hypothesis nine was not supported such that secure couple types do not display more integrated communication than non-secure couple types.

Prior to addressing research questions three and four and testing hypotheses ten and eleven, planned contrasts were conducted to validate Bartholomew and Horowitz's categorical attachment styles measure. Secures scored significantly lower on general avoidance than dismissives and preoccupieds. Secures also scored significantly lower on lack of confidence than dismissives, preoccupieds and fearful avoidants. Preoccupieds scored significantly higher on preoccupation than secures and dismissives. Fearful avoidants and dismissives scored significantly higher than secures on fearful avoidance. The model for relationships as secondary was not significant (see Table 4). 
Table 4.

Study Two Planned Contrasts between Continuous Measures and Categorical Descriptions of Attachment Styles

\begin{tabular}{|c|c|c|c|c|c|}
\hline & \multicolumn{4}{|c|}{ Mean Scores } & \multirow[b]{2}{*}{$F$} \\
\hline & $\begin{array}{l}\text { Secures } \\
(n=53)\end{array}$ & $\begin{array}{l}\text { Dismissives } \\
(n=19)\end{array}$ & $\begin{array}{l}\text { Fearful } \\
\text { Avoidants } \\
(n=11)\end{array}$ & $\begin{array}{l}\text { Preoccupieds } \\
(n=8)\end{array}$ & \\
\hline $\begin{array}{l}\text { General } \\
\text { Avoidance }\end{array}$ & $18.50_{\mathrm{ab}}$ & $25.51_{\mathrm{a}}$ & $27.73_{b}$ & $22.63_{\mathrm{c}}$ & $11.89 *$ \\
\hline $\begin{array}{l}\text { Lack of } \\
\text { Confidence }\end{array}$ & $14.08_{\mathrm{abc}}$ & $18.99_{a}$ & $22.27 \mathrm{~b}$ & $21.88_{\mathrm{c}}$ & $12.94^{*}$ \\
\hline Preoccupation & $15.04_{a}$ & $15.53_{b}$ & 17.55 & $21.75_{\mathrm{ab}}$ & $6.53 *$ \\
\hline $\begin{array}{l}\text { Fearful } \\
\text { Avoidance }\end{array}$ & $13.00_{\mathrm{ab}}$ & $17.11_{\mathrm{a}}$ & $20.73_{b}$ & 16.75 & $10.99 *$ \\
\hline $\begin{array}{l}\text { Relationships } \\
\text { as Secondary }\end{array}$ & $13.00_{a}$ & $14.53_{b}$ & $11.75_{\mathrm{c}}$ & $13.27 \mathrm{~d}$ & 1.78 \\
\hline \multicolumn{6}{|c|}{$\begin{array}{l}\text { Note: Means sharing subscripts across each row are significantly different from each } \\
\text { the small cell sizes, caution should be used when interpreting the results of this test. } \\
{ }^{*} p<.001\end{array}$} \\
\hline
\end{tabular}


Research question three focused on how marital couples’ verbal and nonverbal communication relates to their attachment styles. Analysis was conducted using the continuous measures of attachment. A series of Pearson Correlations were computed using married couples’ self-reported attachment style. Results indicated five significant associations. Couples’ general avoidance, $r(46)=-.35, p<.05$, fearful avoidance, $r(46)$ $=-.34, p<.05$, and relationships as secondary, $r(46)=-.43, p<.01$, scores were negatively associated with impersonal themes of communication. This suggests that couples who were generally avoidant of intimacy and relationships were less likely to communicate at an impersonal level. Couples' lack of confidence, $r(46)=-.44, p<.01$, and fearful avoidance, $r(46)=-.30, p<.05$, scores were negatively associated with couples' observed immediacy behaviors. This suggests that couples engaged in less nonverbal immediacy behaviors during their public performance when they doubted themselves and were fearful of getting close to others.

Research question four inquired about differences in secure versus non-secure marital couples’ nonverbal immediacy behaviors during their public performances. Results of an Independent Samples $t$-test revealed no significant differences, $t(44)=$ $1.17, p>.05$, between secure $(M=128.94, S D=12.91)$ and non-secure $(M=123.27, S D$ $=17.36$ ) couple types in their nonverbal immediacy displays during a public performance. As such, secure couple types are no more or less likely than non-secure couple types to display nonverbal immediacy during public performances.

Hypothesis 10 predicted attachment styles would mediate the association between private self-consciousness and married couples' verbal and nonverbal communication behaviors during their public performances. Several hierarchical regressions were 
computed to test this hypothesis. Married couples' self-reports of each of the attachment styles were entered as the first block of predictor variables and their self-reported private self-consciousness was entered as the second block of predictor variables. Results indicated a significant model for impersonal communication, $R^{2}=.19, F(6,39)=2.71, p$ $<.05$ (see Table 5). In the first block, relationships as secondary $(\beta=-.42, t=-3.02, p<$ .01) emerged as a significant predictor. When the second block was entered, relationships as secondary $(\beta=-.44, t=-3.04, p<.01)$ remained the only significant contributor to the model whereas private self-consciousness did not significantly contribute to the model, $F \Delta(1,39)=.28, p>.05$. No other significant models emerged. Hypothesis 10 was not supported. Private self-consciousness did not mediate the association between attachment styles and couples’ outward behavior during public performances. 
Table 5.

Hierarchical Regressions for Attachment Style Dimensions and Verbal and Nonverbal Communication

\begin{tabular}{|c|c|c|c|c|c|c|c|c|c|c|c|c|}
\hline \multirow[b]{2}{*}{ Variables Entered } & \multicolumn{2}{|c|}{ Communal } & \multicolumn{2}{|c|}{ Individual } & \multicolumn{2}{|c|}{ Impersonal } & \multicolumn{2}{|c|}{ Continuity } & \multicolumn{2}{|c|}{ Hierarchy } & \multicolumn{2}{|c|}{ Immediacy } \\
\hline & $\beta$ & $t$ & $\beta$ & $t$ & $\beta$ & $t$ & $\beta$ & $t$ & $\beta$ & $t$ & $\beta$ & $t$ \\
\hline $\begin{array}{l}\text { Step 1: } \\
\quad \text { General }\end{array}$ & & & & & & & & & & & & \\
\hline $\begin{array}{l}\text { Avoidance } \\
\text { Lack of }\end{array}$ & .52 & 1.58 & -.70 & -2.25 & -.04 & -.12 & -34 & -1.02 & -.22 & -.66 & .20 & .64 \\
\hline Confidence & .06 & .32 & .30 & 1.70 & -.04 & -.25 & -.02 & -.11 & -.14 & -.75 & -.42 & -2.44 \\
\hline $\begin{array}{l}\text { Preoccupation } \\
\text { Fearful }\end{array}$ & .14 & .81 & -.34 & -2.07 & -.08 & -.51 & -.23 & -1.30 & -.18 & -1.03 & .05 & .28 \\
\hline $\begin{array}{l}\text { Avoidance } \\
\text { Relationship }\end{array}$ & -.43 & -1.41 & .50 & 1.72 & -.25 & -.91 & .32 & 1.04 & .36 & 1.20 & -.30 & -1.05 \\
\hline $\begin{array}{l}\text { as Secondary } \\
\text { Step 2: }\end{array}$ & -.10 & -.06 & -.18 & -1.17 & -.42 & $-3.02 *$ & .13 & .78 & .20 & 1.26 & .11 & .73 \\
\hline $\begin{array}{l}\text { General } \\
\text { Avoidance } \\
\text { Lack of }\end{array}$ & .53 & 1.58 & -.72 & -2.28 & -.05 & -.15 & -.31 & -.94 & -.18 & -.57 & .19 & .60 \\
\hline Confidence & .07 & .38 & .27 & 1.53 & -.06 & -.33 & .03 & .18 & .08 & -.46 & -.43 & -2.49 \\
\hline $\begin{array}{l}\text { Preoccupation } \\
\text { Fearful }\end{array}$ & .11 & .59 & -.29 & -1.60 & -.04 & -.26 & -.35 & -1.86 & -.30 & -1.62 & .09 & .49 \\
\hline $\begin{array}{l}\text { Avoidance } \\
\text { Relationship }\end{array}$ & -.45 & -1.43 & .53 & 1.80 & -.22 & -.81 & .25 & .81 & .29 & .97 & -.27 & -.94 \\
\hline $\begin{array}{l}\text { as Secondary } \\
\text { Private Self- }\end{array}$ & .001 & .004 & -.24 & -.20 & -1.27 & $-3.04^{*}$ & .17 & 1.06 & .24 & 1.55 & .09 & .62 \\
\hline Consciousness & .07 & .38 & -.14 & -.13 & -.74 & -.53 & .29 & 1.66 & .28 & 1.66 & -.10 & -.59 \\
\hline
\end{tabular}


Hypothesis 11 proposed that married couples’ public self-consciousness would be directly associated with their nonverbal matching behavior during their public performances. Results of a Pearson correlation revealed couples’ self-reported public self-consciousness scores were not significantly associated with their observed nonverbal matching behavior, $r(46)=-.26, p=.09$. Hypothesis 11 was not supported in that couples who were high publicly self-conscious were no more or less likely to engage in nonverbal matching during their public performances than those couples who were low publicly self-conscious.

Hypothesis 12 predicted that married couples who reported high public selfconsciousness would display more integrated communication in the form of communal themes, blended chains, and nonverbal immediacy. Results of an Independent Samples $t$ test indicated a significant difference in couples’ nonverbal immediacy according to their degree of public self-consciousness, $t(44)=2.16, p<.05$. However, a closer examination of the means revealed that those who were low in public self-consciousness $(n=22, M=$ $130.48, S D=14.85$ ) engaged in greater nonverbal immediacy than those who were high in public self-consciousness $(n=24, M=120.69, S D=15.77)$. Differences were not found for communal themes, $t(44)=-.23, p>.05$, or blended chains, $t(44)=-.64, p>$ .05. As such, married couples who are higher in public self-consciousness are less integrated nonverbally and no different verbally.

\section{Study Two Post Hoc Analyses}

The present study revealed that couples’ experiences with identity gaps were damaging to couples’ perceptions of the public performance as satisfying and appropriate and their feelings of being understood, as predicted by hypothesis eight. Yet, the 
predictions made in this study about when couples would experience identity gaps were not supported. That is, couples did not experience identity gaps as a result of incongruence in their self-reported overlapping identities and communal communication during public performances (hypothesis seven). Although couples who reported high overlapping identities engaged in significantly more communal communication than couples who reported low overlapping identities, differences were not found for couples' use of blending communication during their public performances (hypothesis six). These findings raise a few additional questions. First, how do couples' characteristics, such as their attachment or self-consciousness, relate to couples' reported identity gaps? Second, what characteristics of couples' communication during public performances are associated with identity gaps? Third, how does overlapping couple identity relate to other characteristics of couples' communication (e.g., individual, impersonal, continuity, hierarchy)? Pearson Correlations were conducted to answer these additional questions.

With regard to the first question, three significant associations were found. Couples’ ratings of general avoidance were significantly related to couples’ reported couple-enacted couple identity gaps, $r(46)=.32, p<.05$, and personal-enacted couple identity gaps, $r(46)=.35, p<.05$. Couples' ratings of fearful avoidance were also significantly associated with their personal-enacted couple identity gaps, $r(46)=.35, p<$ .05. However, identity gaps were not significantly related to any other dimensions of attachment or either form of self-consciousness. Altogether, this seems to suggest that couples who have a general tendency to avoid relationships and intimacy experienced identity gaps when engaging in a "get-to-know-you" conversation with another married couple. 
With regard to the second question, three significant associations were found. Couples' use of communal, $r(46)=-.31, p<.05$, and impersonal, $r(46)=-.38, p<.05$, communication during public performances were negatively associated with couples' reported couple-enacted couple identity gaps. This means that couples experienced gaps in how they perceived themselves as a couple and how they behaved during the public performance when they engaged in less communal and less impersonal communication during their public performances. Couples' use of impersonal communication, $r(46)=$ $.44, p<.01$, was also negatively associated with couples' reports of personal-enacted couple identity gaps. Thus, couples experienced gaps in how they perceived themselves as individuals and how they behaved during the public performance when they engaged in less impersonal communication. Couples' individual themes, communication organization, and integration chains (i.e., balancing, differentiating, blending) were not significantly associated with couple-enacted couple or personal-enacted couple identity gaps.

With regard to the third question, one significant association was found. Couples' overlapping couple identity scores were significantly associated with couples' observed impersonal communication, $r(46)=.35, p<.01$. That is, couples who perceived themselves as more overlapping in their identities were more likely to communicate on a more impersonal level. No other significant associations were found.

\section{Summary}

The purpose of this section was to provide the results of studies one and two. Guided by Communication Theory of Identity and prior research, study one utilized married couples' self-reports of their general experiences with identity gaps during public 
performances and their subsequent feelings of communication satisfaction, feelings of being understood, and communication appropriateness as well as their feelings of relationship satisfaction and commitment. Study two utilized observational methods to examine couples’ public performances for their verbal and nonverbal communication and explored the associations between these behaviors with characteristics of couples and their experiences with identity gaps. The following section will address the findings of study one and two in greater detail before discussing the limitations and possible directions for future study. 


\section{CHAPTER IV:}

\section{DISCUSSION}

The primary goal of this dissertation was to study marital couples' public performances. Defined as marital couples’ verbal and nonverbal communication behaviors that occur in the presence of others with whom they are purposefully communicating, the study of public performances is focused on the intentional communication employed by married couples for the protection of their couple identities. It is through public performances that married couples create and establish couple identities as unique entities that outsiders can observe.

Guided by Communication Theory of Identity, study one focused on how marital couples' experiences with identity gaps, or inconsistencies between their personal, couple, and enacted couple frames of identity, relate to their feelings of communication satisfaction, being understood, and appropriateness as well as their overall feelings of relationship satisfaction and commitment to their relationship. Study one focused broadly on marital couples' experiences with identity gaps rather than on any specific communication event. Attachment styles and relationship awareness were likewise examined for how they are associated with marital couples' experiences with identity gaps. Study two further explored marital couples' public performances and outcomes associated with identity gaps by observing marital couples’ verbal and nonverbal communication during a specific public performance. This study likewise examined how attachment styles, private and public self-consciousness, and overlapping identities are associated with the verbal and nonverbal elements of public performances as well as how public performances in turn affect identity gaps and conversational outcomes. Together, 
the results of studies one and two support and extend prior research.

\section{Study One}

Acitelli et al. (1999) argued that the study of couple identity requires conceiving of the relationship or marital couple as a unique entity capable of self-reflection. Such reflection however also means that married couples can be negatively affected by inconsistencies in their identities, or identity gaps (Jung \& Hecht, 2004). An identity gap can occur when a married couple communicates with another married couple in a manner that is not true to how they see themselves as a couple (couple-enacted couple identity gap) or as individuals (personal-enacted couple identity gap). Previously, researchers have found identity gaps can have a negative impact on individuals and their perceptions of communication episodes (Jung \& Hecht, 2004, 2008; Jung et al., 2007; Wadsworth et al., 2008). Prior to the current dissertation, CTI and the concept of identity gaps had not been extended to the study of married couples' communication much less their public performances. Hence, the first study's quest was to explore the salience of studying identity gaps among married couples by focusing on the outcomes associated with such gaps.

Drawing from prior research, this study projected married couples who experienced more identity gaps between their couple and enacted couple identities as well as their personal and enacted couple identities during public performances would report significantly lower feelings of communication satisfaction, being understood, and conversational appropriateness (hypothesis one). In line with Jung and Hecht's (2004) general examination of identity gaps, marital couples' perceptions of public performances were similarly negatively affected by identity gaps. Communication is satisfying when it 
is more rewarding and communication is likely to be more rewarding when it reinforces individuals’ self-images (Jones, Pelham, Carvallo, \& Mirenberg, 2004; Jung \& Hecht, 2004). Married couples can satisfy feelings of being understood when they perceive they have successfully conveyed who they are to others. Appropriateness is achieved when individuals do not violate communication rules in a given situation. These desirable states are not satisfied when identity gaps occur.

This study found that identity gaps not only affected couples’ perceptions of communication episodes but also impacted their feelings about the relationship (hypothesis two). In light of the previously noted findings of this study and prior research (e.g., Jung \& Hecht, 2004), it makes sense that couples who experience inconsistencies in how they see themselves as a couple (or an individual) and how they present themselves during public performances would also report less relationship satisfaction. Weger (2005) noted, "Romantic partners look to their interactions with each other for evidence that their partner understands and accepts them” (p. 21) and when spouses feel more understood by their partners, they tend to indicate greater happiness in their relationship (Cahn, 1990).

Commitment is conceptualized as one's allegiance to his or her relationship that is characterized by a sense of “we-ness” (Agnew et al., 1998). In the current study, when married couples more commonly experienced identity gaps between how they perceived themselves as a couple and how they presented themselves as a couple during public performances, they reported lessened commitment to their marriage. This suggests that there is a connection between couples' communicative displays of "we-ness” and their feelings of commitment. Johnson (1991) commitment model recognizes the salience of 
relational identity to couples’ feelings of commitment. Specifically, his model contends that relational partners who integrate their relationship into their overall self-concept tend to be more committed. CTI declares that all four frames of identity, including one's personal identity (or self-concept), are interwoven (Jung \& Hecht, 2004). As such, it is conceivable that experiencing gaps between how individuals think of themselves as a couple and how they enact their couple identity can in turn affect individuals' perceptions of their relationship.

These results suggest there is a greater need to examine marital couples’ communication outside the boundaries of the home and in situations where more than the couple is present, as is the case with public performances. The contribution and salience of prior research on married couples' communication in private contexts is undeniable, but because identity gaps are only present as a result of communication with an outside party (Wadsworth et al., 2008) and can be damaging, it is necessary to continue couple identity research in the context of public performances.

Beyond exploring how identity gaps were associated with communication and relationship outcomes, this study also examined couple characteristics in conjunction with identity gap experiences. Prior research has identified two reasons why individuals seek similar others. Similarity breeds more enjoyable communication and reinforcement (Bryne, 1971; Burleson \& Denton, 1992). From a CTI perspective, the absence of similarity may cause identity gaps for marital couples, which in turn does not reinforce individuals' self-concepts. In this study’s extension of CTI to the marital context, when partners were not similar in their attachment styles, they were more likely to indicate a gap between how they see themselves and how they present themselves to others during 
public performances (hypothesis three). It was noted early in this dissertation that individuals' attachment styles tend to impact their outward behavior. When couples are mismatched in their attachment styles, one partner is more likely to communicate in a manner that is not congruent with how the second partner sees fit for a public performance because they are operating from different cognitive frameworks, or attachment styles. In support of this interpretation, Burleson and Denton (1992) found couples who were similar in their communication skills were more satisfied in their relationship than couples who were dissimilar, regardless of the quality of skill. Although their study was not focused on couples' identities or identity gaps, being able to avoid identity gaps may be an additional explanation for why they found couples who matched in their skills were more satisfied. Presenting oneself as a unified couple appears to be challenging when the two members of the marital couple perceive and approach relationships and intimacy differently.

Further examination of attachment styles revealed secure couple types were significantly less likely to experience personal-enacted couple identity gaps than insecure and mixed couple types (hypothesis four). Moreover, both secure and mixed couple types were less likely to experience couple-enacted couple identity gaps than insecure couple types. There are a couple of explanations that offer some insight into these findings. In line with the previous explanation of the matched-mismatched finding, purely secure couple types are similar in their attachment styles and therefore, may suffer fewer identity gaps. Equally, secure couples display greater confidence during communication episodes (Bartholomew \& Horowitz, 1991) and pro-social communication within the context of the relationship and with extended networks (Dainton, 2007), which may explain why 
they were the least likely to experience personal-enacted couple identity gaps specifically. It was found that mixed couple types, along with secure couple types, reported significantly lower couple-enacted couple identity gaps than insecure couple types. This finding is intriguing because both mixed and insecure couples are mismatched in their attachment styles, but they differ in their identity gap experiences. Some attachment style researchers argue that as long as one partner is secure in his/her attachment style, the couple as a unit will overcome negative aspects insecure partners may introduce. That is, one partner's security provides a defense against the other's insecurity (Cohn, Silver, Cowan, Cowan, $\&$ Pearson, 1992) because security serves as a relational context in which the other partner interprets behavior (Bachman \& Bippus, 2005; Dainton, 2007). This may explain why mixed couple types reported significantly fewer identity gaps than insecure couple types.

Relationship awareness is the degree to which couples are attentive to their relationship (Acitelli, 2002). This was also inversely associated with couples' reported identity gaps (hypothesis five). Specifically, couples who are higher in relationship awareness think and talk about their relationships to a greater extent. This finding seems to suggest meta-communication is beneficial to married couples. Sillars et al. (1987) discovered that couples who engaged in greater meta-communication reported higher degrees of relationship satisfaction. From a CTI perspective, couples who engage in meta-communication about who they are as individuals and as a couple would be better able to coordinate how they present themselves during public performances, allowing them to avoid identity gaps. Such an interpretation would explain the negative association between relationship awareness and identity gaps found here. 
Study Two

Married couples’ public performances and identity were further explored in study two, which focused on the verbal and nonverbal communication that occurred during a specific public performance. It was predicted that married couples who perceived themselves as more overlapping in their couple identities would utilize more overlapping forms of communication during their performance (hypothesis six). Moreover, as guided by CTI, when couples' communication was incongruent with this self-perception, it was thought that they would experience identity gaps as a result (hypothesis seven). However, the results of this study did not fully support these predictions.

In this study, married couples who reported high degrees of identity overlap engaged in significantly more communal communication during their public performance than those who reported low degrees of identity overlap, as predicted. However, couples’ degree of overlap was not a distinguishing characteristic in couples' use of overall highly integrated, blending communication. That is, couples who perceived themselves as integrated overlapping units did not engage in any more or less integrated communication. Moreover, contrary to the predictions made in this study, couples did not indicate significantly more identity gaps when their self-reported degree of overlap was not congruent with their communication during their public performance. A few explanations emerge for why this finding was not supported. First, only a few couples were categorized as incongruent and the statistical power of the test is a concern. Second, couples were simply coded as incongruent with no distinction between the types of discrepancy. Some couples may have been coded as incongruent because they displayed high degrees of communal communication during their public performance but reported 
low degrees of identity overlap, whereas other couples may have been coded as incongruent because they displayed low degrees of communal communication but reported high degrees of identity overlap. Future research should explore if the manner in which couples are incongruent is a factor in identity gap experiences.

In the current study, married couples' reported identity gaps were directly, negatively related to their communal communication, regardless of how couples perceived themselves as more or less overlapping in their identities. This indicates couples reported experiencing identity gaps to a greater extent when they were less communal during their public performance. Communal communication occurs when couples express togetherness, cooperation, communication, romanticism, and interdependence (Sillars et al., 1987, 1992). They communicate in a manner that presents marriage as a product of joint or interdependent qualities of the couple. For instance, in the current study, couples' addressed the question of how they make major decisions by referencing their discussion of the situation and coming to a joint agreement.

Couples' impersonal communication was also directly, negatively associated with couples' reported identity gaps. Impersonal communication occurs when couples' communication presents marriage as a product of factors outside the couples' control. That is, the content of their communication reflects more organic properties (such as referencing societal norms), more stoicism (such as referencing inherent problems/concerns in marriage), and more environmental influence (such as referencing external factors as imposing on individual choice). For instance, one question married couples discussed during their interaction was "why do you think people get married?" Common responses to this question included (a) receiving a tax deduction, (b) because 
they are expecting a child, and (c) because it is the next logical step for the progression of their relationship.

Together, these findings suggest that married couples’ identity gap experiences after public performances may be norm regulated. Rather than identity gaps being the result of presenting the self in a manner that is not congruent with how they see themselves as a unit, couples' identity gaps may be the result of operating outside the norms for how married couples should communicate when interacting with other married couples. Jones and Gallois’ (1989) examination of marital conflict revealed that couples tend to shift their focus away from resolving conflict to self-presentation goals when in public. A similar shift may occur for married couples’ public performances. Furthermore, just as couples’ develop idiomatic expressions to manage self-face and other face in public (Hopper et al., 1981), couples may place greater emphasis on communicating according to norms rather than their desires to present themselves as an overlapping entity for face-saving reasons. When couples violate norms or engage in face-threatening acts, they may be more likely to experience identity gaps.

Another reason to believe norms guide couples' public performances is because of this study’s nonverbal immediacy results. This study questioned how married couples communicate nonverbally during public performances as well as how nonverbal immediacy related to couples’ self-reported overlapping couple identities (research questions one and two). Analysis of the observed ratings of couples' immediacy behavior indicates couples engaged in relatively low levels of immediacy and their immediacy behaviors were not meaningfully related to their self-reported overlapping identity. Low levels of immediacy may be partly due to the nature of communication that is expected 
during public performances such that married couples may engage in more nonverbal immediacy with the other couple rather than each other to show interaction involvement (Burgoon \& LePoire, 1993; Coker \& Burgoon, 1987). However, couples may also engage in less nonverbal immediacy with each other during their public performances because of the threat to face such behaviors may evoke. Erbert and Floyd (2004) conceptualized affectionate communication as face-threatening when displayed to a non-romantic other. Equally, affectionate communication, which could include high nonverbal immediacy behaviors, displayed in front of non-romantic others may also be face-threatening. The overall low level of nonverbal immediacy and lack of variance in couples' immediacy behaviors also explains the lack of significance in assessing the association between nonverbal immediacy and couples' identity overlap. Due to the low variability of observed nonverbal immediacy, couples' nonverbal immediacy during public performances should be examined again in the future, perhaps with greater attention being paid to the progression of immediacy from the beginning of a public performance to the end.

An interesting finding emerged in the post analysis of couples' overlapping identities with characteristics of couples’ communication. Impersonal communication was associated with couples’ overlapping identities such that couples who perceived themselves as more of an overlapping unit communicated according to more impersonal themes. This finding is rather surprising in light of Sillars et al.’s (1987) discovery that more psychologically interdependent couples communicated according to more communal themes. It should be noted that in support of Sillars et al., married couples in the current study who were high in their degree of identity overlap also communicated 
significantly more communal themes during their public performances than couples who were low in their degree of identity overlap. However, a possible explanation for why overlapping married couples engage in both communal and impersonal communication is perhaps married couples who are more overlapping in their identities are more assimilated to each other with regard to how they approach communication during public performances. Rather than the degree of overlap exerting influence on when couples will communicate closeness in the form of communal communication, the degree of overlap may be more telling of when couples will communicate in a joint manner. This interpretation should be given additional consideration in future research.

This dissertation questioned how married couples’ attachment styles related to married couples’ verbal and nonverbal communication during public performances (research question 3). It was found that couples who reported greater degrees of general avoidance, fearful avoidance, and relationships as secondary engaged in less impersonal communication. At first, this finding seems contradictory to what one would expect from individuals who are avoidant of intimacy and relationships. However, if public performances are more norm-governed and impersonal communication is one such norm, then it is possible that those who are avoidant of intimacy and relationships are less knowledgeable about such norms, perhaps due to less engagement in get-to-know-you conversations. This study's post hoc analysis of the relationship between attachment and identity gaps lends some support to this rationale. Specifically, couples’ ratings of general avoidance and fearful avoidance were significantly, directly related to their reported identity gaps. This seems to suggest that the simple act of engaging in a "get-to-knowyou” conversation may be difficult for these couple types. As one would imagine, 
couples who scored higher in lack of confidence and fearful avoidance were less nonverbally immediate during their public performance. This lack of nonverbal immediacy may be their outward displays of discomfort with communicating about personal matters.

Study two proposed that secure couples would communicate in a manner significantly different from non-secure couples (hypothesis nine). Specifically, it was argued that because secure individuals tend to engage in more reciprocation of their partners' behaviors (Guerrero \& Burgoon, 1996) that they would exhibit more of a joint identity (more communal themes and blending chains) during a public performance than non-secure marital couples. No significant differences were found. Secure couple types were also no more or less likely to display nonverbal immediacy than non-secure couple types (research question four). These findings may be due to the small number of couples that represented the pure secure couple type $(n=17)$ versus the non-secure couple type ( $n$ = 29). An alternative explanation, however, is that classification as secure versus nonsecure couple types is a weak explanation for when couples are more (or less) likely to employ communal, integrated communication. Specifically, in study one, it was found that couples who had at least one secure partner (mixed couple types) experienced fewer identity gaps than those who were purely insecure. In study two, comparisons were made between secure and non-secure couples. As such, some non-secure couples may have consisted of at least one secure partner, which may explain the lack of significant differences. Dividing the sample into three groups was not feasible because this would have resulted in smaller cell sizes and reduced power. For this reason, comparisons were made according to the two groups division. 
This study found little support for extending the study of private and public selfconsciousness to the study of married couples' public performances. Initially, it was believed that couples' private self-consciousness would mediate the associations between attachment and outward behavior such that couples who were high privately selfconsciousness would be more attuned to who they are and therefore more likely to have a heightened awareness of themselves as secure, preoccupied, fearful avoidant, or dismissive in their attachment style (hypothesis 10). Based on prior conceptualization of public self-conscious individuals as more aware of how others see them and more sensitive to other's rejection of them (Fenigstein, 1979), it was predicted that they would behave in socially desirable ways by engaging greater nonverbal matching during their public performances (Crawford \& Novak, 2007; Scheier, 1980) (hypothesis 11) and exhibiting more communal, blended communication (hypothesis 12). Although these aspects were not supported, this study revealed that, contrary to the initial predictions, couples who were lower in public self-consciousness were more nonverbally immediate during their public performances. Again, if public performances are largely normgoverned and lower levels of immediacy are considered normative, it seems plausible that those who are higher in public self-consciousness would be more aware of such norms.

\section{Limitations}

When interpreting the results of this dissertation, there are a few limitations worth noting. The first limitation is in regard to the samples obtained to represent the larger married population of interest in both studies. The samples for both studies were primarily Caucasian couples who resided in the Eastern region of the United States. 
Although there is no documented reason as to why married couples' public performances should differ because of their geographical location, caution should be used when extrapolating the current dissertation's results to other areas of the country. Additionally, a smaller sample size was utilized in study two, which hurts the observed power of the statistical analyses conducted. Future research would benefit from exploring public performances and couple identity among other geographical and racial populations.

The second limitation is in reference to the second study's methodology. In study two, participating married couples engaged in 15-minute conversations with another participating married couple (versus a confederate couple). As such, there was little control over how couples progressed through the questions designed to guide the conversation. This resulted in some couples advancing to more couple-related questions than others. A related concern is the lack of control for couples' matching behaviors when interacting with each other. Specifically, married couples may have engaged in certain communicative behaviors because of how the other married couple behaved. It should be noted that study two was originally designed to include a confederate couple who would interact with all of the participating married couples. However, because of the logistics of having a couple who could serve this role, the study was modified to have participating couples interact with each other. In the future, research would benefit from exploring public performances under more controlled conditions, perhaps through the use of trained confederate couples.

The third limitation pertains to the coding scheme employed for analysis of couples’ public performances. When comparing Sillars and colleagues' $(1987,1992)$ findings to the findings of the second study of this dissertation, the coding scheme does 
not appear to account for marital couples' communication during public performances. Granted, this difference could be because of how the data was coded. Specifically, in the current study two-minute time segments were coded for general ratings on a scale ranging from 0 to 6, whereas Sillars et al. coded each thought unit for the presence or absence of each theme. However, an alternative explanation for these differences is Sillars et al.’s scheme is better suited for married couples’ private interpersonal communication and a more inductive analysis of public performances is needed. By employing a more inductive approach, researchers may better understand when couples are more/less likely to experience identity gaps and suffer from their subsequent effects. This is one avenue for future research on public performances.

The fourth limitation is in regard to the low reliability of some measures utilized in the two studies as well as the low means found for identity gap measures. With regard to the continuous measures of attachment styles, the relationship as secondary and preoccupied subscales achieved low reliabilities, whereas Guerrero and Burgoon (1986) achieved high reliabilities. This is concerning and closer examination of the scale's items is needed. With regard to identity gap measures, researchers should note that the means of these measures were relatively low. Unfortunately, prior research (e.g., Jung \& Hecht, 2004) does not offer a base line for comparison to other samples. Thus, it remains unknown if people in general experience identity gaps to a lesser extent or if this mean is a reflection of the current samples. These methodological concerns should be considered when interpreting the results of this dissertation.

\section{Theoretical and Practical Contributions}

Despite the above-noted limitations, this dissertation contributes to 
communication theory and research generally and our understanding of married couples’ communication specifically. First and foremost, this dissertation introduces the study of married couples' public performances. Evidenced by the research reviewed earlier in this document, research on couples' public behavior was less informative of the intentional communication that married couples engage in when they are communicating with others. Prior research explained why romantic couples develop private forms of communicating as well as offered insight into how couples interact nonverbally, but these studies failed to capture married couples’ public performances specifically. This dissertation addressed a need for further exploration of marital couples who protect their couple identity when interacting with others outside of the relationship.

Second, and related to the first, is this dissertation's extension of CTI to the marital relationship and the public performance context. Both studies of this dissertation found couples' identity gap experiences were damaging to couples’ perceptions of communication events. Study one likewise found this to be damaging to couples' feelings about their relationship. Moreover, these studies revealed a few ways in which couples can avoid identity gaps that have practical value for married persons. Provided that metacommunication increases relationship satisfaction (Sillars et al., 1987) and that relationship awareness appears to contribute to couples' avoidance of identity gaps (study one), couples should be encouraged to discuss how they conceive of themselves as individuals and as a couple. This should promote coordination in how they present themselves during public performances, allowing them to avoid identity gaps. Married couples also should be made aware of the importance of identity congruency and the damage that identity gaps can cause to spouses' perceptions of communicative events and 
the relationship. Knowledge of such outcomes can motivate married partners to strive for identity congruency when engaging in public performances.

Third, this dissertation contributes to research by stimulating of additional research avenues guided by other communication theories. The future directions for research are addressed below.

\section{Future Directions}

A number of directions for future research emerge from this dissertation. First, future research should account for the limitations of these studies. Specifically, researchers should capture public performances among alternative populations, conduct more controlled observations of couples’ public performances, and develop more appropriate schemes for understanding and explaining married couples’ communication during public performances.

Second, research and theory would benefit from examining the rules and norms that guide public performances as well as couples' perceptions of what behaviors are deemed inappropriate. It is possible that, as Expectancy Violations Theory (EVT) (Burgoon \& Hale, 1988) would suggest, couples’ violations of such norms are a better indicator of when couples evaluate public performances more negatively (e.g., less communicatively satisfying), which may offer additional insight to couples’ identity gap experiences. Extant research has identified several negative perceptions of individuals who commit negative expectancy violations (e.g., less attractive, less credibility, lessened hirability) (Burgoon, Coker, \& Coker, 1986). Negative violations committed by marital couples should likewise result in negative outcomes that may hinder couples' ability to develop social networks. Thus, researchers should also explore expectancy violations 
from recipient couples’ perspectives.

Third, researchers should explore more broadly what couples' do (or do not do) when creating and maintaining their social networks. Given the importance of social networks to marital couples (Agnew et al., 2001; Stafford \& Canary, 1991), such research could serve as the foundation for examining how marital couples jointly develop friends. One such approach would be to use network analysis to identify marital couples who are tied to several others, examine their behaviors with each other while in public as well as with others, and compare their behaviors to couples who are tied to only a few others. Without a doubt, some affinity-seeking strategies identified by Bell and Daly (1984) will extend to this context. Yet, it is also necessary to question marital couples' behavior with each other when seeking affinity from others. Equally important, researchers should question the relational health (e.g., relational quality, stability) of “popular” versus

“unpopular” marital couples. Given this dissertation represents the introduction of public performances, the possibilities are vast. These suggestions are a step in the right direction.

\section{Conclusions}

The purpose of this dissertation was to examine marital couples’ public performances. Two studies were conducted from a Communication Theory of Identity theoretical framework to satisfy this goal. Together, these studies suggest negative outcomes are more likely when couples’ public performances are incongruent with how they see themselves as a couple and as individuals. To avoid such experiences, couples should seek similar, securely attached others and aim for greater relationship awareness in their relationships. Public performances appear to norm-governed. Thus far, it appears 
that couples can avoid identity gaps by communicating according to communal and impersonal content themes and engaging in lower levels of nonverbal immediacy. Public performances are necessary for married couples’ development and maintenance of social networks and support systems, but more research is needed to understand the verbal and nonverbal communication elements of such interactions. 


\section{REFERENCES}

Acitelli, L. K. (1993). You, me, and us: Perspectives on relationship awareness. In S. Duck (Ed.), Individuals in relationships (pp. 144-174). Newbury Park, CA: Sage.

Acitelli, L. K. (2002). Relationship awareness: Crossing the bridge between cognition and communication. Communication Theory, 12, 92-112.

Acitelli, L. K., Rogers, S., \& Knee, C. R. (1999). The role of relational identity in the link between relationship thinking and relationship satisfaction. Journal of Social and Personal Relationships, 16, 591-618.

Andersen, P. A. (1993). Cognitive schemata in personal relationships. In S. Duck (Ed.), Individuals in relationships (pp. 1-29). Newbury Park, CA: Sage.

Andersen, J. F., Andersen, P. A., \& Jensen, A. D. (1979). The measurement of nonverbal immediacy. Journal of Applied Communication Research, 7, 153-180.

Afifi, W. A., \& Johnson, M. L. (1999). The use and interpretation of tie signs in a public setting: Relationship and sex differences. Journal of Social and Personal Relationships, 16, 9-38.

Agnew, C. R., Loving, T. J., \& Drigotas, S. M. (2001). Substituting the forest for the trees: Social networks and the prediction of romantic relationship state and fate. Journal of Personality and Social Psychology, 81, 1042-1057.

Agnew, C. R., Van Lange, P. A. M., Rusbult, C. E., \& Langston, C. A. (1998). Cognitive interdependence: Commitment and the mental representation of close relationships. Journal of Personality and Social Psychology, 74, 939-954.

Argyle, M. A., \& Furnham, A. (1983). Sources of satisfaction and conflict in long-term relationships. Journal of Marriage and the Family, 45, 481-493. 
Aron, A., \& Aron, E. N. (1996). Self and self-expansion in relationships. In G. J. O. Fletcher \& J. Fitness (Eds.), Knowledge structures in close relationships: A social psychological approach (pp. 325-344). Mahwah, NJ: Lawrence Erlbaum.

Aron, A., Aron, E. N., \& Smollan, D. (1992). Inclusion of other in self scale and the structure of interpersonal closeness. Journal of Personality and Social Psychology, 63, 596-612.

Aron, A., Paris, M., \& Aron, E. N. (1996). Falling in love: Prospective studies of selfconcept change. Journal of Personality and Social Psychology, 69, 1102-1112.

Attridge, M. (1994). Barriers to dissolution of romantic relationships. In D. J. Canary \& L. Stafford (Eds.), Communication and relational maintenance (pp. 141-164). San Diego, CA: Academic Press.

Bachman, G. F., \& Bippus, A. M. (2005). Evaluations of supportive messages provided by friends and romantic partners: An attachment theory approach. Communication Reports, 18, 85-90.

Baldwin, M. W., Keelan, J. P. R., Fehr, B., Enns, V., \& Koh-Rangarajoo, E. (1996). Social-cognitive conceptualization of attachment working models: Availability and accessibility effects. Journal of Personality and Social Psychology, 71, 94109.

Bartholomew, K. (1990). Avoidance of intimacy: An attachment perspective. Journal of Social and Personal Relationships, 7, 147-178.

Bartholomew, K., \& Horowitz, L. M. (1991). Attachment styles among young adults: A test of a four-category model. Journal of Personality and Social Psychology, 61, 226-244. 
Baumeister, R. F., \& Leary, M. R. (1995). The need to belong: Desire for interpersonal attachments as a fundamental human motivation. Psychological Bulletin, 117, 497-529.

Baxter, L. A. (1987). Symbols of relationship identity in relationship cultures. Journal of Social and Personal Relationships, 4, 261-280.

Baxter, L. A. (1992). Forms and functions of intimate play in personal relationships. Human Communication Research, 18, 336-363.

Baxter, L. A., \& Erbert, L. A. (1999). Perceptions of dialectical contradictions in turning points of development in heterosexual romantic relationships. Journal of Social and Personal Relationships, 16, 547-569.

Baxter, L. A., \& Montgomery, B. M. (1996). Relating: Dialogues and dialectics. New York: Guilford.

Baxter, L. A., \& Widenmann, W. (1993). Revealing and not revealing the status of romantic relationships to social networks. Journal of Social and Personal Relationships, 10, 321-338.

Ben-Ari, A., \& Lavee, Y. (2005). Dyadic characteristics of individual attributes: Attachment, neuroticism, and their relation to marital quality and closeness. American Journal of Orthopsychiatry, 75, 621-631.

Bell, R. A., Buerkel-Rothfuss, N. L., \& Gore, K. E. (1987). “Did you bring the yarmulke for the cabbage patch kid?”: The idiomatic communication of young lovers. Human Communication Research, 14, 47-67.

Bell, R. A., \& Daly, J. A. (1984). The affinity-seeking function of communication. Communication Monographs, 51, 91-115. 
Belsky, J., \& Rovine, M. (1984). Social-network contact, family support, and the transition to parenthood. Journal of Marriage and the Family, 46, 455-462.

Booth-Butterfield, M., \& Booth-Butterfield, S. (1994). The affective orientation to communication: The conceptual and empirical distinctions. Communication Quarterly, 42, 331-344.

Bowlby, J. (1969). Attachment and loss: Vol. 1 Attachment. New York: Basic.

Brown, B. B., Werner, C. M., \& Altman, I. (1998). Choice points for dialecticians: A dialectical-transactional perspective on close relationships. In B. M. Montgomery \& L. A. Baxter (Eds.), Dialectical approaches to studying personal relationships (pp. 137-154). Mahwah, NJ: Lawrence Erlbaum.

Bruess, C. J. S., \& Pearson, J. C. (1997). Interpersonal rituals in marriage and adult friendships. Communication Monographs, 64, 25-46.

Bruess, C. J. S., \& Pearson, J. C. (2000). The function of mundane ritualizing in adult friendship and marriage. Communication Research Reports, 19, 314-326.

Byrne, D. (1971). The attraction paradigm. New York: Academic Press.

Buber, M. (1965). Between man and man. (R. G. Smith, Trans.). New York: MacMillan. Buchanan, M. C., O’Hair, H. D., \& Becker, J. A. H. (2006). Strategic communication during relationship dissolution: Disengagement resistance strategies. Communication Research Reports, 23, 139-147.

Burleson, B. R., \& Denton, W. H. (1992). A new look at similarity and attraction in marriage: Similarities in social-cognitive and communication skills as predictors of attraction and satisfaction. Communication Monographs, 59, 268-287.

Burgoon, J. K., Buller, D. B., Hale, J. L., \& deTurck, M. A. (1984). Relational messages 
associated with nonverbal behaviors. Human Communication Research, 10, 351378.

Burgoon, J. K., Coker, D. A., \& Coker, R. A. (1986). Communicative effects of gaze behavior: A test of two contrasting explanations. Human Communication Research, 12, 495-524.

Burgoon, J. K., \& Hale, J. L. (1988). Nonverbal expectancy violations: Model elaboration and application to immediacy behavior. Communication Monographs, 55, 58-79.

Burgoon, J. K., \& LePoire, B. A. (1993). Effects of communication expectancies, actual communication, and expectancy disconfirmation on evaluations of communicators and their communication behavior. Human Communication Research, 20, 67-96.

Cahn, D. D. (1990). Perceived understanding and interpersonal relationships. Journal of Social and Personal Relationships, 7, 231-244.

Cahn, D. D., \& Shulman, G. M. (1984). The perceived understanding instrument. Communication Research Reports, 1, 122-125.

Canary, D. J., \& Dainton, M. (2006). Maintaining relationships. In A. L. Vangelisti \& D. Perlman (Eds.), The Cambridge handbook of personal relationships (pp. 727743). New York: Cambridge.

Canary, D. J., \& Spitzberg, B. H. (1987). Appropriateness and effectiveness perceptions of conflict strategies. Human Communication Research, 14, 93-118.

Coker, D. A., \& Burgoon, J. K. (1987). The nature of conversational involvement and nonverbal encoding patterns. Human Communication Research, 13, 463-494.

Cohn, D. A., Silver, D. H., Cowan, C. P., Cowan, P. A., \& Pearson, J. (1992). Working 
models of childhood attachment and couple relationships. Journal of Family Issues, 13, 432-449.

Collier, M. J., \& Thomas, M. (1988). Identity in intercultural communication: An interpretive perspective. In Y. Y. Kim \& W. Gudykunst (Eds.), Theories of intercultural communication (pp. 99-120). Newbury Park, CA: Sage.

Collins, N. L., \& Feeney, B. C. (2004). An attachment theory perspective on closeness and intimacy. In D. J. Mashek \& A. Aron (Eds.), Handbook of closeness and intimacy (pp. 163-188). Mahwah, NJ: Lawrence Erlbaum.

Collins, N. L., \& Read, S. J. (1990). Adult attachment, working models, and relationship quality in dating couples. Journal of Personality and Social Psychology, 58, 644663.

Crawford, L. A., \& Novak, K. B. (2007). Resisting peer pressure: Characteristics associated with other-self discrepancies in college students' levels of alcohol consumption. Journal of Alcohol and Drug Education, 51, 35-62.

Crowell, J. A., Treboux, D., \& Waters, E. (2002). Stability of attachment representations: The transition to marriage. Development Psychology, 38, 467-479.

Cupach, W. R., \& Imahori, T. T. (1993). Identity Management Theory: Communication competence in intercultural episodes and relationships. In R. L. Wiseman \& J. Koester (Eds.), Intercultural communication competence (pp. 112-131). Newbury Park, CA: Sage.

Cupach, W. R., \& Metts, S. (1986). Accounts of relational dissolution: A comparison of marital and non-marital relationships. Communication Monographs, 53, 311-334. Dainton, M. (2007). Attachment and marital maintenance. Communication Quarterly, 55, 
283-298.

Dindia, K., \& Baxter, L. A. (1987). Strategies for maintaining and repairing marital relationships. Journal of Social and Personal Relationships, 4, 143-158.

Elkin, F. (1958). Socialization and the presentation of self. Marriage and Family Living, 20, 320-325.

Erbert, L. A., \& Floyd, K. (2004). Affectionate expressions as face-threatening acts: Receivers assessments. Communication Studies, 55, 254-270.

Feeney, J. A. (2003). The systemic nature of couple relationships: An attachment perspective. In P. Erdman \& T. Caffery (Eds.), Attachment and family systems: Conceptual, empirical, and therapeutic relatedness (pp. 139-163). New York: Brunner-Routledge.

Fenigstein, A. (1979). Self-consciousness, self-attention, and social interaction. Journal of Personality and Social Psychology, 37, 75-86.

Fenigstein, A., Scheier, M. F., \& Buss, A. H. (1975). Public and private selfconsciousness: Assessment and theory. Journal of Consulting and Clinical Psychology, 43, 522-527.

Festinger, L. (1954). A theory of social comparison processes. Human Relations, 7, 117140.

Fincham, F. D., \& Beach, S. R. H. (2006). Relationship satisfaction. In A. L. Vangelisti \& D. Perlman (Eds.), The Cambridge handbook of personal relationships (pp. 579-594). New York: Cambridge University Press.

Fitzpatrick, M. A. (1987). Marital interaction. In C. R. Berger \& S. H. Chaffee (Eds.), Handbook of communication science (pp. 564-618). Newbury Park, CA: Sage. 
Fitzpatrick, M. A., \& Best, P. (1979). Dyadic adjustment in traditional, independent, and separate relationships: A validation study. Communication Monographs, 46, 167178.

Flemlee, D. H. (2001). No couple is an island: A social network perspective on dyadic stability. Social Forces, 79, 1259-1287.

Floyd, K., \& Haynes, M. T. (2005). Applications of the theory of natural selection to the study of family communication. Journal of Family Communication, 5, 79-101.

Glenn, N. D., \& Weaver, C. N. (1981). The contribution of marital happiness to global happiness. Journal of Marriage and the Family, 43, 161-168.

Goffman, E. (1967). Interaction ritual: Essays on face-to-face behavior. New York: Pantheon.

Goffman, E. (1971). Relations in public: Microstudies of the public order. New York: Harper \& Row.

Gottman, J. M. (1982). Temporal form: Toward a new language for describing relationships. Journal of Marriage and the Family, 44, 943-962.

Guerrero, L. K. (1996). Attachment-style differences in intimacy and involvement: A test of the four-category model. Communication Monographs, 63, 269-292.

Guerrero, L. K., \& Andersen, P. A. (1991). The waxing and waning of relational intimacy: Touch as a function of relational stage, gender and touch avoidance. Journal of Social and Personal Relationships, 8, 147-166.

Guerrero, L. K., \& Andersen, P. A. (1994). Patterns of matching and initiation: Touch behavior and touch avoidance across romantic relationship stages. Journal of Nonverbal Behavior, 18, 137-153. 
Guerrero, L. K., \& Bachman, G. F. (2006). Associations among relational maintenance behaviors, attachment-style categories, and attachment dimensions. Communication Studies, 57, 341-361.

Guerrero, L. K., \& Burgoon, J. K. (1996). Attachment styles and reactions to nonverbal involvement change in romantic dyads: Patterns of reciprocity and compensation. Human Communication Research, 22, 335-370.

Guerrero, L. K., \& Jones, S. M. (2003). Differences in one’s own and one’s partner’s perceptions of social skills as a function of attachment style. Communication Quarterly, 51, 277-295.

Guerrero, L. K., \& Jones, S. M. (2005). Differences in conversational skills as a function of attachment style: A follow-up study. Communication Quarterly, 53, 305-321.

H. R. 3396, 104d Cong., 142 Cong. Rec. 2419 (1996) (enacted). Accessed October 6, 2008. http://frwebgate.access.gpo.gov

Hall, J. A., \& Veccia, E. M. (1990). More ‘touching’ observations: New insights on men, women, and interpersonal touch. Journal of Personality and Social Psychology, 59, 1155-1162.

Hazan, C., \& Shaver, P. (1987). Conceptualizing romantic love as an attachment process. Journal of Personality and Social Psychology, 52, 511-524.

Hecht, M. L. (1978). The conceptualization and measurement of interpersonal communication satisfaction. Human Communication Research, 4, 253-264.

Hecht, M. L. (1993). 2002—A research odyssey: Toward the development of a communication theory of identity. Communication Monographs, 60, 76-82.

Hecht, M. L., Collier, M. J., \& Ribeau, S. A. (1993). African American communication: 
Ethnic identity and cultural interpretation. Newbury Park, CA: Sage.

Hecht, M. L., Faulkner, S. L., Meyer, C. R., Niles, T. A., Golden, D., \& Cutler, M. (2002). Looking through Northern Exposure at Jewish American identity and the Communication Theory of Identity. Journal of Communication, 52, 852-869.

Hecht, M. L., Jackson, R. L. II., Lindsley, S., Strauss, S., \& Johnson, K. E. (2001). A layered approach to ethnicity: Language and communication. In W. P. Robinson \& H. Giles (Eds.), The new handbook of language and social psychology (pp. 429-449, $2^{\text {nd }}$ ed.). New York: Wiley.

Hecht, M. L., \& Sereno, K. K. (1985). Interpersonal communication satisfaction: Relationship to satisfaction with self and other. Communication Research Reports, 2, 141-148.

Hest, T. L., Pearson, J. C., \& Child, J. T. (2006). Cover stories as family communication practice. In L. H. Turner \& R. West (Eds.), The family communication sourcebook (pp. 129-142). Thousand Oaks, CA: Sage.

Hinkle, L. K. (1999). Nonverbal immediacy communication behaviors and liking in marital relationships. Communication Research Reports, 16, 81-90.

Hopper, K., Knapp, M. L., \& Scott, L. (1981). Couples’ personal idioms: Exploring intimate talk. Journal of Communication, 31, 23-33.

Huston, T. L., \& Robins, E. (1982). Conceptual and methodological issues in studying close relationships. Journal of Marriage and the Family, 44, 901-925.

Johnson, M. P. (1991). Commitment to personal relationships. In W. H. Jones \& D. W. Perlman (Eds.), Advances in personal relationships (Vol. 3, pp. 117-143). London: Jessica Kingsley. 
Johnson, M. P., Caughlin, J. P., \& Huston, T. L. (1999). The tripartite nature of marital commitment: Personal, moral, and structural reasons to stay married. Journal of Marriage and the Family, 61, 160-177.

Jones, E. \& Gallois, C. (1989). Spouses impressions of rules for communication in public and private marital conflict. Journal of Marriage and the Family, 51, 957-967.

Jones, J. T., Pelham, B. W., Carvallo, M., \& Mirenberg, M. C. (2004). How do I love thee? Let me count the J's: Implicit egotism and interpersonal attraction. Journal of Personality and Social Psychology, 87, 665-683.

Julien, D., Tremblay, N., Belanger, I., Dube, M., Begin, J., \& Bouthillier, D. (2000). Interaction structure of husbands' and wives' disclosure of marital conflict to their respective best friends. Journal of Family Psychology, 14, 286-303.

Jung, E., \& Hecht, M. L. (2004). Elaborating the Communication Theory of Identity: Identity gaps and communication outcomes. Communication Quarterly, 52, 265283.

Jung, E., \& Hecht, M. L. (2008). Identity gaps and level of depression among Korean immigrants. Health Communication, 23, 313-325.

Jung, E., Hecht, M. L., \& Wadsworth, B. C. (2007). The role of identity in international students’ psychological well-being in the United States: A model of depression level, identity gaps, discrimination, and acculturation. International Journal of Intercultural Relations, 31, 605-624.

Kelley, H. H., Berscheid, E., Christensen, A., Harvey, J. H., Huston, T. L., Levinger, G., McClintock, E., Peplau, L. A., \& Peterson, D. R. (1983). Analyzing close relationships. In H. H. Kelley, E. Berscheid, A. Christensen, J. H. Harvey, T. L. 
Huston, G. Levinger, E. McClintock, L. A. Peplau, \& D. R. Peterson (Eds.), Close relationships (pp. 20-67). New York: Freeman.

Kirkpatrick, L. E., \& Davis, K. E. (1994). Attachment style, gender, and relationship stability: A longitudinal analysis. Journal of Personality and Social Psychology, 66, 502-512.

Le Poire, B. A., Shepard, C., \& Duggan, A. (1999). Nonverbal involvement, expressiveness, and pleasantness as predicted by parental and partner attachment style. Communication Monographs, 66, 293-311.

Leslie, L. A., Huston, T. L., \& Johnson, M. P. (1986). Parental reactions to dating relationships: Do they make a difference? Journal of Marriage and the Family, 48, 57-66.

Lewis, R. A. (1973). Social reaction and the formation of dyads: An interactionist approach to mate selection. Sociometry, 36, 409-418.

Loving, T. J., Heffner, K. L., \& Kiecolt-Glaser, J. K. (2006). Physiology and interpersonal relationships. In A. L. Vangelisti \& D. Perlman (Eds.), The Cambridge handbook of personal relationships (pp. 385-405). New York: Cambridge University Press.

Luo, S., \& Klohnen, E. C. (2005). Assortative mating and marital quality in newlyweds: A couple-centered approach. Journal of Personality and Social Psychology, 88, 304-326.

McCall, G. J., \& Simmons, J. L. (1978). Identities and interactions. New York: Free Press.

Mehrabian, A. (1971). Silent messages. Belmont, CA: Wadsworth Publishing Company, 
Inc.

Metts, S. (1998). "But I thought that we were more than error variance”: Application of the social relations model to personal relationships. In R. L. Conville \& L. E. Rogers (Eds.), The meaning of "relationship" in interpersonal communication (pp. 107-131). Westport, CT: Preager.

Milardo, R. M. (1982). Friendship networks in developing relationship: Converging and diverging social environments. Social Psychology Quarterly, 45, 162-172.

Milardo, R. M., Johnson, M. P., \& Huston, T. L. (1983). Developing close relationships: Changing patterns of interaction between pair members and social networks. Journal of Personality and Social Psychology, 44, 964-976.

Montgomery, B. M., \& Baxter, L. A. (1998). Dialectical approaches to studying personal relationships. Mahwah, NJ: Lawrence Erlbaum.

Noller, P. (2005). Attachment insecurity as a filter in the decoding and encoding of nonverbal behavior in close relationships. Journal of Nonverbal Behavior, 29, 171-176.

Parks, M. R. (2000). Communication networks and relationship life cycles. In K. Dindia \& S. Duck (Eds.), Communication and personal relationships (pp. 55-75). New York: Wiley \& Sons.

Parks, M. R. (2007). Personal relationships and personal networks. Mahwah, NJ: Lawrence Erlbaum.

Patterson, M. L. (1988). Functions of nonverbal behavior in close relationships. In S. W. Duck (Ed.), Handbook of personal relationships: Theory, research, and interventions (pp. 41-56). Chichester, UK: John Wiley and Sons. 
Perlman, D., \& Duck, S. (2006). The seven seas of the study of personal relationships: From “The Thousand Islands” to interconnected waterways. In A. L. Vangelisti \& D. Perlman (Eds.), The Cambridge handbook of personal relationships (pp. 1134). New York: Cambridge.

Petronio, S. (2002). Boundaries of privacy: Dialectics of disclosure. Albany, NY: State University of New York Press.

Planalp. S. (1985). Relational schemata. Human Communication Research, 12, 3-29.

Pollina, L. K., \& Snell, W. E. (1999). Coping in intimate relationships: Development of the multidimensional intimate coping questionnaire. Journal of Social and Personal Relationships, 16, 133-144.

Rogers, L. E., \& Escudero, V. (2004). Relational communication: An interactional perspective to the study of process and form. Mahwah, NJ: Lawrence Erlbaum.

Rogers, L. E., \& Farace, R. V. (1975). Analysis of relational communication in dyads: New measurement procedures. Human Communication Research, 1, 222-239.

Rubin, R. B., Perse, E. M., \& Barbato, C. A. (1988). Conceptualization and measurement of interpersonal communication motives. Human Communication Research, 14, 602-628.

Rusbult, C. E., Martz, J. M., \& Agnew, C. R. (1998). The investment model scale: Measuring commitment level, satisfaction level, quality of alternatives, and investment size. Personal Relationships, 5, 357-391.

Scheier, M. F. (1980). Effects of public and private self-consciousness on the public expression of personal beliefs. Journal of Personality and Social Psychology, 39, 514-521. 
Scott, R. L., \& Cordova, J. V. (2002). The influence of adult attachment styles on the association between marital adjustment and depressive symptoms. Journal of Family Psychology, 16, 199-208.

Sillars, A. L., Burggraf, C. S., Yost, S., \& Zietlow, P. H. (1992). Conversational themes and marital relationship definitions: Quantitative and qualitative investigations. Human Communication Research, 19, 124-154.

Sillars, A. L., Pike, G. R., Jones, T. S., \& Murphy, M. A. (1984). Communication and understanding in marriage. Human Communication Research, 10, 317-350.

Sillars, A. L., Weisberg, J., Burggraf, C. S., \& Wilson, E. A. (1987). Content themes in marital conversations. Human Communication Research, 13, 495-528.

Simon, E. P., \& Baxter, L. A. (1993). Attachment-style differences in relationship maintenance strategies. Western Journal of Communication, 57, 416-430.

Snell, W. E. Jr., Hampton, B. R., \& McManus, P. (1992). The impact of counselor and participant gender on willingness to discuss relational topics: Development of the relationship disclosure scale. Journal of Counseling \& Development, 70, 409-416.

Spanier, G. B. (1976). Measuring dyadic adjustment: New scales for assessing the quality of marriage and similar dyads. Journal of Marriage and the Family, 38, 15-28.

Spitzberg, B. H., \& Hecht, M. L. (1984). A component model of relational competence. Human Communication Research, 10, 575-599.

Stafford, L., \& Canary, D. J. (1991). Maintenance strategies and romantic relationship type, gender, and relational characteristics. Journal of Social and Personal Relationships, 8, 217-242.

Stafford, L., Dainton, M., \& Haas, S. (2000). Measuring routine and strategic relational 
maintenance: Scale revision, sex versus gender roles, and the prediction of relational characteristics. Communication Monographs, 67, 306-323.

Stewart, J. (1998). Historical frames of relational perspectives. In R. L. Conville \& L. E. Rogers (Eds.), The meaning of "relationship" in interpersonal communication (pp. 23-46). Westport, CT: Preager.

Stier, D. S., \& Hall, J. A. (1984). Gender differences in touch: An empirical and theoretical review. Journal of Personality and Social Psychology, 47, 440-459.

Surra, C. A. (1985). Courtship types: Variations in interdependence between partners and social networks. Journal of Personality and Social Psychology, 49, 357-375.

Titus, S. L. (1980). A function of friendship: Social comparisons as a frame of reference for marriage. Human Relations, 33, 409-431.

Treboux, D., Crowell, J. A., \& Waters, E. (2004). When “new” meets “old”: Configurations of adult attachment representations and their implications for marital functioning. Developmental Psychology, 40, 295-314.

Vangelisti, A. L. (2002). Interpersonal processes in romantic relationships. In M. L. Knapp \& J. A. Daly (Eds.), The handbook of interpersonal communication (3 ${ }^{\text {rd }}$ ed., pp. 643-679). Thousand Oaks, CA: Sage.

VanLear Jr., C. (1991). Testing a cyclical model of communicative openness in relationship development: Two longitudinal studies. Communication Monographs, 58, 337-361.

Venable, K., \& Martin, M. M. (1997). Argumentativeness and verbal aggressiveness in dating relationships. Journal of Social Behavior \& Personality, 12, 955-964.

Wadsworth, B. C., Hecht, M. L., \& Jung, E. (2008). The role of identity gaps, 
discrimination, and acculturation in international students' educational satisfaction in American classrooms. Communication Education, 57, 64-87.

Watzlawick, P., Beavin, J. H., \& Jackson, D. D. (1967). Pragmatics of human communication: A study of interactional patterns, pathologies, and paradoxes. New York: Norton \& Company.

Weger, H. Jr. (2005). Disconfirming communication and self-verification in marriage: Associations among the demand/withdraw interaction pattern, feeling understood, and marital satisfaction. Journal of Social and Personal Relationships, 22, 19-31.

Willis, F. N. Jr., \& Briggs, L. F. (1992). Relationship and touch in public settings. Journal of Nonverbal Behavior, 16, 55-63.

Wood, J. T. (1982). Communication and relational culture: Bases for studying human relationships. Communication Quarterly, 30, 75-83. 


\section{APPENDICES}

\section{Appendix A: Study One Scales}

This first set of questions is interested in learning more about you, your spouse, and your relationship. Please provide the following demographic information. For questions where there is a blank space provided, please place an " $\mathbf{X}$ " in the space that corresponds with how you wish to answer the question. For questions where there are options already provided (e.g., question three), please circle your answer.
1. What is your sex?
Male
Female

2. What is your age?

3. What is your ethnicity?

African American Asian American Caucasian (Not Hispanic)

Hispanic Native American

Other

(please specify)

4. In what state do you and your spouse currently reside?

5. How long have you and your spouse been married?

Years ___ Months

6. How long have you and your spouse been considered a "couple”?

Years Months

\section{Is this your first marriage? Yes \\ No \\ -If no, which number marriage is this for you?}

8. Approximately, how many hours a week do you and your spouse spend as a couple engaging in joint activities (e.g., going to the movies, working out at the gym, going shopping, going dancing, going to concerts, etc.)?
0-1 hour
1.5 to 3 hours
3.5 to 5 hours
$5.5+$ hours

9. Approximately, how many hours a week do you and your spouse spend as a couple interacting with friends?
0-1 hour
1.5 to 3 hours
3.5 to 5 hours
5.5+ hours 
Attachment Styles Continuous Measures (Guerrero, 1996)

The following statements concern how you think about relationships and closeness in general. This could include relationships with friends, family members, and romantic partners. Please indicate your level of agreement with each statement by circling the number that corresponds with how you feel in response to each statement. " 1 " means that you strongly disagree with that statement. " 7 " means that you strongly agree with that statement. “ 4 ” is a neutral point, indicating that you neither agree nor disagree with that statement.

\begin{tabular}{|c|c|c|c|c|c|c|c|}
\hline \multirow[b]{2}{*}{ 1. I find it easy to trust others. } & \multicolumn{2}{|c|}{$\begin{array}{l}\text { Strongly } \\
\text { disagree }\end{array}$} & \multicolumn{3}{|c|}{ Neutral } & \multicolumn{2}{|c|}{$\begin{array}{r}\begin{array}{r}\text { Strongly } \\
\text { agree }\end{array}\end{array}$} \\
\hline & 1 & 2 & 3 & 4 & 5 & 6 & 7 \\
\hline $\begin{array}{l}\text { 2. I sometimes worry that I do } \\
\text { not measure up to other } \\
\text { people. }\end{array}$ & 1 & 2 & 3 & 4 & 5 & 6 & 7 \\
\hline $\begin{array}{l}\text { 3. Intimate relationships are the } \\
\text { most central part of my life. }\end{array}$ & 1 & 2 & 3 & 4 & 5 & 6 & 7 \\
\hline $\begin{array}{l}\text { 4. I would like to trust others, } \\
\text { but I have a hard time doing } \\
\text { so. }\end{array}$ & 1 & 2 & 3 & 4 & 5 & 6 & 7 \\
\hline $\begin{array}{l}\text { 5. Achieving things is more } \\
\text { important to me than building } \\
\text { relationships. }\end{array}$ & 1 & 2 & 3 & 4 & 5 & 6 & 7 \\
\hline $\begin{array}{l}\text { 6. I feel uncomfortable when } \\
\text { people get close to me. }\end{array}$ & 1 & 2 & 3 & 4 & 5 & 6 & 7 \\
\hline $\begin{array}{l}\text { 7. I sometimes worry that I do } \\
\text { not really fit in with other } \\
\text { people. }\end{array}$ & 1 & 2 & 3 & 4 & 5 & 6 & 7 \\
\hline $\begin{array}{l}\text { 8. I feel a very strong need to } \\
\text { have close relationships. }\end{array}$ & 1 & 2 & 3 & 4 & 5 & 6 & 7 \\
\hline $\begin{array}{l}\text { 9. I worry about getting hurt if I } \\
\text { allow myself to get too close } \\
\text { to others. }\end{array}$ & 1 & 2 & 3 & 4 & 5 & 6 & 7 \\
\hline $\begin{array}{l}\text { 10. If something needs to be } \\
\text { done, I prefer to rely on } \\
\text { myself rather than others. }\end{array}$ & 1 & 2 & 3 & 4 & 5 & 6 & 7 \\
\hline $\begin{array}{l}\text { 11. I feel uneasy getting close to } \\
\text { others. }\end{array}$ & 1 & 2 & 3 & 4 & 5 & 6 & 7 \\
\hline $\begin{array}{l}\text { 12. I worry that others will reject } \\
\text { me. }\end{array}$ & 1 & 2 & 3 & 4 & 5 & 6 & 7 \\
\hline $\begin{array}{l}\text { 13. Sometimes others seem } \\
\text { reluctant to get as close to me } \\
\text { as I would like. }\end{array}$ & 1 & 2 & 3 & 4 & 5 & 6 & 7 \\
\hline $\begin{array}{l}\text { 14. I would like to have closer } \\
\text { relationships, but getting } \\
\text { close makes me uneasy. }\end{array}$ & 1 & 2 & 3 & 4 & 5 & 6 & 7 \\
\hline
\end{tabular}




\begin{tabular}{|l|llllllll|}
\hline & $\begin{array}{l}\text { Strongly } \\
\text { disagree }\end{array}$ & Neutral & & $\begin{array}{c}\text { Strongly } \\
\text { agree }\end{array}$ \\
\hline $\begin{array}{l}\text { 15. I put more time and energy } \\
\text { into my relationships than I } \\
\text { put into other activities. }\end{array}$ & 1 & 2 & 3 & 4 & 5 & 6 & 7 \\
\hline 16. I prefer to keep to myself. & 1 & 2 & 3 & 4 & 5 & 6 & 7 \\
\hline $\begin{array}{l}\text { 17. I am confident that other } \\
\text { people will like and respect } \\
\text { me. }\end{array}$ & 1 & 2 & 3 & 4 & 5 & 6 & 7 \\
\hline $\begin{array}{l}\text { 18. I worry a lot about the well- } \\
\text { being of my relationships. }\end{array}$ & 1 & 2 & 3 & 4 & 5 & 6 & 7 \\
\hline $\begin{array}{l}\text { 19. I worry that others do not } \\
\text { care about me as much as I } \\
\text { care about them. }\end{array}$ & 1 & 2 & 3 & 4 & 5 & 6 & 7 \\
\hline $\begin{array}{l}\text { 20. I would like to depend on } \\
\text { others, but it makes me } \\
\text { nervous to do so. }\end{array}$ & 1 & 2 & 3 & 4 & 5 & 6 & 7 \\
\hline $\begin{array}{l}\text { 21. Maintaining good } \\
\text { relationships is always my } \\
\text { top priority. }\end{array}$ & 1 & 2 & 3 & 4 & 5 & 6 & 7 \\
\hline $\begin{array}{l}\text { 22. I worry about people getting } \\
\text { close to me. }\end{array}$ & 1 & 2 & 3 & 4 & 5 & 6 & 7 \\
\hline $\begin{array}{l}\text { 23. I am confident that others will } \\
\text { accept me. }\end{array}$ & 1 & 2 & 3 & 4 & 5 & 6 & 7 \\
\hline $\begin{array}{l}\text { 24. I tend to avoid getting close } \\
\text { to others. }\end{array}$ & 1 & 2 & 3 & 4 & 5 & 6 & 7 \\
\hline $\begin{array}{l}\text { 25. I wonder how I would cope } \\
\text { without someone to love me. }\end{array}$ & 1 & 2 & 3 & 4 & 5 & 6 & 7 \\
\hline $\begin{array}{l}\text { 26. I rarely worry about what } \\
\text { relational partners think of } \\
\text { me. }\end{array}$ & 1 & 2 & 3 & 4 & 5 & 6 & 7 \\
\hline $\begin{array}{l}\text { 27. Pleasing myself is more } \\
\text { important to me than getting } \\
\text { along with others. }\end{array}$ & 1 & 2 & 3 & 4 & 5 & 6 & 7 \\
\hline $\begin{array}{l}\text { 28. I sometimes worry that } \\
\text { relational partners will leave } \\
\text { me. }\end{array}$ & 1 & 2 & 3 & 4 & 5 & 6 & 7 \\
\hline $\begin{array}{l}\text { 29. I find it relatively easy to get } \\
\text { close to others. }\end{array}$ & 1 & 2 & 3 & 4 & 5 & 6 & 7 \\
\hline $\begin{array}{l}\text { 30. I worry that I might get hurt if } \\
\text { I get too close to others. }\end{array}$ & 1 & 2 & 3 & 4 & 5 & 6 & 7 \\
\hline
\end{tabular}


Attachment Styles Categorical Measure (Bartholomew \& Horowitz, 1991)

Please place a check mark $(\checkmark)$ next to the paragraph that best explains how you think about relationships in general. Read all of the paragraphs before marking only ONE that describes you.

It is relatively easy for me to become emotionally close to others. I am comfortable depending on others and having others depend on me. I don't worry about being alone or having others not accept me.

I am comfortable without close emotional relationships. It is important to me to feel independent and self-sufficient, and I prefer not to depend on others or have others depend on me.

I want to be completely emotionally intimate with others, but I often find that others are reluctant to get as close as I would like. I am uncomfortable being without close relationships, but I sometimes worry that others don't value me as much as I value them.

I am somewhat uncomfortable getting close to others. I want emotionally close relationships, but I find it difficult to trust others completely or to depend on them. I sometimes worry that I will be hurt if I allow myself to become too close to others. 
Relationship Awareness (Snell, Hampton, \& McManus, 1992; Stafford, Dainton, \& Haas, 2000)

The following statements concern your degree of thought and discussion about your relationships with your spouse. Please indicate your level of agreement with each of the following statements using the scale ranging from strongly agree to strongly disagree. " 1 " means that you strongly disagree with that statement. "7" means that you strongly aqree with that statement. " 4 " is a neutral point, indicating that you neither agree nor disagree with that statement.

\begin{tabular}{|l|llllllrl|}
\hline & \multicolumn{2}{|l}{$\begin{array}{l}\text { Strongly } \\
\text { disagree }\end{array}$} & & Neutral & & $\begin{array}{r}\text { Strongly } \\
\text { agree }\end{array}$ \\
\hline $\begin{array}{l}\text { 31. I am very aware of what goes on } \\
\text { in my close relationships. }\end{array}$ & 1 & 2 & 3 & 4 & 5 & 6 & 7 \\
\hline $\begin{array}{l}\text { 32. I talk about my fears with my } \\
\text { spouse. }\end{array}$ & 1 & 2 & 3 & 4 & 5 & 6 & 7 \\
\hline $\begin{array}{l}\text { 33. I reflect about my intimate } \\
\text { relationships a lot. }\end{array}$ & 1 & 2 & 3 & 4 & 5 & 6 & 7 \\
\hline $\begin{array}{l}\text { 34. In general, I'm attentive to the } \\
\text { nature of my close relationships. }\end{array}$ & 1 & 2 & 3 & 4 & 5 & 6 & 7 \\
\hline $\begin{array}{l}\text { 35. I disclose to my spouse what I } \\
\text { need or want from the } \\
\text { relationship. }\end{array}$ & 1 & 2 & 3 & 4 & 5 & 6 & 7 \\
\hline $\begin{array}{l}\text { 36. I'm always trying to understand } \\
\text { my close relationships. }\end{array}$ & 1 & 2 & 3 & 4 & 5 & 6 & 7 \\
\hline $\begin{array}{l}\text { 37. I like to have periodic talks about } \\
\text { our relationship. }\end{array}$ & 1 & 2 & 3 & 4 & 5 & 6 & 7 \\
\hline $\begin{array}{l}\text { 38. I'm alert to changes in my } \\
\text { intimate relationships. }\end{array}$ & 1 & 2 & 3 & 4 & 5 & 6 & 7 \\
\hline $\begin{array}{l}\text { 39. I encourage my spouse to share } \\
\text { his or her feelings with me. }\end{array}$ & 1 & 2 & 3 & 4 & 5 & 6 & 7 \\
\hline $\begin{array}{l}\text { 40. I'm very aware of changes in my } \\
\text { intimate relationships. }\end{array}$ & 1 & 2 & 3 & 4 & 5 & 6 & 7 \\
\hline $\begin{array}{l}\text { 41. I am open about my feelings with } \\
\text { my spouse. }\end{array}$ & 1 & 2 & 3 & 4 & 5 & 6 & 7 \\
\hline $\begin{array}{l}\text { 42. My thoughts sometimes drift } \\
\text { toward the nature of my close } \\
\text { relationships. }\end{array}$ & 1 & 2 & 3 & 4 & 5 & 6 & 7 \\
\hline $\begin{array}{l}\text { 43. I simply tell my spouse how I } \\
\text { feel about the relationship. }\end{array}$ & 1 & 2 & 3 & 4 & 5 & 6 & 7 \\
\hline $\begin{array}{l}\text { 44. I talk with my spouse about } \\
\text { where we stand. }\end{array}$ & 1 & 2 & 3 & 4 & 5 & 6 & 7 \\
\hline $\begin{array}{l}\text { 45. I think about my close } \\
\text { relationships more than most } \\
\text { people do. }\end{array}$ & 1 & 2 & 3 & 4 & 5 & 6 & 7 \\
\hline $\begin{array}{l}\text { 46. I usually spend time thinking } \\
\text { about my close relationships. }\end{array}$ & 1 & 2 & 3 & 4 & 5 & 6 & 7 \\
\hline
\end{tabular}


Relationship Commitment (Rusbult, Martz, \& Agnew, 1998)

The following statements concern how you feel about your relationship with your spouse. Please indicate your level of agreement with each of the following statements. " 1 " means that you stronqly disagree with that statement. "7" means that you strongly aqree with that statement. " 4 " is a neutral point, indicating that you neither agree nor disagree with that statement.

\begin{tabular}{|l|llllllll|}
\hline & $\begin{array}{l}\text { Strongly } \\
\text { disagree }\end{array}$ & & Neutral & & $\begin{array}{c}\text { Strongly } \\
\text { agree }\end{array}$ \\
\hline $\begin{array}{l}\text { 47. I am oriented toward the long-term } \\
\text { future of my relationship (for } \\
\text { example, I imagine being with my } \\
\text { spouse several years from now). }\end{array}$ & 1 & 2 & 3 & 4 & 5 & 6 & 7 \\
\hline $\begin{array}{l}\text { 48. I want our relationship to last for a } \\
\text { very long time. }\end{array}$ & 1 & 2 & 3 & 4 & 5 & 6 & 7 \\
\hline $\begin{array}{l}\text { 49. I am committed to maintaining my } \\
\text { relationship with my spouse. }\end{array}$ & 1 & 2 & 3 & 4 & 5 & 6 & 7 \\
\hline $\begin{array}{l}\text { 50. I feel very attached to our } \\
\text { relationship-very strongly linked } \\
\text { to my spouse. }\end{array}$ & 1 & 2 & 3 & 4 & 5 & 6 & 7 \\
\hline $\begin{array}{l}\text { 51. It is likely that I will date someone } \\
\text { other than my spouse within the } \\
\text { next year. }\end{array}$ & 1 & 2 & 3 & 4 & 5 & 6 & 7 \\
\hline $\begin{array}{l}\text { 52. I want our relationship to last } \\
\text { forever. }\end{array}$ & 1 & 2 & 3 & 4 & 5 & 6 & 7 \\
\hline $\begin{array}{l}\text { 53. I would not feel very upset if our } \\
\text { relationship were to end in the } \\
\text { near future. }\end{array}$ & 1 & 2 & 3 & 4 & 5 & 6 & 7 \\
\hline
\end{tabular}


Relationship Satisfaction Scale (Spanier, 1976)

Circle the number that corresponds with how often you have related experiences/discussions. "0" means you never, " 6 " means all the time, and " 3 " means occasionally.

\begin{tabular}{|l|llllllll|}
\hline & Never & \multicolumn{1}{l}{ Occasionally } & & $\begin{array}{r}\text { All of the } \\
\text { time }\end{array}$ \\
\hline $\begin{array}{l}\text { 54. How often do you discuss or } \\
\text { have you considered divorce, } \\
\text { separation, or terminating your } \\
\text { relationship? }\end{array}$ & 0 & 1 & 2 & 3 & 4 & 5 & 6 \\
\hline $\begin{array}{l}\text { 55. How often do you or your } \\
\text { spouse leave the house after a } \\
\text { fight? }\end{array}$ & 0 & 1 & 2 & 3 & 4 & 5 & 6 \\
\hline $\begin{array}{l}\text { 56. In general, how often do you } \\
\text { think that things between you } \\
\text { and your spouse are going well? }\end{array}$ & 0 & 1 & 2 & 3 & 4 & 5 & 6 \\
\hline 57. Do you confide in your spouse? & 0 & 1 & 2 & 3 & 4 & 5 & 6 \\
\hline $\begin{array}{l}\text { 58. Do you ever regret that you } \\
\text { married? }\end{array}$ & 0 & 1 & 2 & 3 & 4 & 5 & 6 \\
\hline $\begin{array}{l}\text { 59. How often do you and your } \\
\text { spouse quarrel? }\end{array}$ & 0 & 1 & 2 & 3 & 4 & 5 & 6 \\
\hline 60. Do you kiss your spouse? & 0 & 1 & 2 & 3 & 4 & 5 & 6 \\
\hline $\begin{array}{l}\text { 61. How often do you and your } \\
\text { spouse "get on each other's } \\
\text { nerves?" }\end{array}$ & 0 & 1 & 2 & 3 & 4 & 5 & 6 \\
\hline
\end{tabular}

62. The dots on the following line represent different degrees of happiness in your relationship. The middle point, "happy," represents the degree of happiness of most relationships. Please circle the dot that best describes the degree of happiness, all things considered of your relationship.

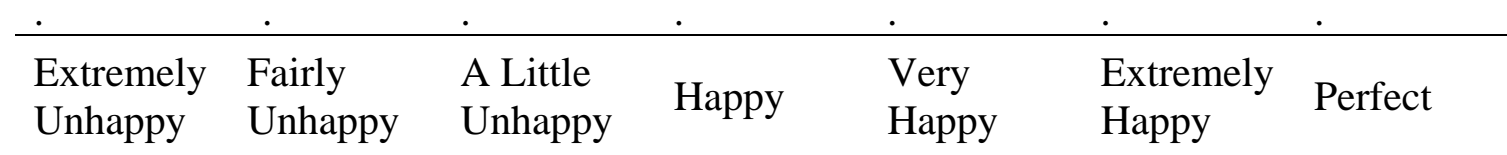

63. Which of the following statements best describes how you feel about the future of your relationship? Please pick only one by placing a check $(\checkmark)$ next to the statement that best reflects how you feel.

\footnotetext{
I I want desperately for my relationship to succeed, and would go to almost any length to see that it does.

I want very much for my relationship to succeed, and will do all I can to see that it does.

I want very much for my relationship to succeed, and will do my fair share to see that it does.

It would be nice if my relationship succeeded, but I refuse to do any more than I am doing now to keep the relationship going. My relationship can never succeed, and there is no more that I can do to keep the relationship going.
} 
Couple-Enacted Couple Identity Gap (Jung \& Hecht, 2004)

The following statements concern how you and your spouse communicate when you are in the presence of other people with whom you are purposely interacting. Please indicate your level of agreement with each of the following statements using the scale. " 1 " means that you strongly disagree with that statement. " 7 " means that you strongly agree with that statement. " 4 " is a neutral point, indicating that you neither agree nor disagree with that statement.

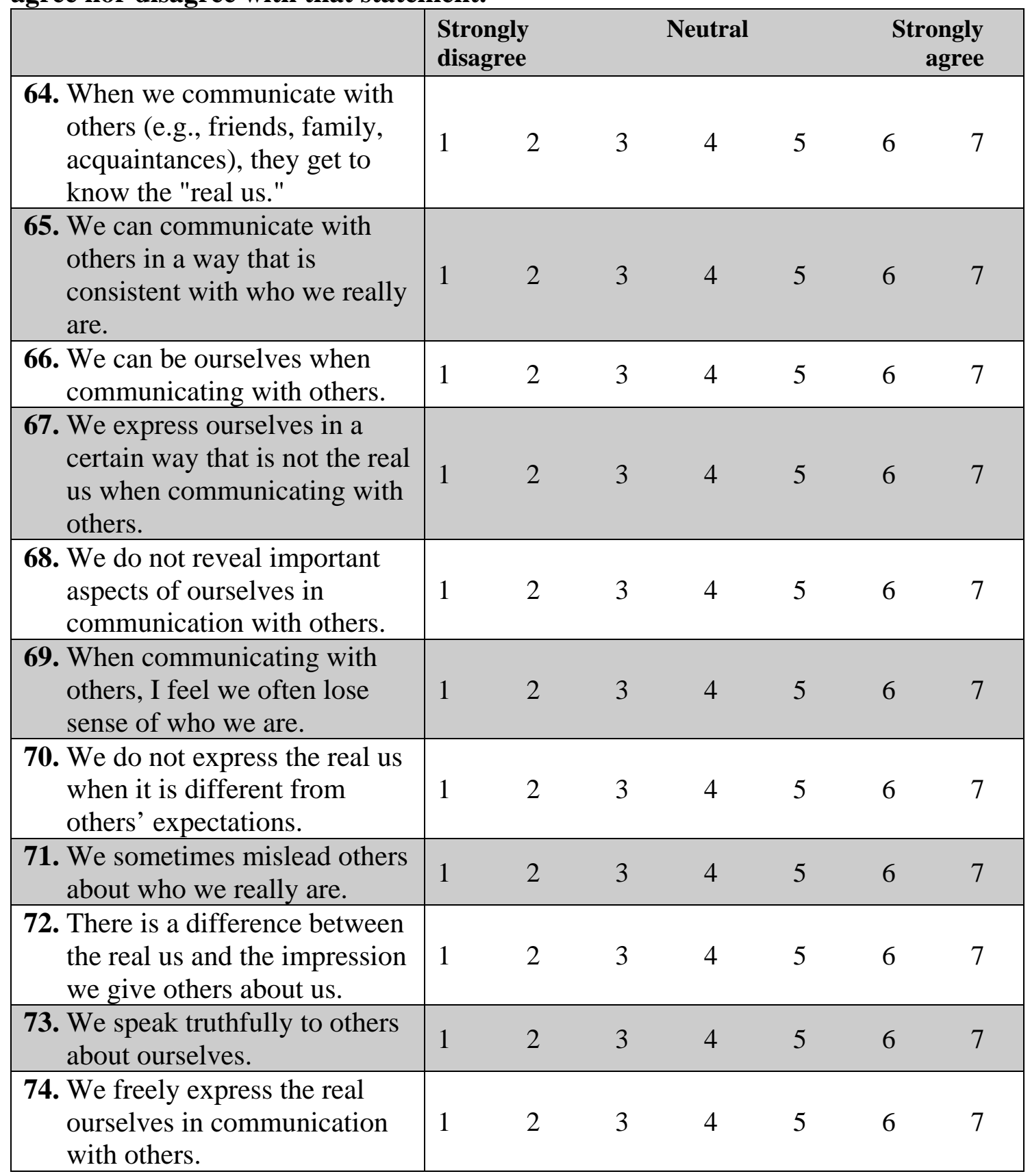


Personal-Enacted Couple Identity Gap (Jung \& Hecht, 2004)

The following statements concern how you communicate when you and your spouse are in the presence of other people with whom you are purposely interacting. Please indicate your level of agreement with each of the following statements using the scale. " 1 " means that you strongly disagree with that statement. " 7 " means that you strongly agree with that statement. " 4 " is a neutral point, indicating that you neither agree nor disagree with that statement.

\begin{tabular}{|c|c|c|c|c|c|c|c|}
\hline & \multicolumn{2}{|l|}{$\begin{array}{l}\text { Strongly } \\
\text { disagree }\end{array}$} & \multicolumn{3}{|c|}{ Neutral } & \multicolumn{2}{|c|}{$\begin{array}{r}\text { Strongly } \\
\text { agree }\end{array}$} \\
\hline $\begin{array}{l}\text { interacting with others, I } \\
\text { communicate in a way so that } \\
\text { they get to know the "real me." }\end{array}$ & 1 & 2 & 3 & 4 & 5 & 6 & 7 \\
\hline $\begin{array}{l}\text { 76. I feel that when my spouse and I } \\
\text { are interacting with others, I can } \\
\text { communicate in a way that is } \\
\text { consistent with who I really am. }\end{array}$ & 1 & 2 & 3 & 4 & 5 & 6 & 7 \\
\hline $\begin{array}{l}\text { 77. I feel that when my spouse and I } \\
\text { are interacting with others, I can } \\
\text { be myself. }\end{array}$ & 1 & 2 & 3 & 4 & 5 & 6 & 7 \\
\hline $\begin{array}{l}\text { 78. When my spouse and I are } \\
\text { interacting with others, I express } \\
\text { myself in a certain way that is not } \\
\text { the real me. }\end{array}$ & 1 & 2 & 3 & 4 & 5 & 6 & 7 \\
\hline $\begin{array}{l}\text { 79. When my spouse and I are } \\
\text { interacting with others, I do not } \\
\text { express the real me when I think } \\
\text { it is different from my spouse’s } \\
\text { expectation. }\end{array}$ & 1 & 2 & 3 & 4 & 5 & 6 & 7 \\
\hline $\begin{array}{l}\text { 80. When my spouse and I are } \\
\text { interacting with others, I } \\
\text { sometimes mislead such others } \\
\text { about who I really am. }\end{array}$ & 1 & 2 & 3 & 4 & 5 & 6 & 7 \\
\hline $\begin{array}{l}\text { 81. When my spouse and I are } \\
\text { interacting with others, there is a } \\
\text { difference between the real me } \\
\text { and the impression I give such } \\
\text { others about me. }\end{array}$ & 1 & 2 & 3 & 4 & 5 & 6 & 7 \\
\hline $\begin{array}{l}\text { 82. When my spouse and I are } \\
\text { interacting with others, I speak } \\
\text { truthfully about myself. }\end{array}$ & 1 & 2 & 3 & 4 & 5 & 6 & 7 \\
\hline $\begin{array}{l}\text { 83. When my spouse and I are } \\
\text { interacting with others, I freely } \\
\text { express the real me in } \\
\text { communication with them. }\end{array}$ & 1 & 2 & 3 & 4 & 5 & 6 & 7 \\
\hline
\end{tabular}




\begin{tabular}{|c|lllllll|}
\hline & $\begin{array}{l}\text { Strongly } \\
\text { disagree }\end{array}$ & & Neutral & & $\begin{array}{c}\text { Strongly } \\
\text { agree }\end{array}$ \\
\hline $\begin{array}{l}\text { 84. When my spouse and I are } \\
\text { interacting with others, I } \\
\text { often lose sense of who I am. }\end{array}$ & 1 & 2 & 3 & 4 & 5 & 6 & 7 \\
\hline $\begin{array}{l}\text { 85. When my spouse and I are } \\
\text { interacting with others, I do } \\
\text { not reveal important aspects } \\
\text { of myself. }\end{array}$ & 1 & 2 & 3 & 4 & 5 & 6 & 7 \\
\hline
\end{tabular}


Communication Satisfaction (Hecht, 1978)

These statements reflect individuals' general feelings about communication. While thinking about you and your spouse's interactions with others (e.g., friends, family, co-workers), indicate your level of agreement with each of the following statements. " 1 " means that you strongly disagree with that statement. " 7 " means that you strongly agree with that statement. " 4 " is a neutral point, indicating that you neither agree nor disagree with that statement.

\begin{tabular}{|l|lllllll|}
\hline & $\begin{array}{l}\text { Strongly } \\
\text { disagree }\end{array}$ & & Neutral & & $\begin{array}{c}\text { Strongly } \\
\text { agree }\end{array}$ \\
\hline $\begin{array}{l}\text { 86. I enjoy our conversations } \\
\text { with others. }\end{array}$ & 1 & 2 & 3 & 4 & 5 & 6 & 7 \\
\hline $\begin{array}{l}\text { 87. We each get to say what we } \\
\text { want during conversations } \\
\text { with others. }\end{array}$ & 1 & 2 & 3 & 4 & 5 & 6 & 7 \\
\hline $\begin{array}{l}\text { 88. I feel other people value what } \\
\text { we have to say. }\end{array}$ & 1 & 2 & 3 & 4 & 5 & 6 & 7 \\
\hline $\begin{array}{l}\text { 89. We are attentive to other's } \\
\text { comments. }\end{array}$ & 1 & 2 & 3 & 4 & 5 & 6 & 7 \\
\hline $\begin{array}{l}\text { 90. We feel accepted and } \\
\text { respected during our } \\
\text { conversations with others. }\end{array}$ & 1 & 2 & 3 & 4 & 5 & 6 & 7 \\
\hline $\begin{array}{l}\text { 91. Other persons show us they } \\
\text { understand what we say. }\end{array}$ & 1 & 2 & 3 & 4 & 5 & 6 & 7 \\
\hline $\begin{array}{l}\text { 92. Our conversations with others } \\
\text { flow smoothly. }\end{array}$ & 1 & 2 & 3 & 4 & 5 & 6 & 7 \\
\hline $\begin{array}{l}\text { 93. Other people express a lot of } \\
\text { interest in what we have to } \\
\text { say. }\end{array}$ & 1 & 2 & 3 & 4 & 5 & 6 & 7 \\
\hline
\end{tabular}


Feelings of Being Understood (Cahn \& Shulman, 1984)

Recall how you generally feel when you and your spouse are talking with (or listening to) other people. The following terms refer to feelings that may be relevant when people attempt to make themselves understood by others. Please indicate the extent to which each term describes how you generally feel during you and your spouse's conversations with others when (and immediately after) you are trying to make yourself understood by others. Respond to each term according to the following scale:

\section{Very Little}

1

1.

2.

3.

4.

5.

6.

7.

8.

$\begin{array}{ll} & \text { Annoyance } \\ & \text { Dissatisfaction } \\ & \text { Satisfaction } \\ & \text { Discomfort } \\ & \text { Relaxation } \\ & \text { Incompleteness } \\ & \text { Pleasure } \\ & \text { Failure }\end{array}$

Little Some

2

3
Great
4
Very Great
9.
10. Insecurity
11._Uninterestingness
12.
13.
14.
15.
16. Acceptance Sadness Comfortableness Happiness Importance 
Conversational Appropriateness (Canary \& Spitzberg, 1987)

The following statements concern your perceptions of your spouse's communication during interactions with others. Indicate your level of agreement with the each of the following statements. " 1 " means that you strongly disagree with that statement. " 7 " means that you strongly agree with that statement. " 4 " is a neutral point, indicating that you neither agree nor disagree with that statement.

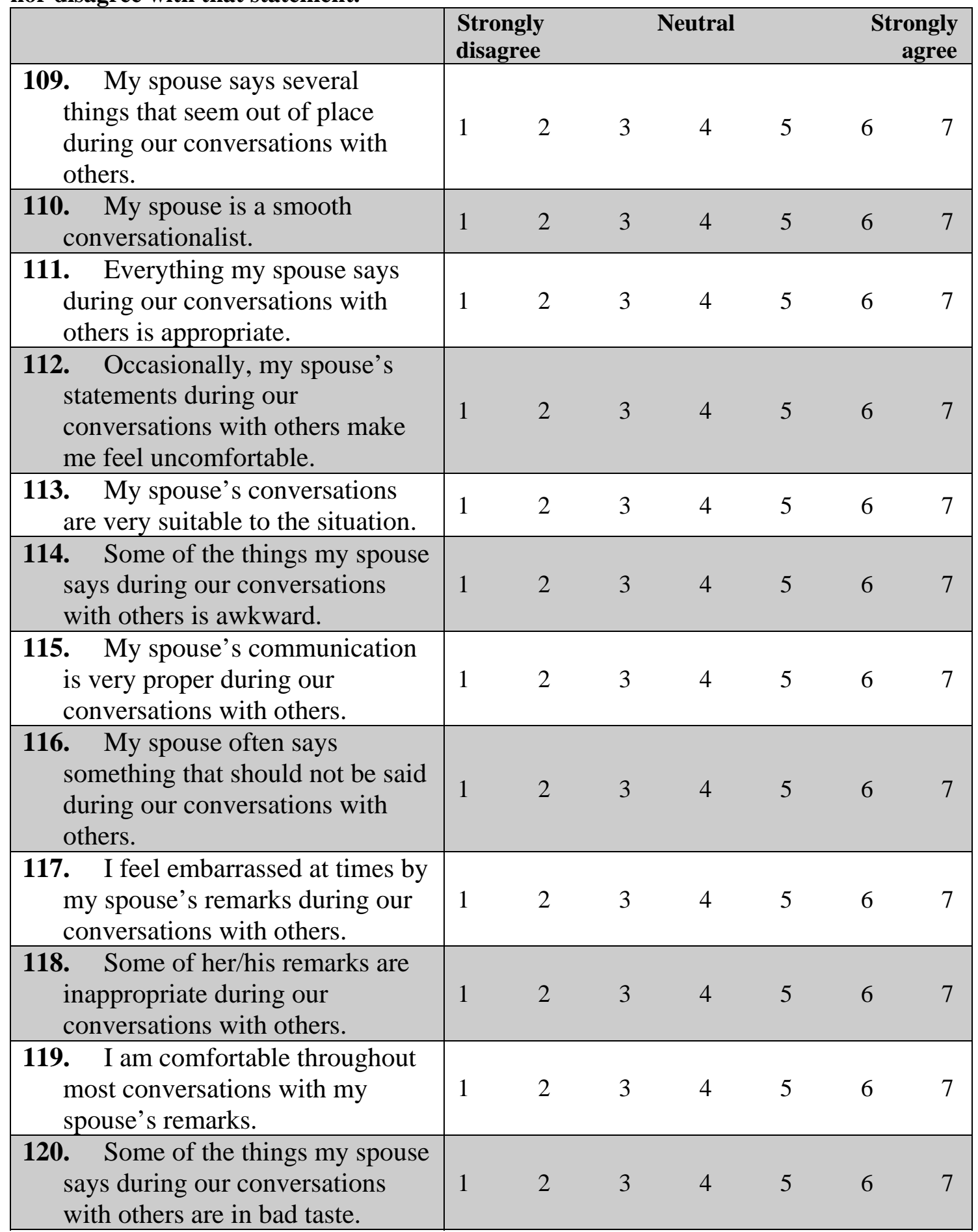




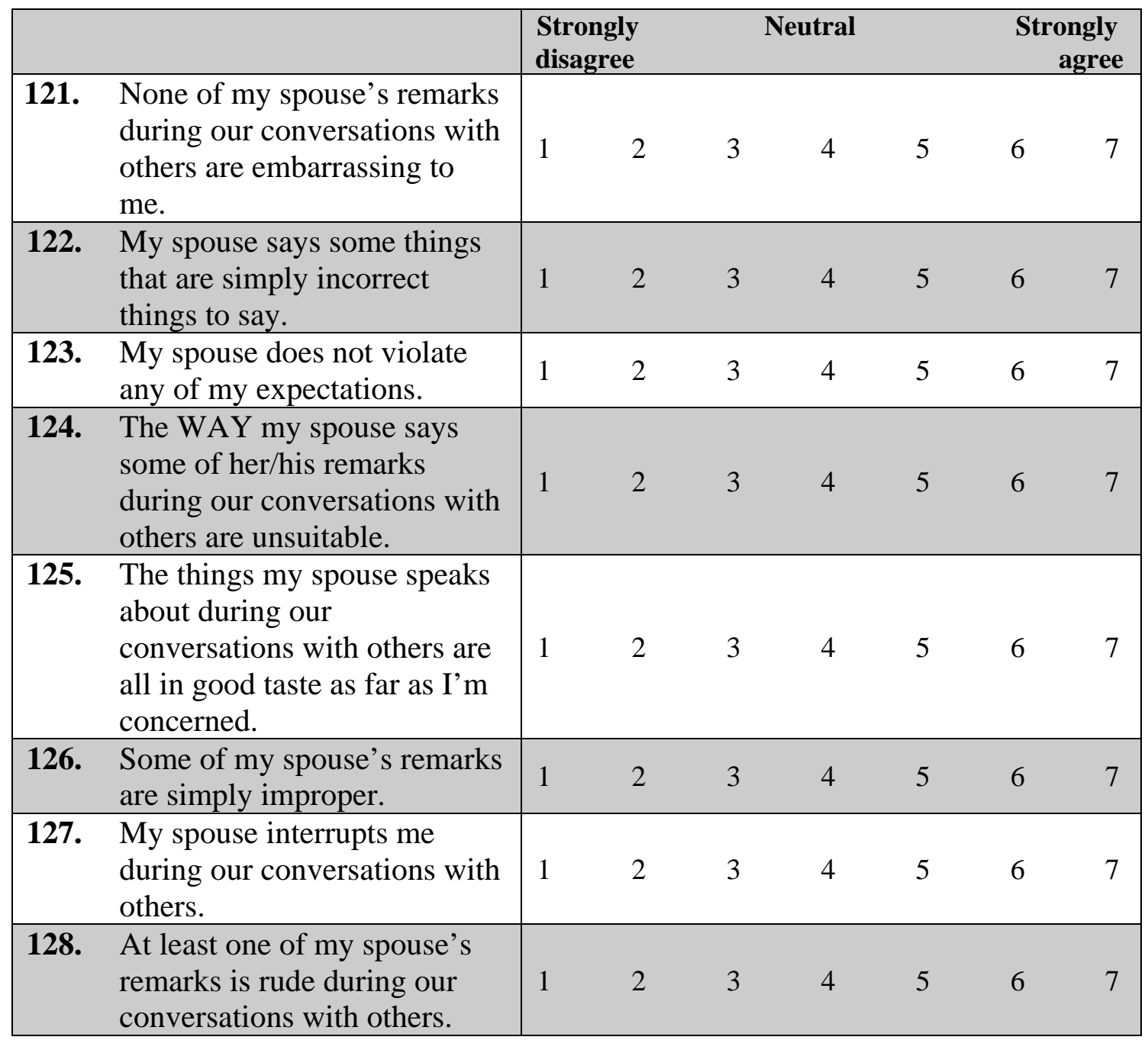




\section{Appendix B: Study Two Pre-Interaction Scales}

This first set of questions is interested in learning more about you, your spouse, and your relationship. Please provide the following demographic information. For questions where there is a blank space provided, please place an " $\mathbf{X}$ " in the space that corresponds with how you wish to answer the question. For questions where there are options already provided (e.g., question three), please circle your answer.
1. What is your sex?
Male
Female

2. What is your age?

3. What is your ethnicity?

African American Asian American Caucasian (Not Hispanic)

Hispanic Native American

Other (please specify)

4. In what state do you and your spouse currently reside?

5. How long have you and your spouse been married?

Years ___ Months

6. How long have you and your spouse been considered a "couple”?

Years Months

7. Is this your first marriage? Yes No

-If no, which number marriage is this for you?

8. Approximately, how many hours a week do you and your spouse spend as a couple engaging in joint activities (e.g., going to the movies, working out at the gym, going shopping, going dancing, going to concerts, etc.)?
0-1 hour
1.5 to 3 hours
3.5 to 5 hours
$5.5+$ hours

9. Approximately, how many hours a week do you and your spouse spend as a couple interacting with friends?

0-1 hour $\quad 1.5$ to 3 hours $\quad 3.5$ to 5 hours $\quad 5.5+$ hours 
Attachment Styles Continuous Measures (Guerrero, 1996)

The following statements are concerned with how you think about relationships in general. Please indicate your level of agreement with each statement by circling the number that corresponds with how you feel in response to each statement. "1" means that you strongly disagree with that statement. "7" means that you strongly agree with that statement. " 4 " is a neutral point, indicating that you neither agree nor disagree with that statement.

\begin{tabular}{|c|c|c|c|c|c|c|c|}
\hline & \multicolumn{3}{|c|}{$\begin{array}{l}\text { Strongly } \\
\text { disagree }\end{array}$} & \multicolumn{2}{|c|}{ Neutral } & \multicolumn{2}{|c|}{$\begin{array}{r}\begin{array}{r}\text { Strongly } \\
\text { agree }\end{array}\end{array}$} \\
\hline 1. I find it easy to trust others. & 1 & 2 & 3 & 4 & 5 & 6 & 7 \\
\hline $\begin{array}{l}\text { 2. I sometimes worry that I do } \\
\text { not measure up to other } \\
\text { people. }\end{array}$ & 1 & 2 & 3 & 4 & 5 & 6 & 7 \\
\hline $\begin{array}{l}\text { 3. Intimate relationships are the } \\
\text { most central part of my life. }\end{array}$ & 1 & 2 & 3 & 4 & 5 & 6 & 7 \\
\hline $\begin{array}{l}\text { 4. I would like to trust others, } \\
\text { but I have a hard time doing } \\
\text { so. }\end{array}$ & 1 & 2 & 3 & 4 & 5 & 6 & 7 \\
\hline $\begin{array}{l}\text { 5. Achieving things is more } \\
\text { important to me than building } \\
\text { relationships. }\end{array}$ & 1 & 2 & 3 & 4 & 5 & 6 & 7 \\
\hline $\begin{array}{l}\text { 6. I feel uncomfortable when } \\
\text { people get close to me. }\end{array}$ & 1 & 2 & 3 & 4 & 5 & 6 & 7 \\
\hline $\begin{array}{l}\text { 7. I sometimes worry that I do } \\
\text { not really fit in with other } \\
\text { people. }\end{array}$ & 1 & 2 & 3 & 4 & 5 & 6 & 7 \\
\hline $\begin{array}{l}\text { 8. I feel a very strong need to } \\
\text { have close relationships. }\end{array}$ & 1 & 2 & 3 & 4 & 5 & 6 & 7 \\
\hline $\begin{array}{l}\text { 9. I worry about getting hurt if I } \\
\text { allow myself to get too close } \\
\text { to others. }\end{array}$ & 1 & 2 & 3 & 4 & 5 & 6 & 7 \\
\hline $\begin{array}{l}\text { 10. If something needs to be } \\
\text { done, I prefer to rely on } \\
\text { myself rather than others. }\end{array}$ & 1 & 2 & 3 & 4 & 5 & 6 & 7 \\
\hline $\begin{array}{l}\text { 11. I feel uneasy getting close to } \\
\text { others. }\end{array}$ & 1 & 2 & 3 & 4 & 5 & 6 & 7 \\
\hline $\begin{array}{l}\text { 12. I worry that others will reject } \\
\text { me. }\end{array}$ & 1 & 2 & 3 & 4 & 5 & 6 & 7 \\
\hline $\begin{array}{l}\text { 13. Sometimes others seem } \\
\text { reluctant to get as close to me } \\
\text { as I would like. }\end{array}$ & 1 & 2 & 3 & 4 & 5 & 6 & 7 \\
\hline $\begin{array}{l}\text { 14. I would like to have closer } \\
\text { relationships, but getting } \\
\text { close makes me uneasy. }\end{array}$ & 1 & 2 & 3 & 4 & 5 & 6 & 7 \\
\hline $\begin{array}{l}\text { 15. I put more time and energy } \\
\text { into my relationships than I } \\
\text { put into other activities. }\end{array}$ & 1 & 2 & 3 & 4 & 5 & 6 & 7 \\
\hline 16. I prefer to keep to myself. & 1 & 2 & 3 & 4 & 5 & 6 & 7 \\
\hline
\end{tabular}




\begin{tabular}{|l|lllllll|}
\hline & $\begin{array}{l}\text { Strongly } \\
\text { disagree }\end{array}$ & Neutral & & $\begin{array}{c}\text { Strongly } \\
\text { agree }\end{array}$ \\
\hline $\begin{array}{l}\text { 17. I am confident that other } \\
\text { people will like and respect } \\
\text { me. }\end{array}$ & 1 & 2 & 3 & 4 & 5 & 6 & 7 \\
\hline $\begin{array}{l}\text { 18. I worry a lot about the } \\
\text { well-being of my } \\
\text { relationships. }\end{array}$ & 1 & 2 & 3 & 4 & 5 & 6 & 7 \\
\hline $\begin{array}{l}\text { 19. I worry that others do not } \\
\text { care about me as much as I } \\
\text { care about them. }\end{array}$ & 1 & 2 & 3 & 4 & 5 & 6 & 7 \\
\hline $\begin{array}{l}\text { 20. I would like to depend on } \\
\text { others, but it makes me } \\
\text { nervous to do so. }\end{array}$ & 1 & 2 & 3 & 4 & 5 & 6 & 7 \\
\hline $\begin{array}{l}\text { 21. Maintaining good } \\
\text { relationships is always my } \\
\text { top priority. }\end{array}$ & 1 & 2 & 3 & 4 & 5 & 6 & 7 \\
\hline $\begin{array}{l}\text { 22. I worry about people } \\
\text { getting close to me. }\end{array}$ & 1 & 2 & 3 & 4 & 5 & 6 & 7 \\
\hline $\begin{array}{l}\text { 23. I am confident that others } \\
\text { will accept me. }\end{array}$ & 1 & 2 & 3 & 4 & 5 & 6 & 7 \\
\hline $\begin{array}{l}\text { 24. I tend to avoid getting } \\
\text { close to others. }\end{array}$ & 1 & 2 & 3 & 4 & 5 & 6 & 7 \\
\hline $\begin{array}{l}\text { 25. I wonder how I would cope } \\
\text { without someone to love } \\
\text { me. }\end{array}$ & 1 & 2 & 3 & 4 & 5 & 6 & 7 \\
\hline $\begin{array}{l}\text { 26. I rarely worry about what } \\
\text { relational partners think of } \\
\text { me. }\end{array}$ & 1 & 2 & 3 & 4 & 5 & 6 & 7 \\
\hline $\begin{array}{l}\text { 27. Pleasing myself is more } \\
\text { important to me than } \\
\text { getting along with others. }\end{array}$ & 1 & 2 & 3 & 4 & 5 & 6 & 7 \\
\hline $\begin{array}{l}\text { 28. I sometimes worry that } \\
\text { relational partners will } \\
\text { leave me. }\end{array}$ & 1 & 2 & 3 & 4 & 5 & 6 & 7 \\
\hline $\begin{array}{l}\text { 29. I find it relatively easy to } \\
\text { get close to others. }\end{array}$ & 1 & 2 & 3 & 4 & 5 & 6 & 7 \\
\hline $\begin{array}{l}\text { 30. I worry that I might get } \\
\text { hurt if I get too close to } \\
\text { others. }\end{array}$ & 1 & 2 & 3 & 4 & 5 & 6 & 7 \\
\hline
\end{tabular}


Attachment Styles Categorical Measure (Bartholomew \& Horowitz, 1991)

\section{Please place a check mark $(\checkmark)$ next to the paragraph that best explains how you} think about relationships in general. Read all of the paragraphs before marking only ONE that describes you.

It is relatively easy for me to become emotionally close to others. I am comfortable depending on others and having others depend on me. I don't worry about being alone or having others not accept me.

I am comfortable without close emotional relationships. It is important to me to feel independent and self-sufficient, and I prefer not to depend on others or have others depend on me.

I want to be completely emotionally intimate with others, but I often find that others are reluctant to get as close as I would like. I am uncomfortable being without close relationships, but I sometimes worry that others don't value me as much as I value them.

I am somewhat uncomfortable getting close to others. I want emotionally close relationships, but I find it difficult to trust others completely or to depend on them. I sometimes worry that I will be hurt if I allow myself to become too close to others. 
Private and Public Self-Consciousness (Fenigstein, Scheier, \& Buss, 1975)

The following statements concern your level of self-reflection. Please indicate your level of agreement with each of the following statements using the scale ranging from strongly agree to strongly disagree. " 1 " means that you strongly disagree with that statement. "7" means that you strongly agree with that statement. " 4 " is a neutral point, indicating that you neither agree nor disagree with that statement.

\begin{tabular}{|c|c|c|c|c|c|c|c|}
\hline & & & & itral & & & \\
\hline $\begin{array}{l}\text { 1. I'm always trying to figure } \\
\text { myself out. }\end{array}$ & 1 & 2 & 3 & 4 & 5 & 6 & 7 \\
\hline $\begin{array}{l}\text { 2. Generally, I'm not very aware of } \\
\text { myself. }\end{array}$ & 1 & 2 & 3 & 4 & 5 & 6 & 7 \\
\hline 3. I reflect about myself a lot. & 1 & 2 & 3 & 4 & 5 & 6 & 7 \\
\hline $\begin{array}{l}\text { 4. I'm often the subject of my own } \\
\text { fantasies }\end{array}$ & 1 & 2 & 3 & 4 & 5 & 6 & 7 \\
\hline 5. I never scrutinize myself. & 1 & 2 & 3 & 4 & 5 & 6 & 7 \\
\hline $\begin{array}{l}\text { 6. I'm generally attentive to my } \\
\text { inner feelings. }\end{array}$ & 1 & 2 & 3 & 4 & 5 & 6 & 7 \\
\hline $\begin{array}{l}\text { 7. I'm constantly examining my } \\
\text { motives. }\end{array}$ & 1 & 2 & 3 & 4 & 5 & 6 & 7 \\
\hline $\begin{array}{l}\text { 8. I sometimes have the feeling that } \\
\text { I'm off somewhere watching } \\
\text { myself. }\end{array}$ & 1 & 2 & 3 & 4 & 5 & 6 & 7 \\
\hline $\begin{array}{l}\text { 9. I'm alert to changes in my } \\
\text { mood. }\end{array}$ & 1 & 2 & 3 & 4 & 5 & 6 & 7 \\
\hline $\begin{array}{l}\text { 10. I'm aware of the way my mind } \\
\text { works when I work through a } \\
\text { problem. }\end{array}$ & 1 & 2 & 3 & 4 & 5 & 6 & 7 \\
\hline $\begin{array}{l}\text { 11. I'm concerned about my style of } \\
\text { doing things. }\end{array}$ & 1 & 2 & 3 & 4 & 5 & 6 & 7 \\
\hline $\begin{array}{l}\text { 12. I'm concerned about the way I } \\
\text { present myself. }\end{array}$ & 1 & 2 & 3 & 4 & 5 & 6 & 7 \\
\hline $\begin{array}{l}\text { 13. I'm self-conscious about the } \\
\text { way I look. }\end{array}$ & 1 & 2 & 3 & 4 & 5 & 6 & 7 \\
\hline $\begin{array}{l}\text { 14. I usually worry about making a } \\
\text { good impression. }\end{array}$ & 1 & 2 & 3 & 4 & 5 & 6 & 7 \\
\hline $\begin{array}{l}\text { 15. One of the last things I do } \\
\text { before I leave my house is look } \\
\text { in the mirror. }\end{array}$ & 1 & 2 & 3 & 4 & 5 & 6 & 7 \\
\hline $\begin{array}{l}\text { 16. I'm concerned about what other } \\
\text { people think of me. }\end{array}$ & 1 & 2 & 3 & 4 & 5 & 6 & 7 \\
\hline $\begin{array}{l}\text { 17. I'm usually aware of my } \\
\text { appearance. }\end{array}$ & 1 & 2 & 3 & 4 & 5 & 6 & 7 \\
\hline
\end{tabular}


Overlapping Couple Identity (Agnew, Van Lange, Rusbult, \& Langston, 1998; Aron, Aron, \& Smollan, 1992)

Please think about your relationship with your spouse specifically when reading the following statements. These statements are focused on the degree of importance your relationship is to you. " 1 " means that you believe other things are of some importance. "7" means that you believe nothing else is of any importance.

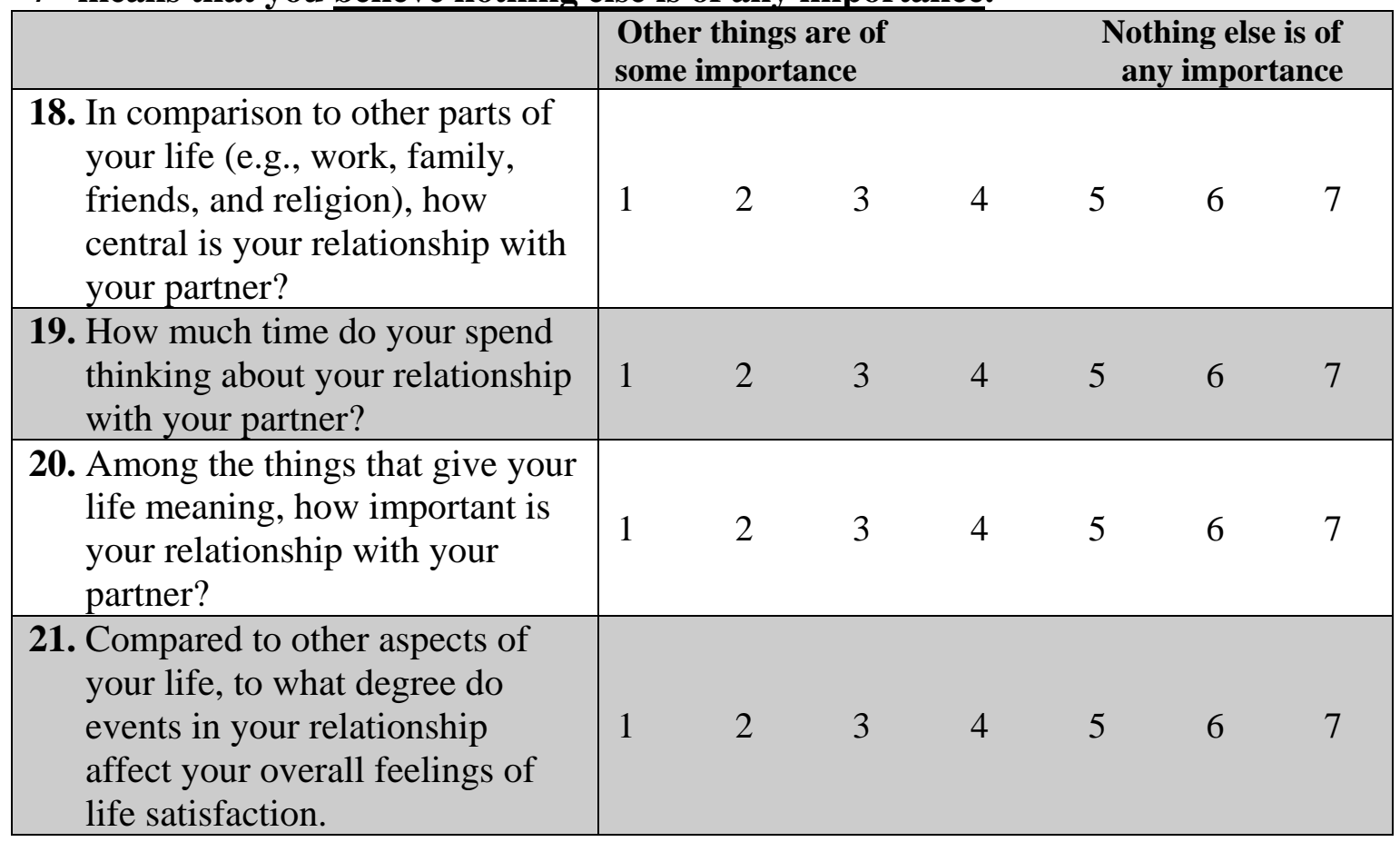

Please circle the picture below which best describes how you see yourself in relation to your partner.

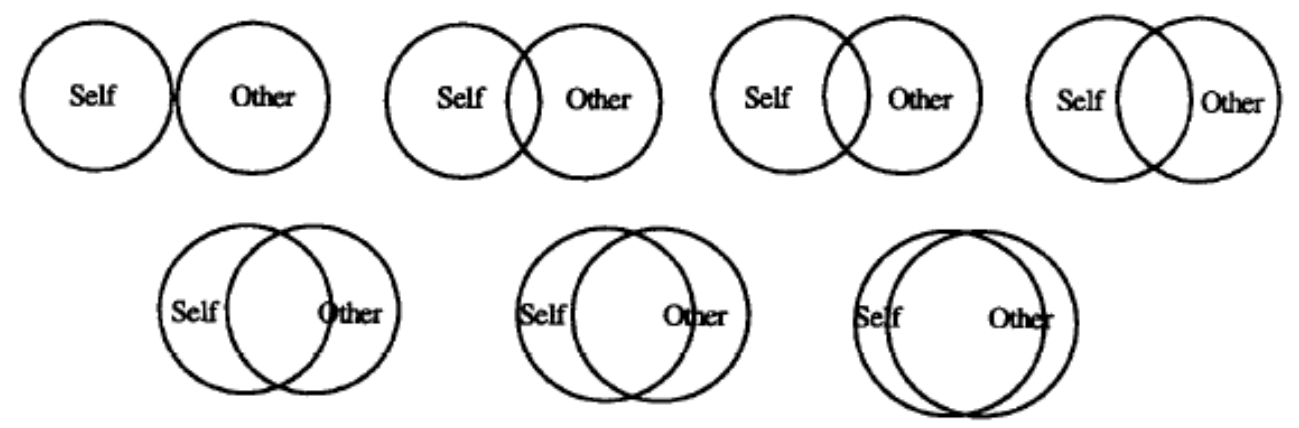


Appendix C: Study Two Post-Interaction Scales

Couple-Enacted Couple Identity Gap (Jung \& Hecht, 2004)

The following section is interested in your perceptions of how you and your spouse communicated during the interaction the two of you just engaged in with another marital couple. Please indicate your level of agreement with each of the following statements using the scale. " 1 " means that you strongly disagree with that statement. "7" means that you strongly agree with that statement. "4" is a neutral point, indicating that you neither agree nor disagree with that statement.

\begin{tabular}{|c|c|c|c|c|c|c|c|}
\hline \multirow[b]{2}{*}{$\begin{array}{l}\text { 1. They got to know the "real us" } \\
\text { during that interaction. }\end{array}$} & \multicolumn{2}{|c|}{$\begin{array}{l}\text { Strongly } \\
\text { disagree }\end{array}$} & \multicolumn{3}{|c|}{ Neutral } & \multicolumn{2}{|c|}{$\begin{array}{r}\begin{array}{r}\text { Strongly } \\
\text { agree }\end{array} \\
\text { and }\end{array}$} \\
\hline & 1 & 2 & 3 & 4 & 5 & 6 & 7 \\
\hline $\begin{array}{l}\text { 2. We communicated with them } \\
\text { in a way that is consistent with } \\
\text { who we really are. }\end{array}$ & 1 & 2 & 3 & 4 & 5 & 6 & 7 \\
\hline $\begin{array}{l}\text { 3. We could be ourselves when } \\
\text { communicating with them. }\end{array}$ & 1 & 2 & 3 & 4 & 5 & 6 & 7 \\
\hline $\begin{array}{l}\text { 4. We expressed ourselves in a } \\
\text { certain way that was not the } \\
\text { real us during that } \\
\text { conversation. }\end{array}$ & 1 & 2 & 3 & 4 & 5 & 6 & 7 \\
\hline $\begin{array}{l}\text { 5. We did not reveal important } \\
\text { aspects of ourselves during } \\
\text { that conversation. }\end{array}$ & 1 & 2 & 3 & 4 & 5 & 6 & 7 \\
\hline $\begin{array}{l}\text { 6. We lost sense of who we are } \\
\text { during that conversation. }\end{array}$ & 1 & 2 & 3 & 4 & 5 & 6 & 7 \\
\hline $\begin{array}{l}\text { 7. We did not express the real us } \\
\text { when it was different from } \\
\text { their expectations. }\end{array}$ & 1 & 2 & 3 & 4 & 5 & 6 & 7 \\
\hline $\begin{array}{l}\text { 8. We occasionally misled them } \\
\text { about who we really are. }\end{array}$ & 1 & 2 & 3 & 4 & 5 & 6 & 7 \\
\hline $\begin{array}{l}\text { 9. There was a difference } \\
\text { between the real us and the } \\
\text { impression we gave them } \\
\text { about us. }\end{array}$ & 1 & 2 & 3 & 4 & 5 & 6 & 7 \\
\hline $\begin{array}{l}\text { 10. We spoke truthfully to them } \\
\text { about ourselves. }\end{array}$ & 1 & 2 & 3 & 4 & 5 & 6 & 7 \\
\hline $\begin{array}{l}\text { 11. We freely expressed our real } \\
\text { selves in that conversation. }\end{array}$ & 1 & 2 & 3 & 4 & 5 & 6 & 7 \\
\hline
\end{tabular}


Personal-Enacted Couple Identity Gap (Jung \& Hecht, 2004)

The following statements concern how you perceive you communicated during the interaction you just had with another marital couple. Please indicate your level of agreement with each of the following statements using the scale. " 1 " means that you strongly disagree with that statement. " 7 " means that you strongly agree with that statement. " 4 " is a neutral point, indicating that you neither agree nor disagree with that statement.

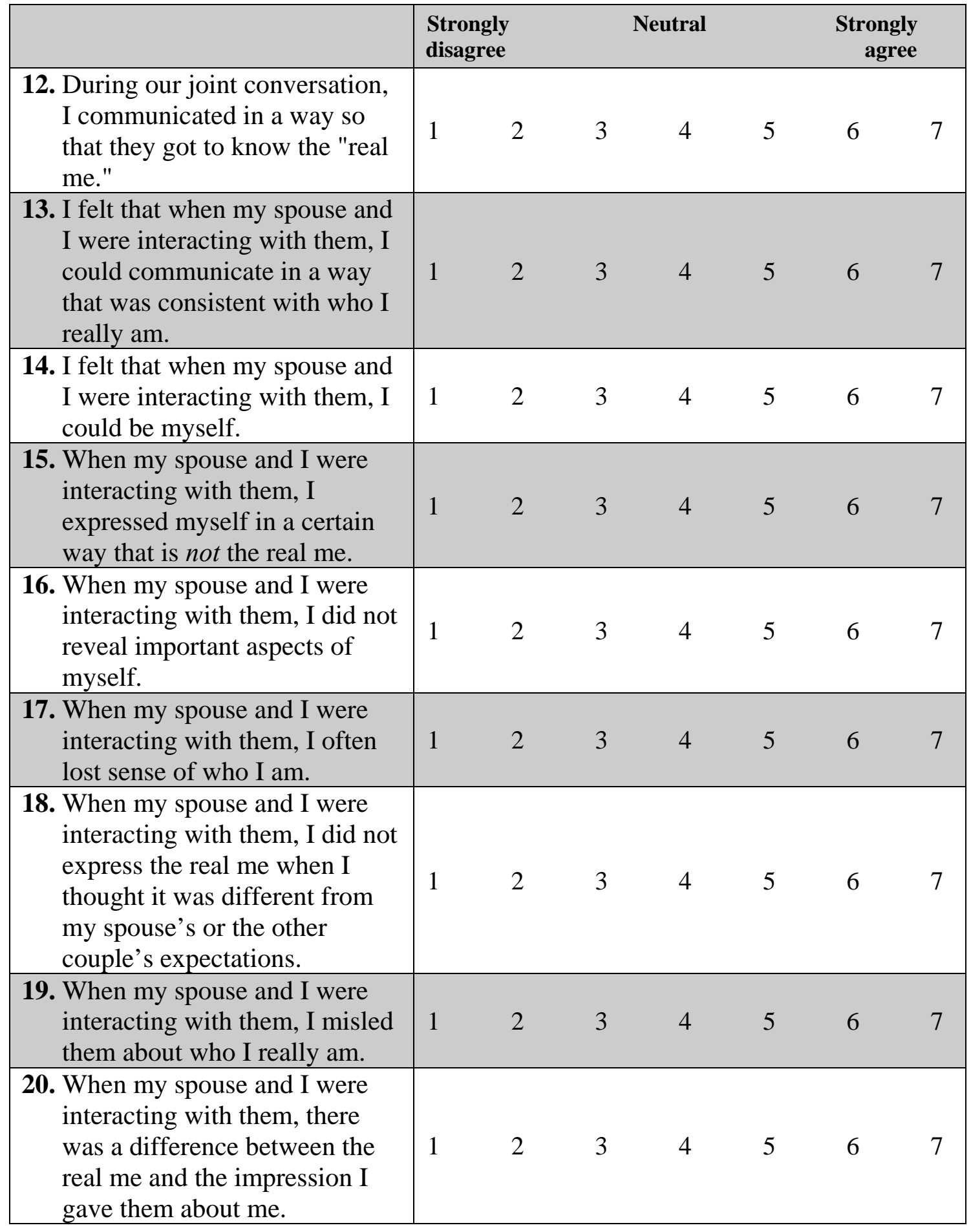




\begin{tabular}{|l|lllllll|}
\hline & $\begin{array}{l}\text { Strongly } \\
\text { disagree }\end{array}$ & & Neutral & & $\begin{array}{c}\text { Strongly } \\
\text { agree }\end{array}$ \\
\hline $\begin{array}{l}\text { 21. When my spouse and I were } \\
\text { interacting with them, I spoke } \\
\text { truthfully about myself. }\end{array}$ & 1 & 2 & 3 & 4 & 5 & 6 & 7 \\
\hline $\begin{array}{l}\text { 22. When my spouse and I were } \\
\text { interacting with them, I freely } \\
\text { expressed the real me. }\end{array}$ & 1 & 2 & 3 & 4 & 5 & 6 & 7 \\
\hline
\end{tabular}


Communication Satisfaction (Hecht, 1978)

The following statements are concerned with how you felt about the conversation you and your partner just engaged in with another marital couple. Please indicate your level of agreement with each of the following statements. These statements reflect individuals' general degree of satisfaction with communication. " 1 " means that you strongly disagree with that statement. " 7 " means that you strongly agree with that statement. "4" is a neutral point, indicating that you neither agree nor disagree with that statement.

\begin{tabular}{|c|c|c|c|c|c|c|c|}
\hline \multirow[b]{2}{*}{ 23. I enjoyed our conversation. } & \multicolumn{2}{|c|}{$\begin{array}{l}\text { Strongly } \\
\text { disagree }\end{array}$} & \multicolumn{3}{|c|}{ Neutral } & \multicolumn{2}{|c|}{$\begin{array}{r}\begin{array}{r}\text { Strongly } \\
\text { agree }\end{array} \\
\end{array}$} \\
\hline & 1 & 2 & 3 & 4 & 5 & 6 & 7 \\
\hline $\begin{array}{l}\text { 24. I felt my spouse valued what I } \\
\text { had to say. }\end{array}$ & 1 & 2 & 3 & 4 & 5 & 6 & 7 \\
\hline $\begin{array}{l}\text { 25. My spouse and I each got to say } \\
\text { what we wanted. }\end{array}$ & 1 & 2 & 3 & 4 & 5 & 6 & 7 \\
\hline $\begin{array}{l}\text { 26. My spouse and I were attentive } \\
\text { to each other's comments. }\end{array}$ & 1 & 2 & 3 & 4 & 5 & 6 & 7 \\
\hline $\begin{array}{l}\text { 27. I felt accepted and respected by } \\
\text { my spouse during the } \\
\text { conversation. }\end{array}$ & 1 & 2 & 3 & 4 & 5 & 6 & 7 \\
\hline $\begin{array}{l}\text { 28. My spouse showed me that } \\
\text { he/she understood what I said. }\end{array}$ & 1 & 2 & 3 & 4 & 5 & 6 & 7 \\
\hline $\begin{array}{l}\text { 29. Our conversation flowed } \\
\text { smoothly. }\end{array}$ & 1 & 2 & 3 & 4 & 5 & 6 & 7 \\
\hline $\begin{array}{l}\text { 30. My spouse expressed a lot of } \\
\text { interest in what I had to say. }\end{array}$ & 1 & 2 & 3 & 4 & 5 & 6 & 7 \\
\hline $\begin{array}{l}\text { 31. I felt the other couple valued } \\
\text { what we had to say. }\end{array}$ & 1 & 2 & 3 & 4 & 5 & 6 & 7 \\
\hline $\begin{array}{l}\text { 32. We all (including the other } \\
\text { couple) got to say what we } \\
\text { wanted. }\end{array}$ & 1 & 2 & 3 & 4 & 5 & 6 & 7 \\
\hline $\begin{array}{l}\text { 33. We all (including the other } \\
\text { couple) were attentive to each } \\
\text { other's comments. }\end{array}$ & 1 & 2 & 3 & 4 & 5 & 6 & 7 \\
\hline $\begin{array}{l}\text { 34. I felt accepted and respected by } \\
\text { the other couple during the } \\
\text { conversation. }\end{array}$ & 1 & 2 & 3 & 4 & 5 & 6 & 7 \\
\hline $\begin{array}{l}\text { 35. The other couple showed me } \\
\text { that they understood what I said. }\end{array}$ & 1 & 2 & 3 & 4 & 5 & 6 & 7 \\
\hline $\begin{array}{l}\text { 36. The other couple expressed a lot } \\
\text { of interest in what we had to } \\
\text { say. }\end{array}$ & 1 & 2 & 3 & 4 & 5 & 6 & 7 \\
\hline
\end{tabular}


Feelings of Being Understood (Cahn \& Shulman, 1984)

Recall how you generally feel when you and your spouse are talking with (or listening to) other people. The following terms refer to feelings that may be relevant when people attempt to make themselves understood by others. Please indicate the extent to which each term describes how you generally feel during you and your spouse's conversations with others when (and immediately after) you are trying to make yourself understood by others. Respond to each term according to the following scale:

Very

Little

1

1.

2.

3.

4.

5.

6.

7.

8.

Annoyance
Dissatisfaction
Satisfaction
Discomfort
Relaxation
Incompleteness
Pleasure
Failure

Some 3

Great

4

Very

Great

5
17.
18. Insecurity
19. Good
20. Uninterestingness
21. Acceptance
22. Sadness
23. Comfortableness
24 Happiness Importance 
Conversational Appropriateness (Canary \& Spitzberg 1987)

The following statements concern your perceptions of spouse's communication. While thinking about the conversation you and your spouse just had with another marital couple, indicate your level of agreement with the following statements. " 1 " means that you strongly disagree with that statement. "7" means that you strongly aqree with that statement. " 4 " is a neutral point, indicating that you neither agree nor disagree with that statement.

\begin{tabular}{|c|c|c|c|c|c|c|c|}
\hline & \multicolumn{2}{|c|}{$\begin{array}{l}\text { Strongly } \\
\text { disagree }\end{array}$} & \multicolumn{3}{|c|}{ Neutral } & \multicolumn{2}{|c|}{$\begin{array}{r}\begin{array}{r}\text { Strongly } \\
\text { agree }\end{array} \\
\end{array}$} \\
\hline $\begin{array}{l}\text { things that seemed out of } \\
\text { place during our } \\
\text { conversation. }\end{array}$ & 1 & 2 & 3 & 4 & 5 & 6 & 7 \\
\hline $\begin{array}{l}\text { 48. My spouse is a smooth } \\
\text { conversationalist. }\end{array}$ & 1 & 2 & 3 & 4 & 5 & 6 & 7 \\
\hline $\begin{array}{l}\text { 49. Everything my spouse said } \\
\text { during our conversation } \\
\text { was appropriate. }\end{array}$ & 1 & 2 & 3 & 4 & 5 & 6 & 7 \\
\hline $\begin{array}{l}\text { 50. Occasionally, my spouse's } \\
\text { statements made me feel } \\
\text { uncomfortable. }\end{array}$ & 1 & 2 & 3 & 4 & 5 & 6 & 7 \\
\hline $\begin{array}{l}\text { 51. My spouse's conversation } \\
\text { was very suitable to the } \\
\text { situation. }\end{array}$ & 1 & 2 & 3 & 4 & 5 & 6 & 7 \\
\hline $\begin{array}{l}\text { 52. Some of the things my } \\
\text { spouse said were awkward. }\end{array}$ & 1 & 2 & 3 & 4 & 5 & 6 & 7 \\
\hline $\begin{array}{l}\text { 53. My spouse’s } \\
\text { communication was very } \\
\text { proper. }\end{array}$ & 1 & 2 & 3 & 4 & 5 & 6 & 7 \\
\hline $\begin{array}{l}\text { 54. My spouse said something } \\
\text { that should not be said } \\
\text { during conversations with } \\
\text { others. }\end{array}$ & 1 & 2 & 3 & 4 & 5 & 6 & 7 \\
\hline $\begin{array}{l}\text { 55. I felt embarrassed at times } \\
\text { by my spouse's remarks } \\
\text { during our conversation. }\end{array}$ & 1 & 2 & 3 & 4 & 5 & 6 & 7 \\
\hline $\begin{array}{l}\text { 56. Some of my spouse's } \\
\text { remarks were } \\
\text { inappropriate. }\end{array}$ & 1 & 2 & 3 & 4 & 5 & 6 & 7 \\
\hline $\begin{array}{l}\text { 57. I was comfortable } \\
\text { throughout the } \\
\text { conversations with my } \\
\text { spouse's remarks. }\end{array}$ & 1 & 2 & 3 & 4 & 5 & 6 & 7 \\
\hline $\begin{array}{l}\text { 58. Some of the things my } \\
\text { spouse said during our }\end{array}$ & 1 & 2 & 3 & 4 & 5 & 6 & 7 \\
\hline
\end{tabular}




\begin{tabular}{|c|c|c|c|c|c|c|c|}
\hline $\begin{array}{l}\text { conversation was in bad } \\
\text { taste. }\end{array}$ & & & & & & & \\
\hline $\begin{array}{l}\text { 59. None of my spouse's } \\
\text { remarks were embarrassing } \\
\text { to me. }\end{array}$ & 1 & 2 & 3 & 4 & 5 & 6 & 7 \\
\hline $\begin{array}{l}\text { 60. My spouse said some } \\
\text { things that were simply } \\
\text { incorrect things to say. }\end{array}$ & 1 & 2 & 3 & 4 & 5 & 6 & 7 \\
\hline $\begin{array}{l}\text { 61. My spouse did not violate } \\
\text { any of my expectations. }\end{array}$ & 1 & 2 & 3 & 4 & 5 & 6 & 7 \\
\hline $\begin{array}{l}\text { 62. The WAY my spouse said } \\
\text { some of her/his remarks } \\
\text { were unsuitable. }\end{array}$ & 1 & 2 & 3 & 4 & 5 & 6 & 7 \\
\hline $\begin{array}{l}\text { 63. The things my spouse } \\
\text { spoke about during our } \\
\text { conversation were all in } \\
\text { good taste as far as I'm } \\
\text { concerned. }\end{array}$ & 1 & 2 & 3 & 4 & 5 & 6 & 7 \\
\hline $\begin{array}{l}\text { 64. Some of my spouse's } \\
\text { remarks were simply } \\
\text { improper. }\end{array}$ & 1 & 2 & 3 & 4 & 5 & 6 & 7 \\
\hline $\begin{array}{l}\text { 65. My spouse interrupted me } \\
\text { during our conversation. }\end{array}$ & 1 & 2 & 3 & 4 & 5 & 6 & 7 \\
\hline $\begin{array}{l}\text { 66. At least one of my spouse's } \\
\text { remarks was rude. }\end{array}$ & 1 & 2 & 3 & 4 & 5 & 6 & 7 \\
\hline
\end{tabular}




\section{Appendix D: Conversation Directions and Questions}

You're going to engage in a 15-minute conversation with another married couple. To guide the conversation we have provided some questions on note cards for you to discuss. Please allow each couple time to answer the question (to the degree to which they feel comfortable) on each note card before proceeding to the next card. You do not have to discuss ALL of the questions during the 15-minutes, but we do ask that you proceed through the cards in this order. You can ask additional questions related to the question provided on the note card, but do not deviate too much from the general topic of discussion solicited by the card. There is NO right answer to any of these questions. We simply ask that you are honest and speak about each topic to the extent that you feel comfortable with. After the 15 minutes has passed, I will return to stop your conversation and direct you to another room where you will answer some more questions. Do you have any questions for me?

What is your name?

Where are you originally from?

Why are you here?

Do you like it here?

Do you have any kids? If not, do you plan to have any kids?

What do you do for a living?

How did you come to work where you work?

How many hours do you work a week and why?

If you could be anywhere right now where would you be?

How did you meet?

How long were you engaged before you got married?

Why do you think people get married?

What advice would you give to a new married couple?

How do you manage household tasks?

How do you manage disagreements?

How do you make major decisions?

Where do see yourself in 5 years? 10 years?

What are your hobbies?

What do you do for fun?

What do you think is important in life?

What makes you really mad? Really happy?

What is your idea of the perfect day?

What is your idea of a bad day?

What do you consider to be a significant life-changing event?

If you won a million dollars what would you do with it?

If you could have one wish what would it be?

What is your favorite holiday? Why?

What is your favorite time of day? Why?

What is your favorite room where you live? Why?

What is your favorite memory? Why?

What are some of your beliefs?

If you could change one thing about yourself what would it be? 
Appendix E: Study Two Codebook

\section{Verbal Behaviors-Content}

Communal Themes: Marriage is seen as the product of join or interdependent qualities of the couple.

\begin{tabular}{|c|c|}
\hline Subcategories \& Description & Examples \\
\hline \multicolumn{2}{|l|}{ Togetherness } \\
\hline $\begin{array}{l}\text { References to sharing of time, } \\
\text { activities, interests, attitudes, beliefs, } \\
\text { and values; enjoying each other's } \\
\text { company, having basic similarities } \\
\text { and compatibilities, and working } \\
\text { toward togetherness. }\end{array}$ & $\begin{array}{l}\text { - "We enjoy the same things." } \\
\text { - "We enjoy doing chores together." } \\
\text { - "We don’t take enough time to do }\end{array}$ \\
\hline $\begin{array}{lllll}\text { No Togetherness } & 0 & 1 & 2 & 3 \\
\end{array}$ & $6 \quad$ High Togetherness \\
\hline \multicolumn{2}{|c|}{ Cooperation (conscious, active working together to resolve problems) } \\
\hline $\begin{array}{l}\text { Working collectively to resolve } \\
\text { disputes and problems; joint decision } \\
\text { making; letting the other person know } \\
\text { about problems; having shared rights } \\
\text { and responsibilities; mutual respect } \\
\text { and consideration; managing } \\
\text { arguments and conflicts. }\end{array}$ & $\begin{array}{l}\text { - "We talk out disagreements so that we } \\
\text { don’t confuse the children." } \\
\text { - "We work together in paying things." } \\
\text { - "I don’t have the right to be irritable with } \\
\text { you and vice-versa." }\end{array}$ \\
\hline $\begin{array}{lllll}\text { No Cooperation } & 0 & 1 & 2 & 3 \\
\end{array}$ & High Cooperation \\
\hline \multicolumn{2}{|c|}{ Communication (expressive communication and verbal sharing) } \\
\hline $\begin{array}{l}\text { Talking and sharing thoughts and } \\
\text { feelings as a couple; having } \\
\text { understanding of one another }\end{array}$ & $\begin{array}{l}\text { - "We talk all the time." } \\
\text { - "I feel better if I get it off my chest." }\end{array}$ \\
\hline $\begin{array}{llll}\text { No Communication } & 0 & 1 & 2 \\
\end{array}$ & High Communication \\
\hline \multicolumn{2}{|l|}{ Romanticism } \\
\hline $\begin{array}{l}\text { - Having shared affection, being in } \\
\text { love, having mutual physical affection } \\
\text { and attraction. }\end{array}$ & $\begin{array}{l}\text { - "If two people don’t show affection, } \\
\text { chances are they're not in love." } \\
\text { - "Lack of affection stems from people } \\
\text { marrying for the wrong reasons." }\end{array}$ \\
\hline No Romanticism & $\begin{array}{llll}4 & 5 & 6 & \text { High Romanticism }\end{array}$ \\
\hline \multicolumn{2}{|c|}{ Interdependence (Mutual influence) } \\
\hline $\begin{array}{l}\text { Recognizing the reciprocal effects of } \\
\text { each person's behavior on the other; } \\
\text { having joint. Negotiated patterns of } \\
\text { behavior }\end{array}$ & $\begin{array}{l}\text { - "It's hard to be depressed when someone } \\
\text { else is not." } \\
\text { - "If you're irritable and I'm feeling } \\
\text { irritable, then that makes it worse." }\end{array}$ \\
\hline $\begin{array}{lllll}\text { No Interdependence } & 0 & 1 & 2 \\
\end{array}$ & $\begin{array}{llll}4 & 5 & 6 & \text { High Interdependence }\end{array}$ \\
\hline
\end{tabular}


Individual Themes: Marriage is seen as the product of separate identities or roles.

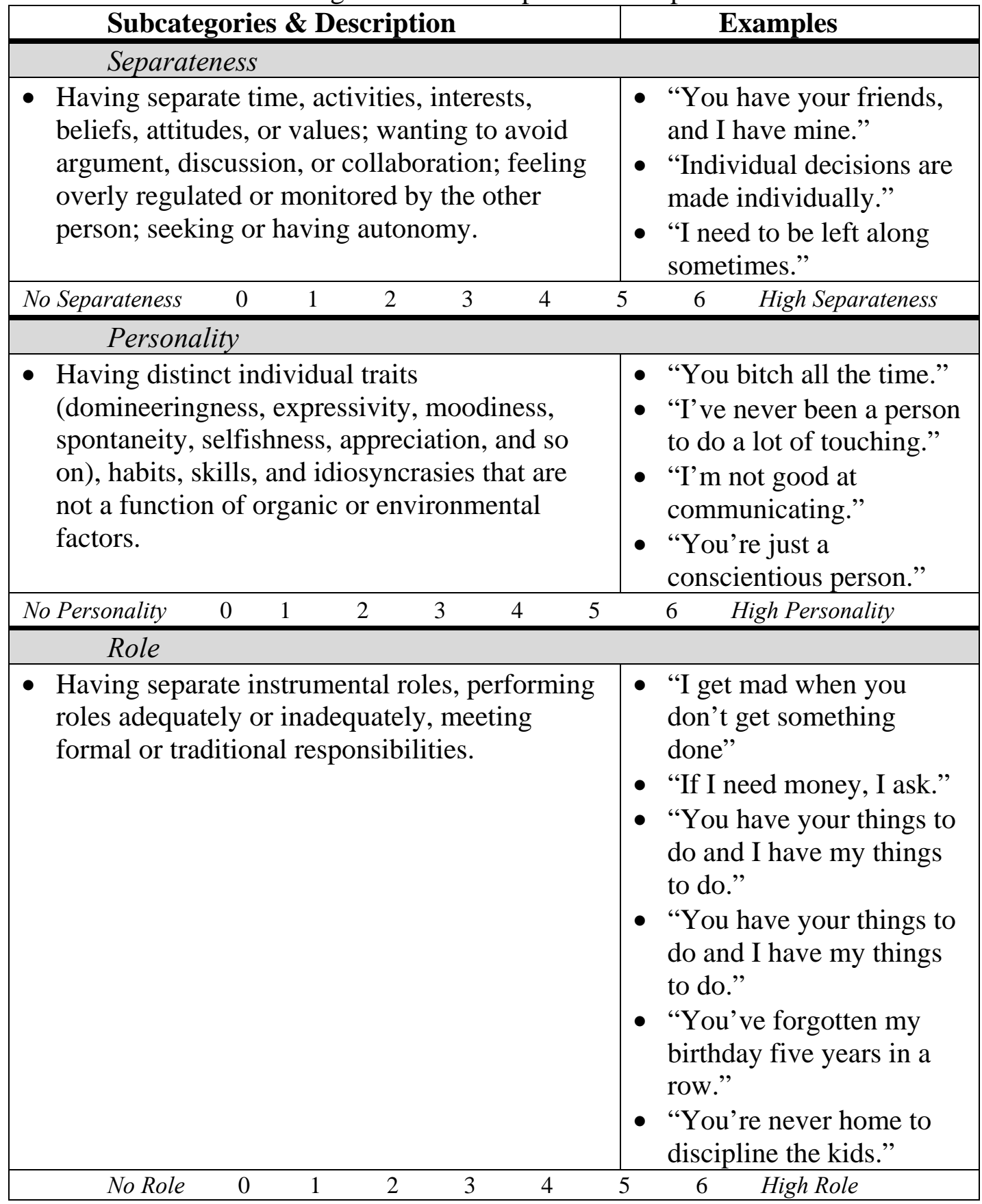


Impersonal Themes: Marriage is seen as the product of factor that are largely or partly beyond the direct, personal control of the couple.

\begin{tabular}{|c|c|}
\hline Subcategories \& Description & Examples \\
\hline \multicolumn{2}{|l|}{ Organic Properties } \\
\hline $\begin{array}{l}\text { Normative, developmental, and intrinsic, } \\
\text { characteristics of individuals, society, or the } \\
\text { institution of marriage that are seen as } \\
\text { predetermining the nature of marriage, } \\
\text { including gender, family background, } \\
\text { developmental experiences, age, the } \\
\text { duration of marriage, God and religion, } \\
\text { one's physical condition or physical } \\
\text { characteristics, inherent cyclical or seasonal } \\
\text { factors, and accepted social norms. }\end{array}$ & $\begin{array}{l}\text { - "Men aren’t used to showing } \\
\text { affection." } \\
\text { - "We discipline according to the } \\
\text { Bible." } \\
\text { - "It's hard for you to relax since you } \\
\text { had the heart attack." } \\
\text { - "You've mellowed with age." }\end{array}$ \\
\hline \multicolumn{2}{|c|}{$\begin{array}{lllllllll}\begin{array}{l}\text { No Organic } \\
\text { Properties }\end{array} & 0 & 1 & 2 & 3 & 4 & 5 & 6 & \text { High Organic Properties } \\
\end{array}$} \\
\hline \multicolumn{2}{|c|}{$\begin{array}{l}\text { Stoicism (recognition that conflicts and problem are inherent in marriage and } \\
\text { acceptance of moderate standards for satisfaction) }\end{array}$} \\
\hline $\begin{array}{l}\text { Establishing modest needs and expectations, } \\
\text { putting problems aside or in perspective, } \\
\text { coping, setting relative standards for } \\
\text { satisfaction, or making comparisons with } \\
\text { less favorable or similar marriages. }\end{array}$ & $\begin{array}{l}\text { - "We just don’t worry about money." } \\
\text { - "Going out sometimes is enough." } \\
\text { - won't" } \\
\text { - "We don't have that problem in } \\
\text { - "Couples determine for themselves } \\
\text { how much affection they need." }\end{array}$ \\
\hline No Stoicism & High Stoicism \\
\hline \multicolumn{2}{|c|}{ Environmental Influence (the couple's situation is seen as preempting individual choice) } \\
\hline $\begin{array}{l}\text { References to externally imposed stress, } \\
\text { scarce resources (e.g., time, money), } \\
\text { preoccupation with outside responsibilities, } \\
\text { or forced separation due to factors such as } \\
\text { work and extended family obligations. }\end{array}$ & $\begin{array}{l}\text { - "I've been involved with classes.” } \\
\text { - "We do things when money, time, } \\
\text { and opportunity permits." } \\
\text { - "I'm too busy on Sunday to attend } \\
\text { church.” } \\
\text { - "There’s just not enough hours in } \\
\text { the day." }\end{array}$ \\
\hline \multicolumn{2}{|l|}{$\begin{array}{l}\text { No Environmental } \\
\text { Influence } 0\end{array}$} \\
\hline
\end{tabular}


Verbal Behaviors-Organization

\begin{tabular}{|c|c|c|c|c|c|c|c|c|}
\hline \multicolumn{4}{|c|}{ Organization Type } & \multicolumn{5}{|c|}{ Description } \\
\hline \multicolumn{4}{|c|}{$\begin{array}{l}\text { Continuity - the extension of } \\
\text { content, implication, and topic by } \\
\text { successive speakers. }\end{array}$} & \multicolumn{5}{|c|}{$\begin{array}{l}\text { - Agreement or disagreement between spouses } \\
\text { on the literal ideas that are expressed. } \\
\text { - Agreement or disagreement between spouses } \\
\text { on the evaluative implications of statements } \\
\text { (e.g., whether a behavior or situation was } \\
\text { labeled positively or negatively, whether it } \\
\text { was seen as excusable or inexcusable). } \\
\text { - Topic continuity from spouse to spouse. }\end{array}$} \\
\hline No Continuity & 0 & 1 & 2 & & 4 & 5 & 6 & High Continuity \\
\hline \multicolumn{4}{|c|}{$\begin{array}{l}\text { Hierarchy-The extension of } \\
\text { themes to different behaviors, } \\
\text { contexts, and topics. }\end{array}$} & \multicolumn{5}{|c|}{$\begin{array}{l}\text { - The abstractness versus concreteness of the } \\
\text { discussion. } \\
\text { - Elaboration, or the amount of discussion } \\
\text { evoked by particular themes } \\
\text { - Mention of the same or a similar theme } \\
\text { elsewhere in the transcript during discussion } \\
\text { of different topics. }\end{array}$} \\
\hline No Hierarchy & 0 & 1 & 2 & 3 & 4 & 5 & 6 & High Hierarchy \\
\hline
\end{tabular}


Verbal Behaviors-Integration Chains

\begin{tabular}{|c|c|c|}
\hline Integration Chain Type & Description & Assigned Code \\
\hline $\begin{array}{l}\text { Blending-Couples } \\
\text { produced undifferentiated } \\
\text { and interchangeable } \\
\text { account of the } \\
\text { relationship. }\end{array}$ & $\begin{array}{l}\text { - Communal themes (especially } \\
\text { togetherness). } \\
\text { - High degree of continuity and } \\
\text { hierarchy. } \\
\text { - Mutually confirming and overlapping } \\
\text { talk about shared rules, } \\
\text { interpretations, activities, } \\
\text { backgrounds and experiences }\end{array}$ & $\begin{array}{l}0=\text { no blending } \\
1=\text { blending }\end{array}$ \\
\hline $\begin{array}{l}\text { Differentiating-Couples } \\
\text { produced an un-integrated } \\
\text { discussion of individual } \\
\text { characteristics. }\end{array}$ & $\begin{array}{l}\text { - Individual themes (especially } \\
\text { personality and separateness). } \\
\text { - Lack of continuity except for a } \\
\text { reciprocal focus on individual } \\
\text { behaviors and personality issues. } \\
\text { - Frequent topic shifts, counter- } \\
\text { complaints, and leading questions. } \\
\text { - High autonomy and low consensus. }\end{array}$ & $\begin{array}{l}0=\text { no } \\
\text { differentiating } \\
1= \\
\text { differentiating }\end{array}$ \\
\hline $\begin{array}{l}\text { Balancing-Couples } \\
\text { produced a discussion of } \\
\text { individual characteristics } \\
\text { balanced by integrative } \\
\text { higher-order themes. }\end{array}$ & $\begin{array}{l}\text { - Bridge between the two extremes } \\
\text { above. } \\
\text { - Personality themes were interspersed } \\
\text { with communication themes. } \\
\text { - Individual differences/characteristics } \\
\text { with a high degree of continuity } \\
\text { between spouses. }\end{array}$ & $\begin{array}{l}0=\text { no } \\
\text { balancing } \\
1=\text { balancing }\end{array}$ \\
\hline
\end{tabular}


Nonverbal Behaviors

Eye Behavior Between Spouses

$\begin{array}{lllllllll}\text { Unsteady Eye Gaze } & 1 & 2 & 3 & 4 & 5 & 6 & 7 & \text { Steady }\end{array}$

Eye Gaze

$\begin{array}{lllllllll}\text { No Gaze } & 1 & 2 & 3 & 4 & 5 & 6 & 7 & \text { Constant Eye }\end{array}$

$\begin{array}{llllllllll}\text { Never Gazing } & 1 & 2 & 3 & 4 & 5 & 6 & 7 & \text { Always }\end{array}$

Gazing

Smiling

$\begin{array}{llllllllll}\text { Frequent } & 1 & 2 & 3 & 4 & 5 & 6 & 7 & \text { None }\end{array}$

$\begin{array}{lllllllll}\text { Inappropriate } & 1 & 2 & 3 & 4 & 5 & 6 & 7 & \text { Appropriate }\end{array}$

Touch

Frequency count-tally mark of discrete initiated touch

Frequency count—tally mark of discrete received touch

Body Lean

$\begin{array}{lllllllll}\text { Lean Toward Partner } 1 & 2 & 3 & 4 & 5 & 6 & 7 & \text { Lean Away }\end{array}$

$\begin{array}{lllllllll}\text { Short Duration } & 1 & 2 & 3 & 4 & 5 & 6 & 7 & \text { Long Duration }\end{array}$

Lean Toward

Behavioral Matching of the Couple

$\begin{array}{lllllllll}\begin{array}{l}\text { Couple Did Not } \\ \text { Match } \\ \text { Each Other }\end{array} & 1 & 2 & 3 & 4 & 5 & 6 & 7 & \begin{array}{l}\text { Couple Did } \\ \text { Match } \\ \text { Each Other }\end{array}\end{array}$




\section{Carrie Delane Kennedy-Lightsey}

P.O. Box 1013 ø Dellslow, WV 26531 ø 304-906-8723 ø cdklightsey@gmail.com

\section{EDUCATION}

$\mathrm{PhD}$

Communication Studies, May 2009

Primary: Interpersonal, Secondary: Instructional

West Virginia University, Morgantown, WV

Advisor: Dr. Matthew M. Martin

Dissertation: When Two become One: Marital Couples' Public

Performances and Couple Identity

MA Communication Studies, December 2005

Texas State University, San Marcos, TX

Advisor: Dr. Timothy Mottet

Capstone Project: Researching Family Conflict: A Fresh

Perspective

BA Communication Studies, May 2004

St. Edward's University, Austin, TX

AA English, May 2002

Blinn College, Brenham, TX

\section{PUBLICATIONS}

Kennedy-Lightsey, C. D., \& Myers, S. A. (2009). College students' use of behavioral alteration techniques as a function of aggressive communication. Communication Education, 58, 54-73.

Kennedy-Lightsey, C. D., \& Booth-Butterfield, M. (in press). Responses to jealousy situations that evoke uncertainty in married and dating relationships. Communication Quarterly.

Madlock, P. E., \& Kennedy-Lightsey, C. D. (in press). The effects of supervisors’ verbal aggressiveness and mentoring on their subordinates. Journal of Business Communication.

Madlock, P. E., Kennedy-Lightsey, C. D., \& Myers, S. A. (2007). Employees’ communication attitudes and dislike for working in a group. Psychological Reports, 101, 1037-1040.

Myers, S. A., Horan, S. M., Kennedy-Lightsey, C. D., Madlock, P. E., Sidelinger, R. J., Byrnes, K. A., Frisby, B. N. \& Mansson, D. (in press). The relationship between college students' self-reports of class participation and perceived instructor impressions. Communication Research Reports. 


\section{MANUSCRIPTS UNDER REVIEW}

Kennedy-Lightsey, C. D., \& Dillow, M. R. Initiating and avoiding communication with mothers: Young adult children's perceptions of hurtfulness and affirming styles. Communication Quarterly.

Kennedy-Lightsey, C. D. Recognizing contributions: Face support/threat influences students' emotional and communicative responses. Communication Research Reports.

Kennedy-Lightsey, C. D. \& Martin, M. M. The predictive validity of the interpersonal attraction scale (IAS) in the instructional context. Communication Education.

\section{MANUSCRIPTS IN PROGRESS}

Kennedy-Lightsey, C. D. The dark days of friendship: Hurt feelings and satisfaction.

Kennedy-Lightsey, C. D. The dark days of friendship: Jealousy and uncertainty.

Kennedy-Lightsey, C. D., \& Chory, R. M. Blowing the whistle on teacher misconduct: Effects of severity and peer type.

\section{COMPETITIVE CONFERENCE PAPERS}

Kennedy-Lightsey, C. D. \& Martin, M. M. (2009, November). The predictive validity of the interpersonal attraction scale (IAS) in the instructional context. Paper accepted for presentation at the annual meeting of the National Communication Association, Chicago, IL. [Top Four Competitive Paper in the Instructional Development Division]

Dillow, M. R., Kennedy-Lightsey, C. D., \& Fowler, C. (2009). Love styles and communication in romantic relationships: Communication of forgiveness, relational repair, and termination strategies after transgressions. Paper accepted for presentation at the annual meeting of the National Communication Association, Chicago, IL. [Top Four Competitive Paper for Interpersonal Division]

Kennedy-Lightsey, C. D. \& Martin, M. M. (2009, April) Perceptions of teacher credibility, clarity, and relevance: An expectancy violations model. Paper accepted for presentation at the annual meeting of the Eastern Communication Association, Philadelphia, PA. [A Top Competitive Paper in the Instructional Division]

Kennedy-Lightsey, C. D. (2009, April). When two become one: A preliminary paper of marital couples' public behavior. Paper submitted for presentation at the annual meeting of the Eastern Communication Association, Philadelphia, PA.

Frisby, B., \& Kennedy-Lightsey, C. D. (2009, April). It's all about a name: An examination of parents' naming decision-making processes. Paper accepted for presentation at the annual meeting of the Eastern Communication Association, Philadelphia, PA. 
Kennedy-Lightsey, C. D., \& Booth-Butterfield, M. (2008, November). Relational investments, hurt feelings, and communication responses: From day 1 to day 14. Paper presented at the annual meeting of the National Communication Association, San Diego, CA.

Kennedy-Lightsey, C. D., Madlock, P. E., Horan, S. M., \& Booth-Butterfield, M. (2008, November). Predicting future interactions: Predicted outcome value judgments, attraction, homophily and immediacy. Paper presented at the annual meeting of the National Communication Association, San Diego, CA.

Dillow, M. R., Fowler, C., \& Kennedy-Lightsey, C. D. (2008, November). Love styles and communication in romantic relationships: Maintenance, trait and episodic willingness to forgive and communication of forgiveness. Paper presented at the annual meeting of the National Communication Association, San Diego, CA.

Myers, S. A., Horan, S. M., Kennedy-Lightsey, C. D., Madlock, P. E., Sidelinger, R. J., Byrnes, K. A., Frisby, B. N. \& Mansson, D. (2008, November). College student class participation as a function of perceived instructor communicative attributes. Paper presented at the annual meeting of the National Communication Association, San Diego, CA.

Kennedy-Lightsey, C. D., \& Booth-Butterfield, M. (2008, May). Responses to jealousy situations that evoke uncertainty in married and dating relationship. Paper presented at the annual meeting of the International Communication Association, Montreal, Canada.

Kennedy-Lightsey, C. D., \& Chory, R. M. (2008, May). Blowing the whistle on teacher misconduct: Effects of severity and peer type. Paper presented at the annual meeting of the International Communication Association, Montreal, Canada.

Kennedy-Lightsey, C. D., \& Dillow, M. R. (2008, May). Mothers' hurtful messages and affirming communicator style: Extrapolating Interaction Adaptation Theory. Paper presented at the annual meeting of the International Communication Association, Montreal, Canada.

Kennedy-Lightsey, C. D. (2008, May). Small group confirmation and perceptions of equity: The impact of "thank you." Paper presented at the annual meeting of the Eastern Communication Association, Pittsburgh, PA.

Martin, M. M., Dunleavy, K. N., \& Kennedy-Lightsey, C. D. (2008, May). Can verbally aggressive messages in the instructor-student relationship be constructive? Paper presented at the annual meeting of the Eastern Communication Association, Pittsburgh, PA.

Kennedy-Lightsey, C. D. (2007, November). Expressing dissent and blowing the whistle: A conceptual consideration. Paper presented at the annual meeting of the National Communication Association, Chicago, IL.

Madlock, P., \& Kennedy-Lightsey, C. D. (2007, November). The effects of supervisors' verbal 
aggressiveness and mentoring on their subordinates. Paper presented at the annual meeting of the National Communication Association, Chicago, IL.

Kennedy-Lightsey, C. D., Thompson, M., Leezer, K., \& Zackery, B. (2007, April). Communication Privacy Management Theory: Exploring negotiated ownership. Paper presented at the annual meeting of the Eastern Communication Association, Providence, RI.

Kennedy-Lightsey, C. D. (2006, November). Researching family conflict: A fresh perspective. Paper presented at annual meeting of the National Communication Association, San Antonio, TX. Received “Top Student Papers in Family Communication.”

Kennedy-Lightsey, C. D. (2006, November). Communication in instructional settings: A chapter on teacher self-disclosure. Paper presented at annual meeting of the National Communication Association, San Antonio, TX.

Kennedy, C. D., \& Furler, L. A. (2006, April). Gender-linked language differences in single-sex and mixed-sex classrooms: A social learning theoretical perspective. Paper presented at annual meeting of the Eastern Communication Association, Philadelphia, PA.

Kennedy, C. D. (2005, November). The rhetorical visions of the Promise Keepers movement: A calling from God through the power of prayer to become "Godly men" of divine brotherhood. Paper presented at annual meeting of the National Communication Association, Boston, MA.

\section{CONFERENCE PANELS}

Fighting the frenzy: Challenges facing organizations. Panel at annual meeting of the Eastern Communication Association, Pittsburgh, PA.

\section{ACADEMIC/TEACHING EXPERIENCE}

2006-2009

2006

2004-2005

2003-2004
West Virginia University, Morgantown, WV

Graduate Teaching Assistant

Course Administrator for COMM 102: Interpersonal

Communication (2006 - 2008)

Research Assistant - Dr. Megan Dillow (2007 - present)

Website Manager (2007 - present)

St. Edward's University, Austin, TX

Adjunct Professor

Texas State University, San Marcos, TX

Graduate Teaching Assistant

St. Edward's University, Austin, TX

Research Assistant 


\section{COURSES TAUGHT}

- Communication in the Classroom (COMM 600 - WVU MA Comm in Instruction)

- Communication Theory (COMM 200 - WVU)

- Nonverbal Communication (COMM 308 - WVU)

- Intercultural Communication (COMM 316 - WVU)

- Gender Communication (COMM 212 - WVU)

- Public Communication (COMM 104 - WVU)

- Interpersonal Communication (COMM 102; Course Administrator - WVU)

- Special Topics in Communication and Culture: Professional Portfolio Preparation (COMM 4351 - St. Edward's University)

- Gender Communication (COMM 2321 - St. Edward's University)

- Fundamentals of Human Communication (COMM 1310 - Texas State)

\section{SERVICE}

2009

$2008-2010$

2007

2007

$2006-2008$

$2006-2008$

2006
Reviewer, Instructional Development Division, National Communication Association

Secretary, Interpersonal Division, Eastern

Communication Association

Guest Lecturer, Interpersonal Communication Course (COMM 102), WVU

Guest Lecturer, Principles of Human Communication

Course (COMM 100), WVU

Registration Coordinator, Department of

Communication Studies Annual Commencement

Ceremony, WVU

Participated in annual "Pie your COMM Professor"

fundraiser hosted by WVU Lambda Pi Eta chapter

Volunteer training session in conflict communication at Monongalia County Hospital for the United Way

\section{MEMBERSHIP IN PROFESSIONAL AND HONORARY ORGANIZATIONS}

- Phi Kappa Phi (2008)

- International Communication Association (2008)

- National Communication Association (2005-Present)

- Eastern Communication Association (2006-Present)

\section{AWARDS}

- HERF Fellowship Recipient. 2007-2008, 2008-2009. (WVU).

- Awarded Outstanding Teaching by a Graduate Student at the Instructional \& Developmental Division of the International Communication Association. 2008. (WVU).

- Nominated Outstanding Departmental Graduate Student. 2006. (Texas State). 